\title{
Nine new species of Bennelongia De Deckker \& McKenzie, 1981 (Crustacea, Ostracoda) from Western Australia, with the description of a new subfamily
}

\begin{abstract}
Martens K., Halse S. \& Schön I. 2012. Nine new species of Bennelongia De Deckker \& McKenzie, 1981 (Crustacea, Ostracoda) from Western Australia, with the description of a new subfamily. European Journal of Taxonomy 8: 1-56. http://dx.doi.org/10.5852/ejt.2012.8
\end{abstract}

\author{
Koen MARTENS ${ }^{1,2}$, Stuart HALSE ${ }^{3}$ and Isa SCHÖN ${ }^{1,4}$ \\ ${ }^{1}$ Royal Belgian Institute of Natural Sciences, Freshwater Biology, Vautierstraat 29, \\ B-1000 Brussels, Belgium (corresponding author) \\ E-mail: koen.martens@,naturalsciences.be \\ ${ }^{2}$ University of Ghent, Department of Biology, K.L. Ledeganckstraat 35, B-9000 Gent, Belgium \\ ${ }^{3}$ Bennelongia Environmental Consultants, 5 Bishop Street, Jolimont WA 6014, Australia \\ ${ }^{4}$ University of Hasselt, Research Group Zoology, Agoralaan Building D, \\ B-3590 Diepenbeek, Belgium
}

\begin{abstract}
The genus Bennelongia De Deckker \& McKenzie, 1981 is most likely endemic to Australia and New Zealand and, up to now, only two described species in this genus had been reported from Western Australia. Extensive sampling in Western Australia revealed a much higher specific diversity. Here, we describe nine new species in three lineages, within the genus Bennelongia: B. cygnus sp. nov. and $B$. frumenta sp. nov. in the $B$. cygnus lineage, $B$. gwelupensis sp. nov., $B$. coondinerensis sp. nov., $B$. cuensis sp. nov., $B$. lata sp. nov. and $B$. bidgelangensis sp. nov. in the $B$. australis lineage, and $B$. strellyensis sp. nov. and $B$. kimberleyensis sp. nov. (from the Pilbara and Kimberley regions respectively) in the B. pinpi-lineage. For six of the nine species, we were also able to construct molecular phylogenies and to test for cryptic diversity with two different methods based on the evolutionary genetic species concept, namely Birky's $4 \mathrm{x}$ rule and the GYMC model. These analyses support the specific nature of at least four of the five new species in the B. australis lineage and of the two new species in the B. pinpi lineage. We also describe Bennelongiinae n.subfam. to accommodate the genus. With the nine new species described here, the genus Bennelongia now comprises 15 species, but several more await formal description.
\end{abstract}

Keywords. Evolution, Ostracoda, cryptic species, biodiversity, Western Australia.

\section{Introduction}

Non-marine habitats cover only about $0.8 \%$ of the total surface and only $0.01 \%$ of the total water supply of the planet Earth. Yet freshwater comprises about $12 \%$ of all known animal species $(c .126,000-$ Lévêque et al. 2005; Balian et al. 2008), including c. $25 \%$ of all known vertebrate species, and $40 \%$ of all known fish species. Temporary habitats are strongly neglected compared to permanent lakes and rivers when it comes to research on biodiversity, including ecosystem functioning, and especially regarding taxic and molecular diversity. Nevertheless, $60 \%$ of all red list species from England (IUCN 2012) occur 
in temporary ponds and, when corrected for surface areas, temporary ponds have significantly higher levels of biodiversity than most lakes and rivers. Gnammas (small, usually shallow rock pools) and freshwater clay pans are often the only available surface water in the interior parts of (Western) Australia, and thus constitute important habitats for aquatic biodiversity on this continent (Pinder et al. 2000).

There are presently about 2000 subjective species and c. 200 genera of extant non-marine ostracods (Martens et al. 2008). But large parts of ostracod diversity remain undescribed today, and notable hotspots for such undocumented diversity are African and Australian temporary habitats (Martens et al. loc.cit.). Half of the known specific (1000 species) and generic (100 genera) diversity of non-marine ostracods belongs to one of the 13 known families, the Cyprididae. Many representatives of this group occur in temporary water bodies, because several of their biological attributes (drought resistant eggs, mixed / parthenogenetic reproduction and ability to swim) pre-adapt them to form successful radiations in these habitats (Horne \& Martens 1998; Whatley 1992).

Australia comprises less than $10 \%$ of all described non-marine ostracod species (176 against a total of 1936), but the continent has one of the highest levels of endemicity (Martens et al. 2008). These measures of Australian taxic diversity and endemism are undoubtedly underestimates for three main reasons. Firstly, because much taxonomic work remains to be done across a great variety of animal and plant groups, especially in the lesser known ones such as Ostracoda. Screening of extant collections reveals a large number of easily recognisable, yet thus far undescribed species and genera (e.g. Halse 2002). Secondly, new collections from thus far less explored areas and ecosystems will doubtlessly yield undescribed taxa. A case in point is the high and previously completely unknown biodiversity of Ostracoda in ground waters in the Pilbara region (Karanovic 2007). Finally, several traditional 'species' are actually turning out to be species complexes, comprising sometimes dozens of cryptic species, such as in the European (Bode et al. 2010) and the Australian (Koenders et al submitted) populations of the morphospecies Eucypris virens (Jurine, 1820).

The genus Bennelongia is interesting for reasons that go beyond a general knowledge of the biodiversity of Australian inland waters. Horne \& Martens (1998) foreshadowed that Bennelongia might be the last true descendant genus of the Mesozoic (and now extinct) lineage of Cypridea Bosquet, 1852, which was also characterised by the anterior beak-like expansion of the left valve and which was the dominant ostracod lineage in Cretaceous non-marine waters when dinosaurs ruled the Earth. This could mean that the true Cyprididae, which now comprise c. 50\% of all living non-marine ostracods (Martens et al. 2008), might be unrelated to Cypridea and could have descended from a few Jurassic ancestral lineages that already existed while Cypridea dominated non-marine freshwaters, much like the mammals could only expand their diversity after the dinosaurs had died out. Horne \& Colin (2005) meanwhile further developed this idea and showed that Bennelongia is the one genus that somewhat resembles true Cypridea in the internal marginal valve morphology, while other candidate genera such as Cypris O.F. Müller, 1776 and Chlamydotheca Saussure, 1858 have completely different morphologies.

The aim of our revision of Bennelongia is firstly to identify the lineages within Bennelongia and describe the overall diversity of species in these lineages and, secondly, to analyse the phylogeny of these species using morphological and molecular data. We will use this information to test the hypothesis that Bennelongia is the only true descendant genus of the Cypridea fauna with an antero-ventral beak. The present paper is thus the first in a series of contributions that sets out to test the "Bennelongia as surviving Cypridea" hypothesis.

Here, we describe nine new species of Bennelongia from Western Australia. Five of these are sibling species within the $B$. australis lineage and for four of these their specific status is confirmed by molecular methods. In addition, we reveal the existence of two sibling species within the $B$. pinpi lineage by molecular methods and describe these as new species. We do this because closer morphological examination revealed stable, micro-scale character states that allow their identification. Two further new species are described in a new lineage in the genus, the B. cygnus lineage. 


\section{Material and methods}

\section{Collections}

Ostracods were collected from pans and lakes with a hand net with mesh size of $250 \mu \mathrm{m}$ during field trips between 2006 and 2011 (see below). Material for morphological analyses originated from both these 'new' collections and earlier collections from all over Western Australia, mostly collected by SH and preserved in a collection housed at the Department of Environment and Conservation (Woodvale, Perth). The molecular analyses worked only with newly collected material, for which analyses were of either living specimens or specimens sorted in the field and preserved in 100\% ethanol. Consequently, molecular analyses were limited to six of the nine new species. Fieldtrips for recent collections were in Gascoyne/Murchinson (April 2006 and July 2011), Pilbara (April 2006), Kimberley (July 2010) and the surroundings of Bunbury and Perth (July 2010). Locations of populations used for the present paper are indicated on the map in Figure 1. Type material of the new species is deposited in the Western Australian Museum, Perth, WA (WAM numbers) and in the Ostracod Collection of the Royal Belgian Institute of Natural Sciences, Brussels, Belgium (OC numbers).

\section{Morphological analyses}

Ostracods were dissected with valves stored dry in micropalaeontological slides and soft parts in glycerine in sealed slides. Drawings of soft parts were made with a camera lucida with a compound

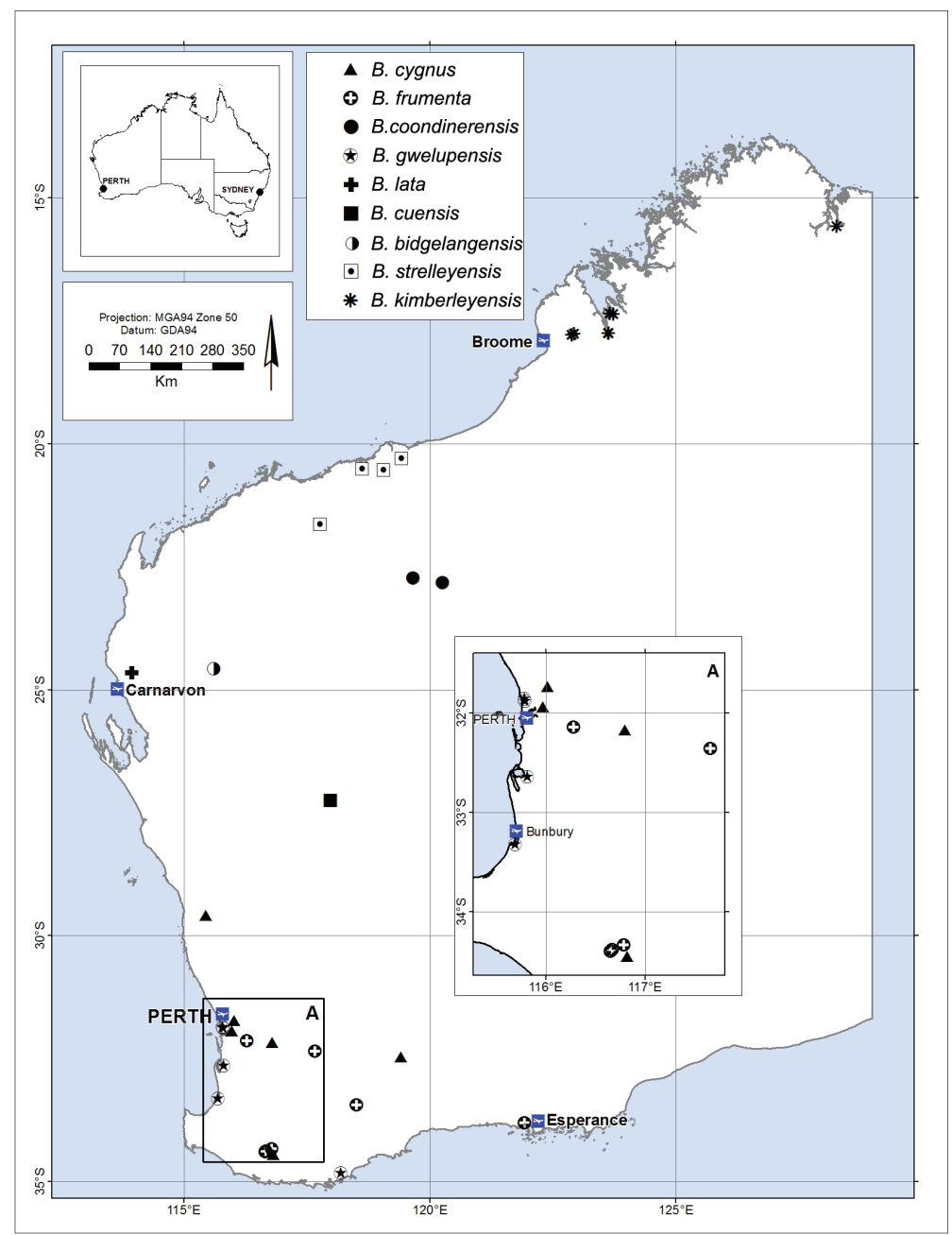

Fig. 1. Map of Western Australia with localities of Bennelongia - species described in the present paper. 
microscope (Leica, DM 2500 at Bennelongia Environmental Consultants, Perth). Valves were illustrated and measured using scanning electron microscopy (Philips XL30 SEM at RBINS, Brussels).

\section{Molecular analysis}

We used the Qiagen Blood and Tissue extraction kit to extract DNA from 53 individual ostracods, belonging to four species of the Bennelongia australis and two species of the $B$. pinpi, lineages respectively, following the manufacturer's protocol. PCR amplification of part of the mitochondrial COI region was conducted with universal primers (Folmer et al. 1994) in a $T$ personal Thermoblock (Biometra) with the following conditions: $25 \mu \mathrm{l}$ volumes of the HotStar Master Mix (Qiagen; $1.5 \mathrm{mM}$ $\mathrm{MgCl} 2,0.1 \mu \mathrm{M}$ primer, $200 \mu \mathrm{M}$ dNTP, Tris $\cdot \mathrm{Cl}, \mathrm{KCl},\left(\mathrm{NH}_{4}\right)_{2} \mathrm{SO}_{4}, 1.25 \mathrm{U}$ Taq) and $15 \mathrm{~min}$ at $95^{\circ} \mathrm{C}, 40$ to 42 cycles of $1 \mathrm{~min}$ at $95^{\circ} \mathrm{C}, 1 \mathrm{~min}$ at $42^{\circ}$ to $44^{\circ} \mathrm{C}, 1 \mathrm{~min}$ at $72^{\circ} \mathrm{C}$ and a final extension step for 10 min at $72^{\circ} \mathrm{C}$. Success of PCR amplifications was verified by agarose gel electrophoresis. Gels were stained with Gelred and photographed. PCR products were cleaned with the GFX ${ }^{\mathrm{TM}}$ PCR DNA and gel band purification kit (GE Healthcare) according to the manufacturer's protocol and sequenced in both directions on an $\mathrm{ABI} 3130 \mathrm{X}$ with the universal COI primers and the Big Dye kit (ABI) following the manufacturer's protocol.

As no fresh (living) material of the two species in the B. cygnus sp. nov. lineage could be obtained, these species are not represented in the molecular phylogenetic tree and network.

\section{Analyses of sequence data}

Sequence chromatograms were visualised with Chromas (Technelysium. Pty Ltd.). For each individual, the two strands were aligned with ClustalX (Larkin et al. 2007), subsequently checked by eye for ambiguities, corrected and finally trimmed to obtain sequences of equal lengths. We used BLAST (Altschul et al. 1990) to confirm the identity of the obtained sequences in Genbank. The optimal model of molecular COI evolution was identified with jModeltest (Posada 2008) using 88 or 24 models and AICc analysis. For phylogenetic reconstructions, we used a reduced dataset applying Bayesian Inference (BI) in Mr Bayes 3.1.2 (Huelsenbeck \& Ronquist 2001; with 2 million generations, sampling every $100^{\text {th }}$ generation, a burn-in of $25 \%$ and the parameters identified by jModeltest for 24 different models) and the Maximum-Likelihood method in PhyML (Guindon \& Gascuel 2003; with 1000 bootstrap replicates and the parameters of jModeltest for all 88 models). TCS 1.21 (Clement et al. 2000) was used to construct a parsimonious network at the $95 \%$ probability limit for connecting different sequences (or haplotypes) by using all sequence data to illustrate genetic diversities and genetic relationships within and between populations. Selected sequences of all species have been submitted to Genbank (accession numbers JQ432553-JQ432558).

\section{Testing for cryptic diversity}

We applied two different methods based on the evolutionary genetic species concept (Birky \& Barraclough 2009), namely the 4 x rule (Birky et al. 2010) and the GYMC model (Pons et al. 2006), to identify species boundaries and unravel cryptic diversities. Similar approaches have successfully been used in bdelloid rotifers (Fontaneo et al. 2007, 2009; Birky \& Barraclough 2009; Birky et al. 2011), marine ostracods (Nunes Brandao et al. 2010) and a wide range of asexual prokaryotes (Birky et al. 2010).

For the $4 \mathrm{x}$ rule, we used the obtained phylogenies to define as sister clades the closest two neighbours, with high statistical support, which could potentially be different species. Sequence diversity within and between these clades were estimated with MEGA 5.0 (Tamura et al. 2011) using the number of differences (p) or the TN model (allowing for multiple hits) and 1000 bootstrap replicates. Sequence diversities were further corrected for sample size and sequence lengths, following the procedure by Birky et al. (2010). In order to fulfil the criteria of the $4 \mathrm{x}$ rule, the sequence diversity between two sister clades must be at least 4 to 4.3 times higher than within the two clades, depending on the number 
of samples per clade (Birky et al. 2010). If the ratio is close to 4, it is necessary to also compare the sequence diversities $\mathrm{K}$ within and between sister clades allowing for multiple hits. For applying the GYMC model, we first tested whether the assumption of clock-wise substitution rates was fulfilled by conducting likelihood ratio tests in TREE-PUZZLE 5.0 (Schmidt et al. 2002). In PAUP 4.0 (Swofford 1998), the Maximum-Likelihood approach was used with clock assumption to construct an ultrametric tree with all Bennelongia sequences. This tree was imported into Ape (Paradis et al. 2004) and Geiger (Harmon et al. 2008) in the R working environment, multifurcations were randomly resolved with Ape and the GYMC model was applied to the latter ultrametric tree.

Finally, unconnected networks from the parsimonious network analyses were considered as possible, species-like entities following the arguments of Hart \& Sunday (2007).

\section{Abbreviations used in text and figures}

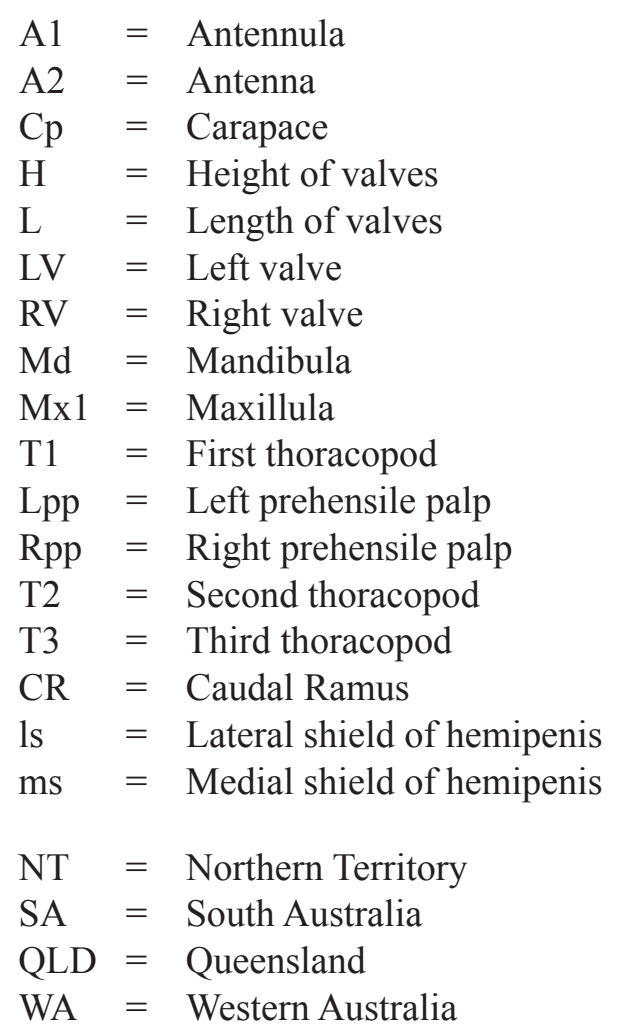

Chaetotaxy of the limbs follows the model proposed by Broodbakker and Danielopol (1982), revised for the A2 by Martens (1987) and for the T3 by Meisch (2000). Higher taxonomy of the Ostracoda follows the synopsis by Horne et al. (2002).

\section{Results}

\section{Results of molecular screening}

We obtained COI sequences for 37 specimens from the Bennelongia australis lineage and 16 for the $B$. pinpi lineage with a length of $522 \mathrm{bp}$ each (for taxonomic definition of these lineages, see below). In BLAST searches, these sequences gave low e values and clustered with COI sequences from other nonmarine ostracods, confirming their genetic identity and excluding possible contamination. Amongst 88 models, jModeltest identified the TIM $1+\mathrm{I}+\mathrm{G}$ model as the best fitting with the following parameters: freq $\mathrm{A}=0.3101$, freqC $=0.1676$, freqG $=0.1418$, freq $=0.3806 ;[\mathrm{AC}]=1.0000,[\mathrm{AG}]=50.4377$, $[\mathrm{AT}]$ 
$=11.2835,[\mathrm{CG}]=11.2835,[\mathrm{CT}]=81.8876,[\mathrm{GT}]=1.0000 ; \mathrm{p}-\mathrm{inv}=0.5870$ and gamma shape $=1.6460$. Among 24 models, the GTR + I model was chosen.

In the phylogenetic tree, the outgroups (Heterocypris spec. and Eucypris virens) cluster clearly outside of the Bennelongia sequences (Figure 2). We can furthermore distinguish six well-supported clusters in the phylogenetic tree (Figure 2) with high posterior probabilities and bootstrap values. The specimens belonging to the $B$. australis lineage form four groups, consisting of the species $B$. gwelupensis sp. nov., $B$. coondinerensis sp. nov., $B$. lata sp. nov. and $B$. cuensis sp. nov., while the specimens belonging to the $B$. pinpi lineage form two distinctive groups, here described as $B$. kimberleyensis sp. nov. from the Kimberley and B. strellyensis sp. nov. from the Pilbara, respectively. Phylogenetic relationships among

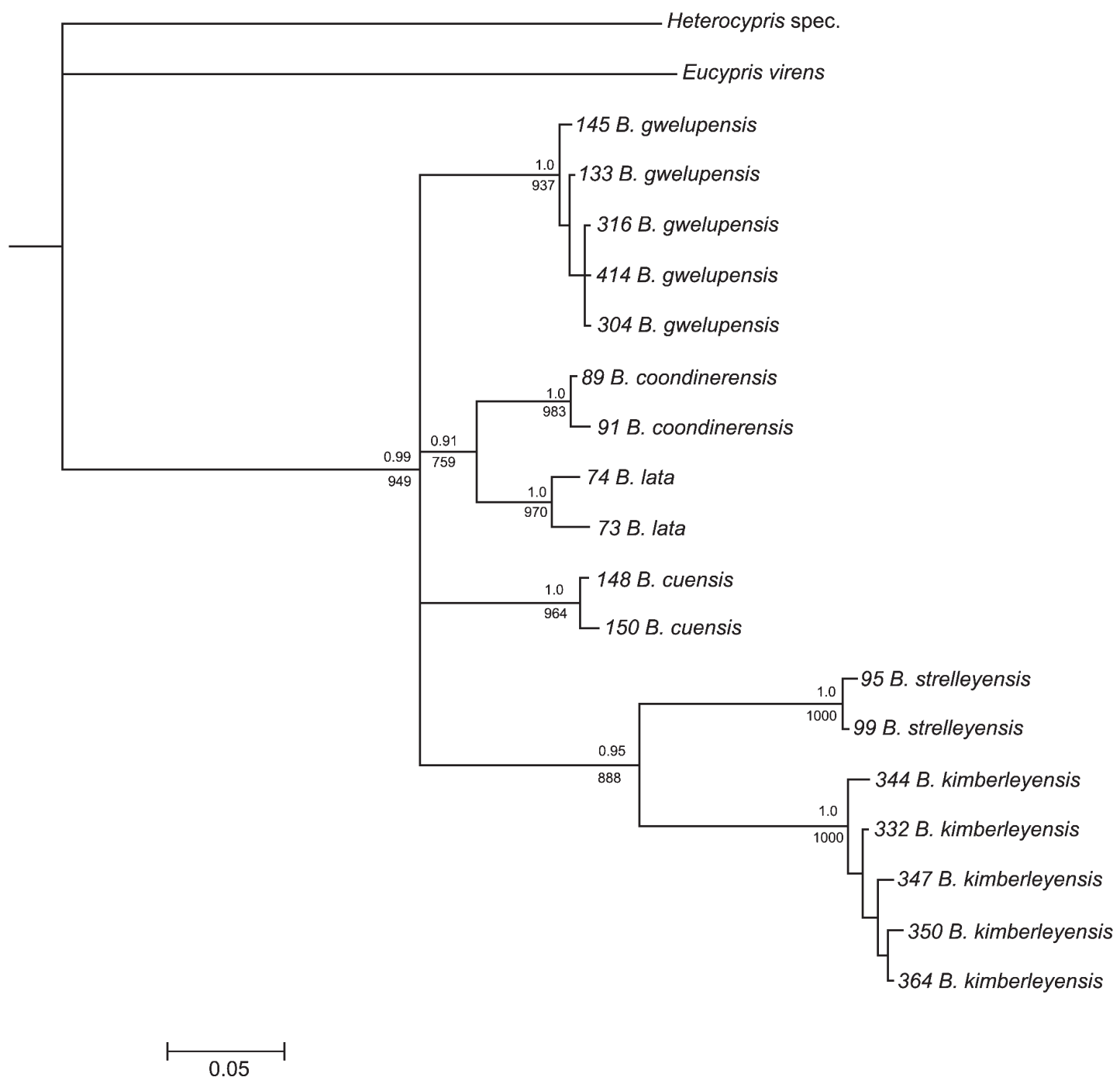

Fig. 2. Phylogenetic tree constructed with Baysian Inference of $53 \mathrm{COI}$ sequences of Bennelongia and with Heterocypris spec. and Eucypris virens as outgroups. Numbers above and below nodes show statistical support for this particular node. Numbers above nodes are Baysian posterior probabilities (ranging from 0 to 1), below nodes bootstrap values of Maximum Likelihood (ML) analyses of 1000 replicates are provided. Both methods, BI and ML, resulted in the same tree topology. The tree shows four supported clusters in the B. australis lineage, congruent with species described in the present paper, and two supported clusters for the sibling species in the B. pinpi lineage. 
these six new Bennelongia species cannot be fully resolved with our COI data, as the deeper nodes are polytomous and only weakly supported.

Besides phylogenetic trees, sequences are also visualized in the form of genetic networks (Figure 3), which are more suitable to display close genetic relationships (Clement et al. 2000). Six distinct and unconnected network groups can be identified from the analysed Bennelongia individuals. Almost all of the 11 individuals belonging to $B$. kimberleyensis sp. nov. contain different sequences or haplotypes (with one exception, where one haplotype is shared between two individuals), while $B$. coondinerensis
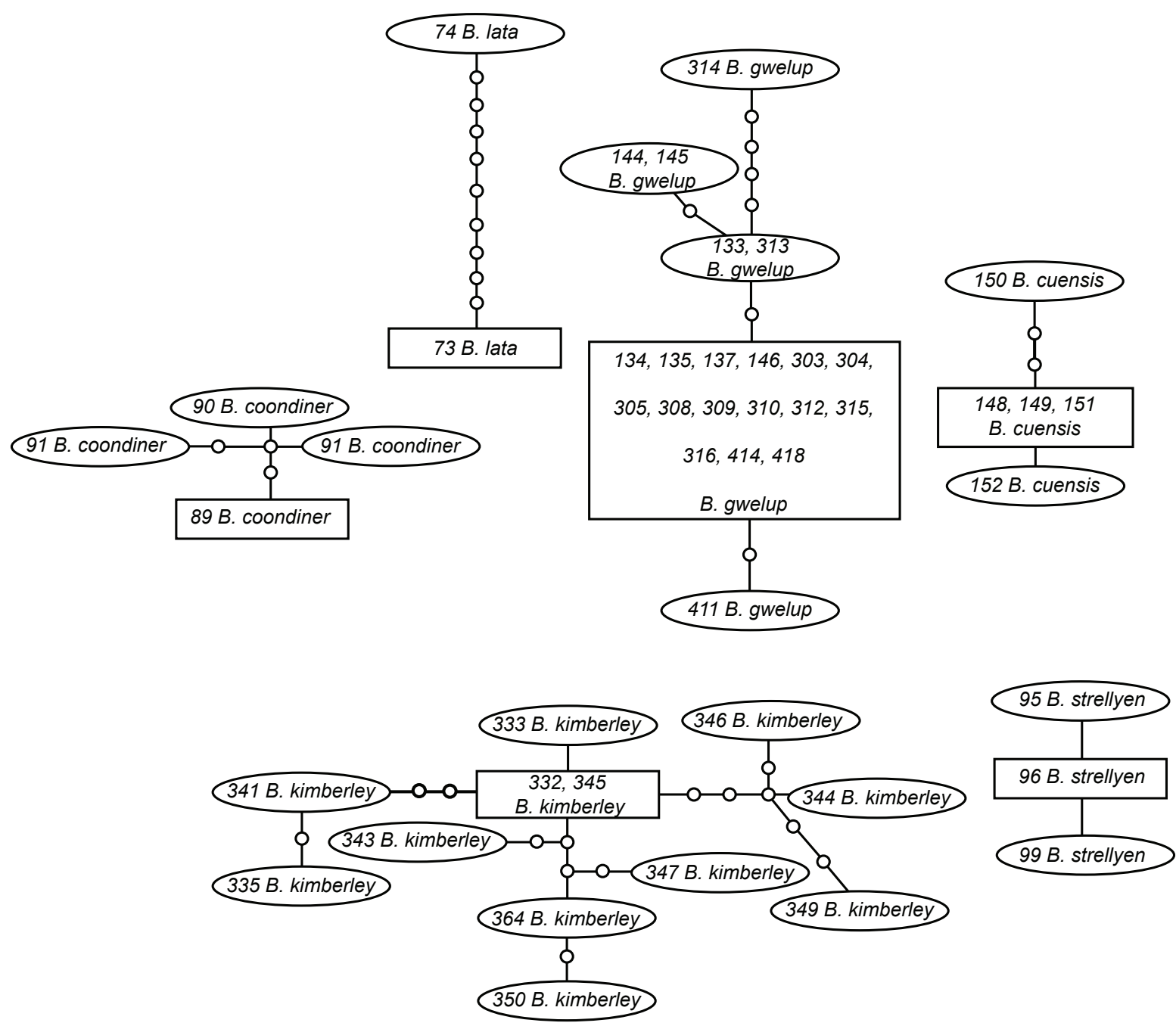

Fig. 3. Parsimonious network, based on COI sequences of Bennelongia. Squares represent ancestral sequences (or haplotypes), small circles missing haplotypes. The size of squares and large circles is proportional to the number of individuals with the same sequence in the analyses population. The network was constructed at the $95 \%$ probability limit, which usually includes up to 8 steps for connecting different sequences (or haplotypes). Thus, the two sequences of $B$. lata being 10 mutational steps apart needed to be connected manually by lowering the connection probability. The specimens belonging to the $B$. australis group form four groups, consisting of the species $B$. gwelupensis sp. nov., $B$. coondinerensis sp. nov., $B$. lata sp. nov. and B. cuensis sp. nov., while the specimens belonging to the $B$. pinpi group forms two distinctive lineages, with $B$. kimberleyensis sp. nov. and B. strelleyensis sp. nov. from the Kimberly and the Pilbara, respectively. 
sp. nov., B. cuensis sp. nov. and B. strelleyensis sp. nov. from Pilbara have few, closely related haplotypes. Bennelongia gwelupensis sp. nov. is characterized by a single, common sequence appearing in 15 different specimens from different populations. Also three of the four remaining haplotypes from this species are shared between individuals. Finally, B. lata sp. nov. comprises the most distant sequences, as the two haplotypes are separated by 10 mutational steps, which is beyond the $95 \%$ probability limit for connecting haplotypes with TCS.

For the $4 \mathrm{x}$ rule, we used three different methods for phylogenetic reconstructions to identify closest neighbours within phylogenetic trees. The following three sister clades were found: Bennelongia kimberleyensis sp. nov. - B. strelleyensis sp. nov., Bennelongia gwelupensis sp. nov. - B. cuensis sp. nov. and $B$. lata sp. nov. - B. coondinerensis sp. nov. As required for the $4 \mathrm{x}$ rule, we then compared sequence diversity $\theta$ within and between the representatives of each of the three sister clades. In all cases (see Table 1), sequence diversity was higher than the required $4 \mathrm{x}$ and varied between $4.8 \times$ (B. gwelupensis sp. nov. - B. cuensis sp. nov.) up to $16.4 \mathrm{x}$ (B. lata sp. nov. - B. coondinerensis sp. nov.). Even when using $\mathrm{K}$ as the measure of sequence diversity (taking multiple hits into account), the ratio was higher than $4 \mathrm{x}$ and varied between 4.7 and 55.6 (see Table 1). Thus, the criteria of the $4 \mathrm{x}$ rule are fulfilled for all three sister clades and we identify a total of six different Bennelongia species. The conducted likelihood ratio tests confirm that COI substitution rates behave in a clock-like fashion among all analysed Bennelongia specimens. Therefore, the ultrametric COI tree can be constructed with a single, global molecular clock. When applying the GYMC algorithm to this ultrametric tree, the likelihood of the null model is 350.4, which is significantly lower than the likelihood of the GYMC model (445.0) and the likelihood ratio test is highly significant $(\mathrm{p}<0.001)$. The better fit of the GYMC model to our data implies that specieslike entities can indeed be recognized. In our ultrametric tree (available from IS on request), the GYMC model recognizes 29 different sequences (with no standard deviation) and five species (again, with no standard deviation): the outgroup, Heterocypris spec., a second species consisting of $B$. cuensis sp. nov., $B$. coondinerensis sp. nov. and B. lata sp. nov., a third species with $B$. gwelupensis sp. nov., a fourth with B. strelleyensis sp. nov. from the Pilbara and a fifth with B. kimberleyensis sp. nov. from the Kimberley. In conclusion, the GYMC model identifies fewer species than the $4 \mathrm{x}$ rule and the parsimonious networks.

Table 1. Results of tests using the $4 \mathrm{x}$ rule in six sibling species in 2 lineages of Bennelongia.

\begin{tabular}{|c|c|c|c|c|}
\hline Sister clades & $\begin{array}{c}\max . \theta / K \\
\text { within clade }\end{array}$ & $\begin{array}{c}\theta / K \text { between } \\
\text { clades }\end{array}$ & Ratio $\theta / \mathbf{K}$ & $\mathrm{n} 1, \mathrm{n} 2$ \\
\hline $\begin{array}{l}\text { B. kimberlyensis - } \\
\text { B. strellyensis }\end{array}$ & $\begin{array}{l}0.012 / \\
0.012\end{array}$ & $\begin{array}{l}0.140 / \\
0.300\end{array}$ & $\begin{array}{l}11.4 / \\
25.2\end{array}$ & 12.3 \\
\hline $\begin{array}{l}\text { B. gwelupensis - } \\
\text { B. cuensis }\end{array}$ & $\begin{array}{l}0.039 / \\
0.003\end{array}$ & $\begin{array}{c}0.189 / \\
0.189\end{array}$ & $\begin{array}{l}4.9 / \\
55.6\end{array}$ & 21.5 \\
\hline $\begin{array}{l}\text { B. lata - } \\
\text { B. coondinerensis }\end{array}$ & $\begin{array}{c}0.050 / \\
0.020\end{array}$ & $\begin{array}{l}0.810 / \\
0.093\end{array}$ & $\begin{array}{c}16.4 / \\
4.7\end{array}$ & 2.4 \\
\hline
\end{tabular}

$\theta=$ sequence diversity; $\mathrm{K}=$ sequence diversity taking multiple hits into account. Nearest neighbours or sister clades were defined from the COI tree constructed with Bayesian Inference (see Figure 2), Maximum Likelihood (not shown) and Neighbour-joining (not shown). In order to fulfil the criteria of the $4 \mathrm{x}$ rule for species status, the ratio of the mean sequence diversity within as compared to between the two nearest neighbours of one sister clade needs to be 4 or more, depending on the number of specimens per clade (Birky et al. 2010). In our analyses, these criteria are clearly fulfilled for all three sister clades and regardless whether sequence diversity is estimated as $\theta$ or $\mathrm{K}$. 


\section{Taxonomic descriptions}

Class Ostracoda Latreille, 1806

Subclass Podocopa G. W. Müller, 1894

Order Podocopida G.O. Sars, 1866

Suborder Cypridocopina Baird, 1845

Superfamily Cypridoidea Baird, 1845

Family Cyprididae Baird, 1845

Subfamily Bennelongiinae subfam. nov.

\section{Diagnosis}

Adults with asymmetrical valves with LV overlapping RV. LV antero-ventrally with a beak-like expansion of the valve margin; anterior calcified inner lamella with two incomplete inner lists, forming a sulcus and extending in the lip-like structure. RV with short antero-ventral inner list, and antero-ventrally either with a small, transparent 'lapel' (see below) or with the valve forming a bulbous expansion.

A1 and A2 with medium-long natatory setae; expopodite of A2 with two long and one short seta. Mdpalp with alpha-seta long and smooth, beta-seta stout and hirsute in distal half, gamma-seta relatively slender and hirsute in distal half. T2 (walking leg) with penultimate segment divided. T3 a cleaning leg. Caudal ramus and attachment slender. Hemipenis consisting of at least two asymmetrical penal sheets.

\section{Genus allocated:}

Bennelongia De Deckker \& McKenzie, 1981

\section{Remarks}

Bennelongia was previously allocated to the subfamily Cypridinae Baird, 1845 within the family Cyprididae Baird, 1845, but since the regional revision of this subfamily by Martens $(1990,1992,2007)$ it is clear that Bennelongia lacks the additional post-labyrinthal coils of the spermiduct in the hemipenis that are characteristic of Cypridinae s.s. In addition, the remarkable morphology of the anterior part of the valves sets this genus aside from all other extant genera in the Cyprididae. Whether Bennelongiinae subfam. nov. will eventually need to be transferred to the Cyprideidae Martin, 1940 will, hopefully, be resolved by the time our revision of Bennelongia is completed. Meanwhile the new subfamily is lodged in the Cyprididae.

Some general aspects of the morphology of Alboa De Deckker, 1981 indicate that it might be close to Bennelongia and thus might also be a candidate to be included in Bennelongiinae subfam. nov., but initial molecular screening shows that Alboa is closer to Eucypris (Vavra, 1891) Daday, 1900 and Heterocypris Claus, 1832 than to Bennelongia (results not shown).

Genus Bennelongia De Deckker \& McKenzie, 1981

\section{Diagnosis (modified after De Deckker \& McKenzie 1981)}

Adults with asymmetrical valves, especially anteriorly. LV overlapping RV anteriorly, ventrally and posteriorly, sometimes also dorsally.

LV antero-ventrally with a beak-like expansion of the valve margin; anterior calcified inner lamella with two incomplete inner lists, a ventro-proximal one and a dorso-distal one, both extending to about the 
middle of the valve and slightly or significantly overlapping each other; ventro-proximal list protruding and forming a sulcus running along the proximal inner list and extending in the lip-like structure.

RV with short antero-ventral inner list, and antero-ventrally either with a small, transparent flange (here termed 'lapel') or with valve forming a bulbous expansion; RV set with tubercles along most of the anterior, ventral and posterior valve margin.

Juveniles with completely different valve morphology, with symmetrical valves, without beak-like expansion on LV or lapel on RV and with external surface either pitted or reticulated or set with wartlike tubercles in most lineages in the genus.

A1 and A2 with medium-long natatory setae. Md-palp with alpha-seta long and smooth, beta-seta stout and hirsute in distal half, gamma-seta relatively slender and hirsute in distal half. Mx1-palp with distal segment rectangular. $\mathrm{T} 1$ with prehensile palps in males strongly asymmetrical, right palp with broad terminal segment, left palp with sickle shaped distal segment. T2 with seta $\mathrm{d} 1>\mathrm{d} 1$, sometimes twice as long, penultimate segment of endopod (segment 3) divided. T3 a cleaning leg. Caudal ramus and attachment slender. Hemipenis consisting of at least two, asymmetrical penal sheets.

\section{Remarks}

The extent of the difference in morphology between juveniles and adults in most lineages of Bennelongia is unusual in non-marine Ostracoda. The difference of the extent of this dimorphism between the lineages, and its relevance, will be discussed elsewhere in a separate paper.

\section{Differential diagnosis}

Bennelongia is immediately distinguishable from all other cypridid genera by the peculiar morphology of the anterior parts of the valves, especially of the LV (see above).

\section{Type species}

Bennelongia harpago De Deckker \& McKenzie, 1981 (Queensland, Australia).

\section{Other species allocated (only area of type locality given)}

See Table 2.

Table 2. Species presently described in Bennelongia and their distribution (species in bold are newly described here). Only certain distributions, based on type localities, are given here. $*=$ type species

Bennelongia australis (Brady, 1886): SA
Bennelongia barangaroo De Deckker, 1981: WA
Bennelongia bidgelongensis sp. nov.: WA, Gascoyne
Bennelongia coondinerensis sp. nov.: WA, Pilbara
Bennelongia cuensis sp. nov.: WA, Yilgarn
Bennelongia cygnus sp. nov.: WA, Swan Valley
Bennelongia frumenta sp. nov.: WA, Wheatbelt
Bennelongia gwelupensis sp. nov.: WA, Perth, southwest coast
*Bennelongia harpago De Deckker \& McKenzie, 1981: QLD
Bennelongia kimberleyensis sp. nov.: WA, Kimberley
Bennelongia lata sp. nov.: WA, Gascoine-Murchinson region
Bennelongia nimala De Deckker, 1981: NT
Bennelongia pinpi De Deckker, 1981: QLD
Bennelongia strellyensis sp. nov.: WA, Pilbara
Bennelongia tunta De Deckker, 1982: QLD




\section{Distribution}

The genus is most likely endemic to Australia and New Zealand and can be considered as one of the more typical ostracod groups of the Australasian region. De Deckker (1981a) suggested that Strandesia flavescens Klie, 1932 and Strandesia feuerborni Klie, 1932, both from Indonesia (Sumatra, Java), might also belong in this genus, but Savatenalinton \& Martens (2010) and Martens \& Savatenalinton (2011) retained both species in their original genus, Strandesia Stuhlmann, 1888.

\section{General valve morphology (Figure 4)}

In order to allow accurate descriptions of species in this genus, it is necessary to unequivocally establish the homology of the different marginal structures in both valves, as these have undergone remarkable evolutionary changes (Figure 4A).

In the LV, the valve margin and two inner lists are of importance. The valve margin shows an anteroventral beak-like expansion. The anterior calcified inner lamella carries two inner lists, a proximal ventral and a distal dorsal one. Together, these lists line a sulcus, a depression in the calcified inner lamella which further expands in the beak-like expansion. The proximal inner list can be significantly elevated (Figure 4B).

In the RV, an outer list, the valve margin, a selvage and two inner lists form a complex structure. The outer list is invariably modified, completely or partially. In B. cygnus sp. nov., the middle part of the outer list is still a list, the posterior part is modified into a row of tubercles and the anterior part in a row of tubercles and a lapel (Figure 4C). In most (all?) species of the B. australis group (see below), the entire outer list is modified into a row of tubercles and the antero-ventral lapel (Figure 4D). In the species of the $B$. pinpi lineage, the entire outer list is modified into a row of tubercles, which stops where in other species the lapel is formed and where in these species the bulbous expansion occurs (Figure 4E). What looks to be the anterior valve margin in the RV is actually a selvage, which can be modified in places, with swollen or flange-like parts near the lapel. The actual anterior valve margin is strongly reduced, but can in most species still be detected as a row of small tubercles set with setae (Figure 4C-E). The calcified inner lamella also has two incomplete inner lists, here the ventral one is distal and the dorsal one more proximal. Internal to the ventral inner list, the calcified inner lamella forms a shallow sulcus, which matches the deeper one in the LV. The posterior selvage is more easily recognizable as such.

Most Bennelongia species have some form of valve ornamentation, either a pitted surface or set with tubercles and/or with long setae. This is species-dependent (though seemingly with similar patterns within a lineage) and can vary with water-chemistry. But even species with almost smooth valve surfaces (e.g. the B. cygnus lineage, see below) invariably have a field of external tubercles along the anterior margin on the RV (see Figure 4F, G - not to be confused with the marginal row of tubercles in the RV, which is mostly internally visible). This field can be narrower or wider, according to species, but is always present. Its function remains unknown.

\section{Bennelongia cygnus - lineage}

\section{Remarks}

This lineage so far consists of two species, here described as new: B. cygnus sp. nov. and B. frumenta sp. nov. They are characterized by a relatively small carapace $(\mathrm{L}=1.6 \mathrm{~mm})$ with triangular shape in lateral view, a RV with a pointed lapel and by a hemipenis of the $B$. australis-type, i.e. with ms with oblique, nearly straight distal margin and a boot-shaped LS, a sickle shape Lpp and a Rpp with elongated second segment. 


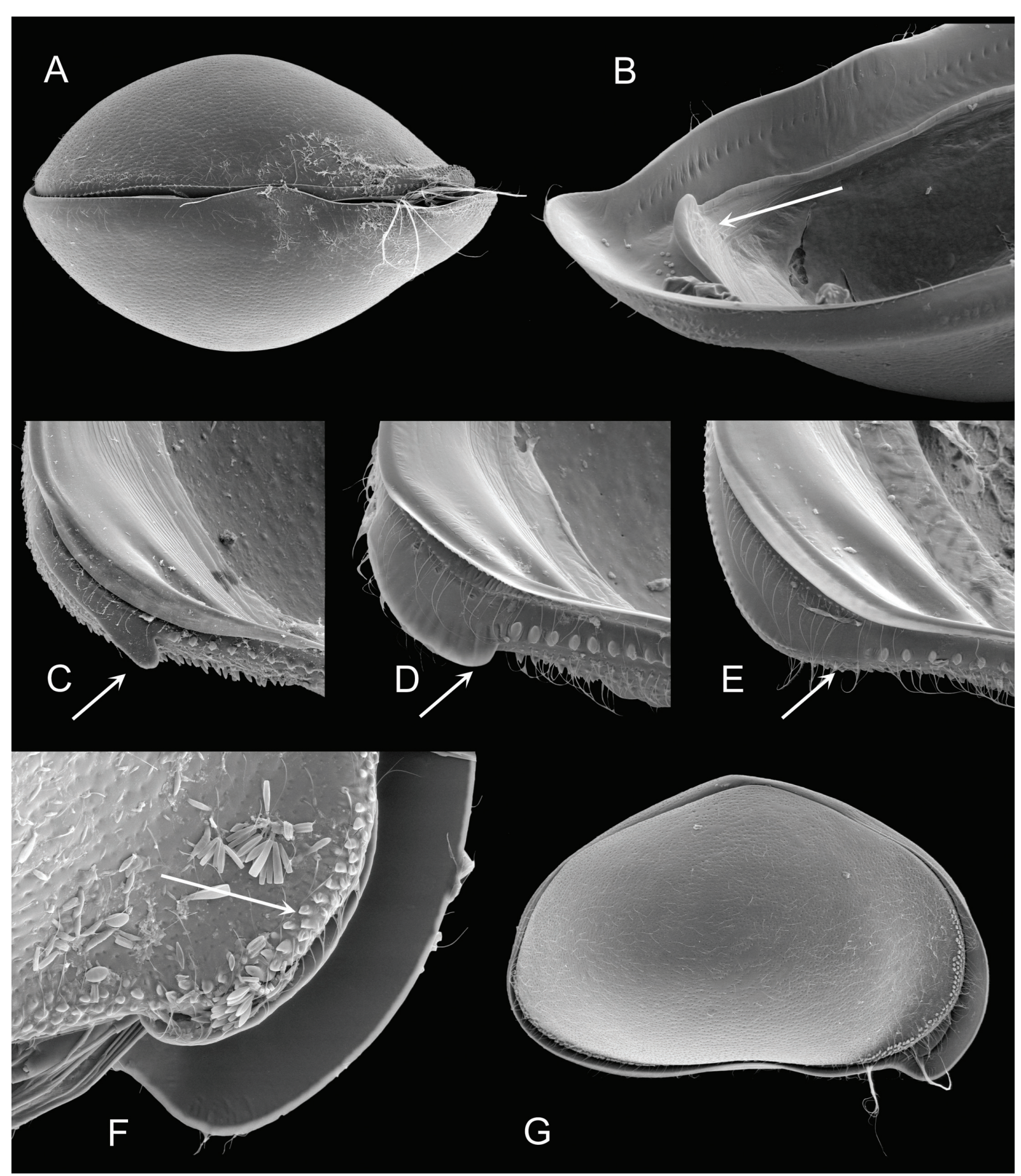

Fig. 4. General morphology of Bennelongia valves. A. B. cygnus sp. nov., ㅇ, CpV (WAM.C49378). B. B. cuensis sp. nov., + , LV dorso-anterior view, tilted, showing elevated inner list (WAM.C49408). C. B. cygnus sp. nov., + , RV, antero-ventral view, tilted, showing tear-like lapel and row of tubercles (OC.3311). D. B. lata sp. nov., + , RV, antero-ventral view, tilted, showing broad lapel and row of tubercles (specimen lost). E. B. kimberleyensis sp. nov., + , RV, antero-ventral view, tilted, showing absence of lapel and expansion of valve (WAM.C49433 allotype). F. B. frumenta sp. nov. $\$$, CpRL view (WAM.C49383). G. B. gwelupensis sp. nov. + , CpRL view, detail of antero-ventral part (WAM. C49395A). Not to scale. 
Bennelongia cygnus sp. nov.

(Figs 5-9)

Bennelongia sp. - Davies \& Christidis, 1997: 82, fig. 8.3.22.

\section{Etymology}

The type locality of this new species is situated in the Swan Valley near Perth. We thus name this species after the (black) swan, Cygnus in Latin.

\section{Diagnosis}

Valves triangular in lateral view, weakly pitted, relatively narrow in dorsal view and with rostrum weakly developed. LV with beak weakly developed. RV with lapel long and narrow, ventrally tear-like, almost pointed. Hemipenis with ls extending beyond $\mathrm{ms}$, ls distally rounded and with bluntly pointed apex. ms dorsally with additional lobe-like expansion. Lpp with distal segment sickle-shaped, but relatively short. Rpp with sub-trapezoidal distal segment.

\section{Measurements (all measurements in $\mu \mathrm{m}$ )}

Male: RV: $\mathrm{L}=1330 ; \mathrm{H}=933-954$. $\mathrm{LV}: \mathrm{L}=1330-1410 ; \mathrm{H}=968-969$.

Female: RV: $\mathrm{L}=1450-1600 ; \mathrm{H}=1000-1070 . \mathrm{LV}: \mathrm{L}=1550-1750 ; \mathrm{H}=1030-1130 . \mathrm{Cp}: \mathrm{L}=1690-1790$; $\mathrm{W}=1120-1130 ; \mathrm{H}=1100$.

\section{Type locality}

Ellen Brook Nature Reserve, Swan Valley, near Perth (WA); approximate coordinates: $31^{\circ} 44^{\prime}$ 00"S $116^{\circ} 01^{\prime} 00^{\prime \prime} \mathrm{E}$. Material used for the present description was collected on 25 Sep. 1991, 3 Oct. 1997 and 2 Oct. 1998, all by SH.

\section{Type material}

\section{Holotype}

Male (WAM.C49370), with soft parts dissected in a sealed slide and valves stored dry in a micropalaeontological slide.

Allotype

Female (WAM.C49371), with soft parts dissected in a sealed slide, and valves stored dry in a micropalaeontological slide.

\section{Paratypes}

Five males dissected and stored as the holotype (WAM.C49372-49375, OC.3310); RV + LV of one female (OC.3311).

Several in toto specimens in EtOH (voucher specimens WAM.C49376).

\section{Other material investigated}

Perth Airport unnamed swamp, collected by SH on 12 Sep. 1995, approximate coordinates: $31^{\circ} 56^{\prime}$ 00 "'S $115^{\circ} 58^{\prime} 00^{\prime \prime} \mathrm{E}$

Goonaping Swamp, collected by Adrian Pinder and Jane McRae on 3 Oct. 1997, approximate coordinates: $32^{\circ} 27^{\prime} 46^{\prime \prime} \mathrm{S} 119^{\circ} 25^{\prime} 1^{\prime \prime} \mathrm{E}$. (illustrated specimens from this locality: RV + LV of a female (WAM.C49377); two female carapaces (WAM.C49378) all from OST11C).

Christopher Brook, collected by Adrian Pinder and Jane McRae on 28 Oct. 1997, approximate coordinates: $32^{\circ} 10^{\prime} 12^{\prime \prime S} 116^{\circ} 47^{\prime} 39^{\prime \prime E}$. (illustrated specimens from this locality: RV + LV of a female (WAM.C49379) from OST11A). 
Cobertup Swamp, collected by Andrew Storey and SH on 19 Oct. 1996, approximate coordinates: $34^{\circ}$ 27'00'S 116 49'00'E.

One Tree Hill, collected by SH and Adrian Pinder on 11 Aug. 1999, approximate coordinates: $29^{\circ} 35^{\prime}$ 19 'S $115^{\circ} 26^{\prime} 31$ 'E.

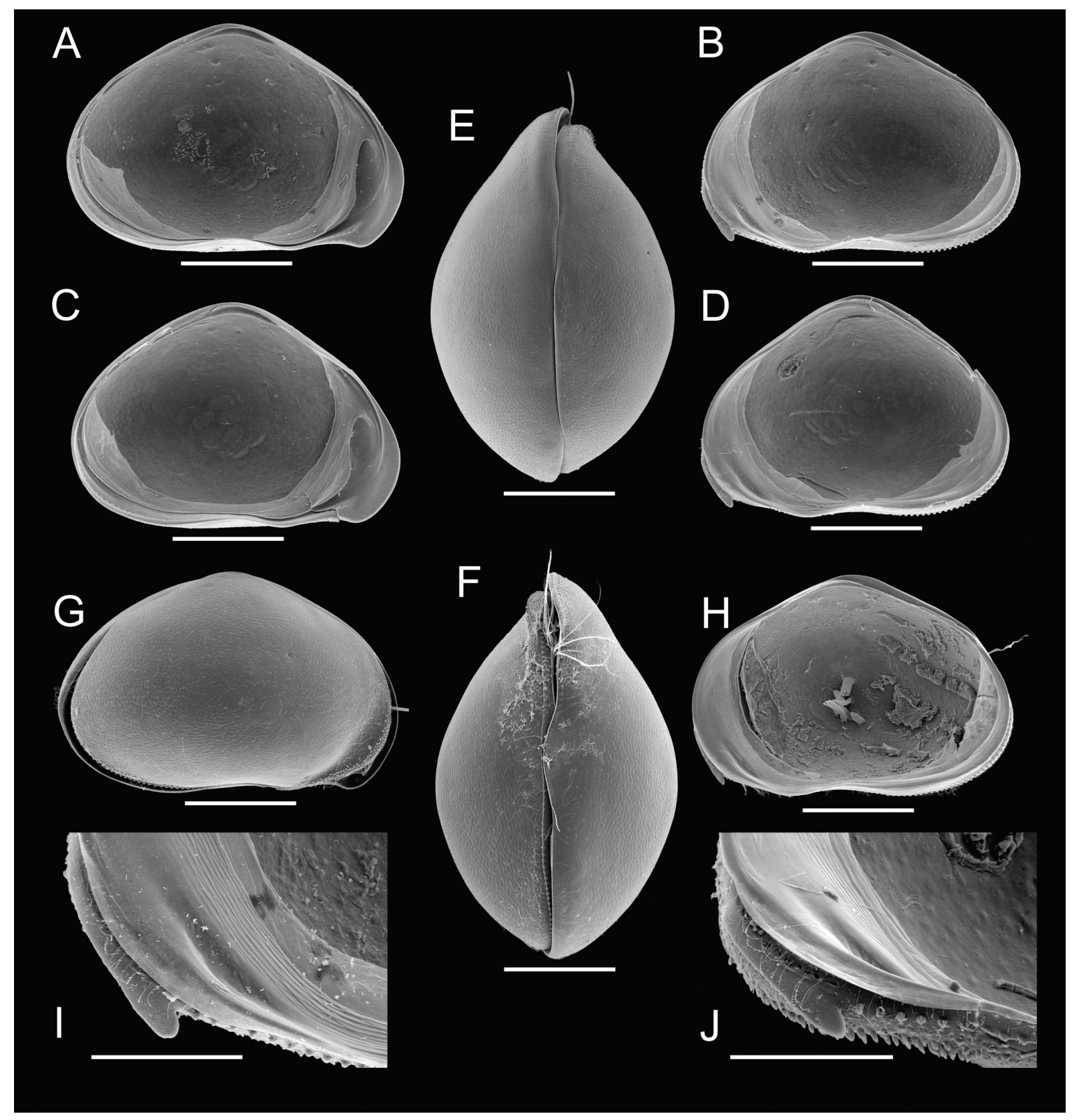

Fig. 5. Bennelongia cygnus sp. nov. A. LVi (†, Ellen Brook, OC.3311). B. RVi (q, Ellen Brook, Idem). C. LVi (ô, Ellen Brook, OC.3310). D. LVi (ô, Ellen Brook, Idem). E. Cp dorsal (†, Goonaping Swamp, WAM.C49378A). F. Cp ventral ( + , Goonaping Swamp, Idem). G. CpRe ( + , Goonaping, WAM. C49378B). H. RVi ( , Goonaping, WAM.C49377). I. RVi (detail anteriorly, ㅇ, Ellen Brook, OC.3311).

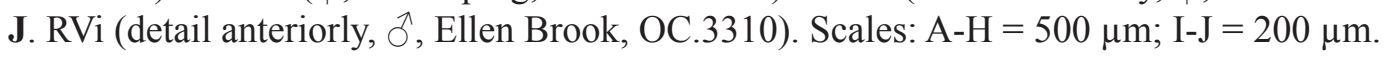




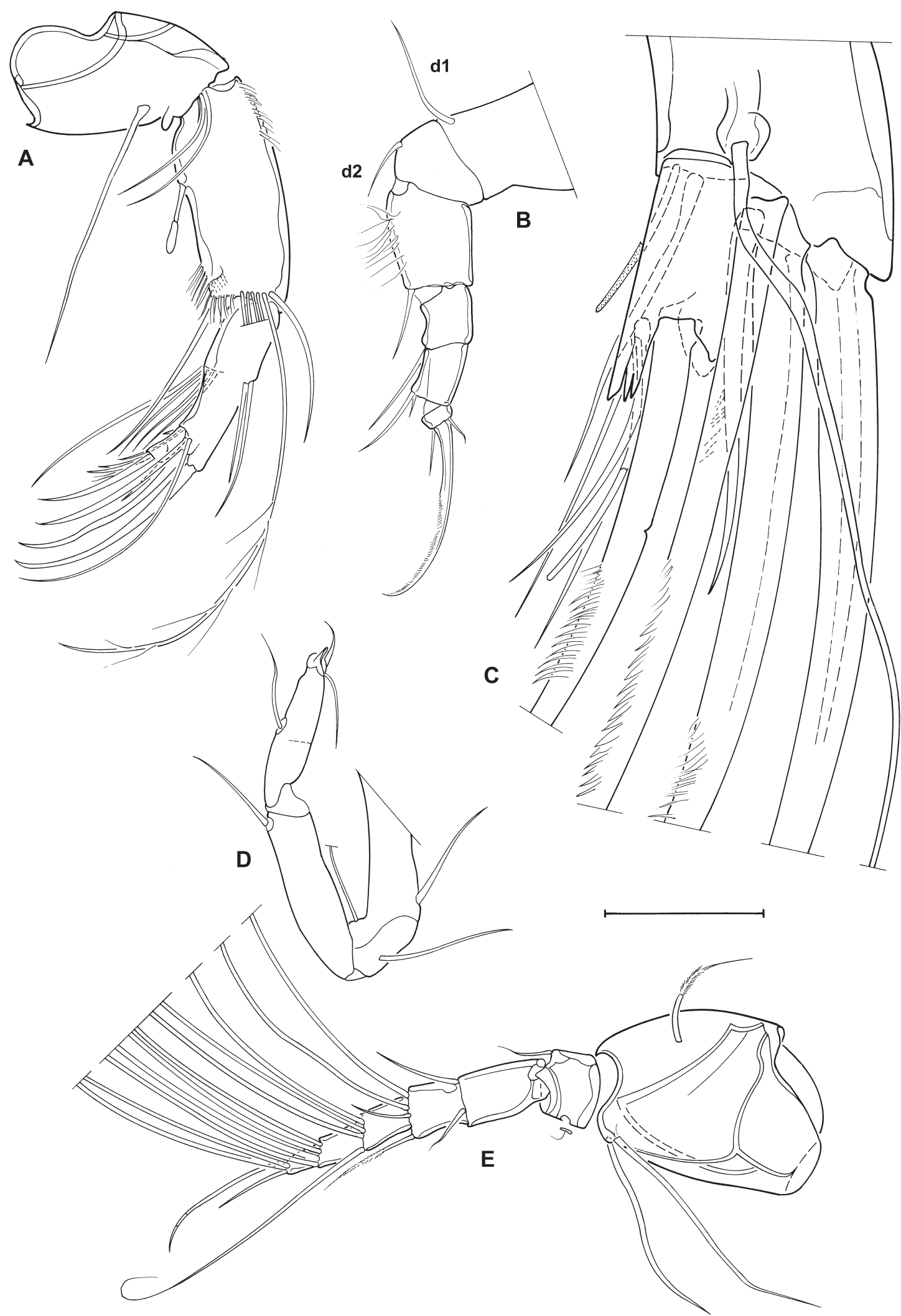

Fig. 6. Bennelongia cygnus sp. nov. (all from holotype $\widehat{\jmath}$, WAM.C49370). A. A2. B. T2. C. A2, detail of distal chaetotaxy. D. T3. E. A1. Scales: A, B, E $=232 \mu \mathrm{m} ; \mathrm{D}=184 \mu \mathrm{m} ; \mathrm{E}=37 \mu \mathrm{m}$. 


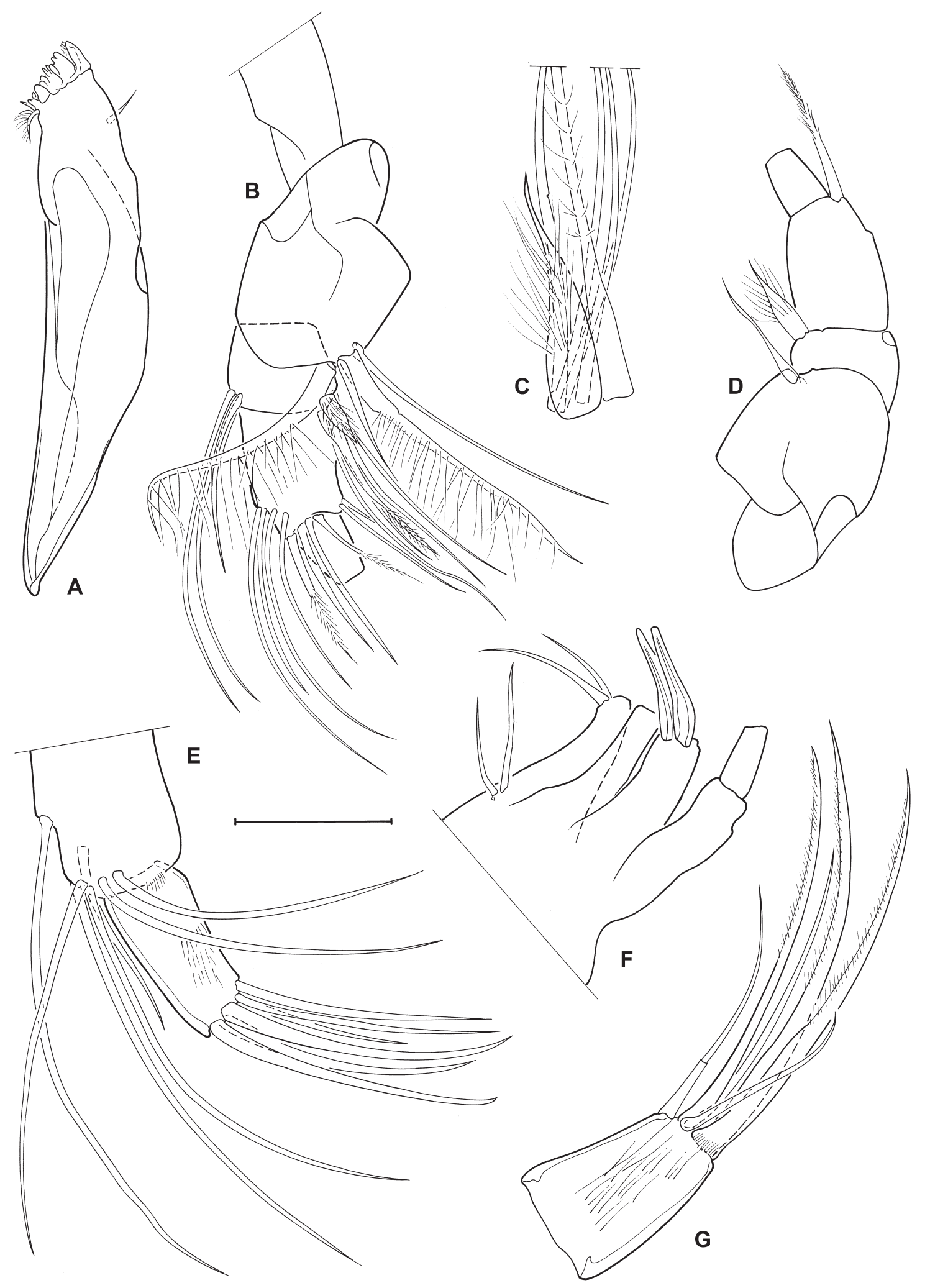

Fig. 7. Bennelongia cygnus sp. nov. (all from holotype $\widehat{\jmath}$, WAM.C49370). A. Md-coxa. B. Md-palp. C. Md-palp. Detail of $\beta$-seta and accompanying setae. D. Md-palp, showing $\alpha, \beta$, and $\gamma$-setae. E. Mx1-palp, distal chaetotaxy. F. Mx1, partial chaetotaxy. G. Md-palp, chaetotaxy of distal segment. Scales: $\mathrm{A}=232 \mu \mathrm{m} ; \mathrm{B}, \mathrm{D}, \mathrm{F}=92 \mu \mathrm{m} ; \mathrm{C}, \mathrm{E}, \mathrm{G}=37 \mu \mathrm{m}$. 


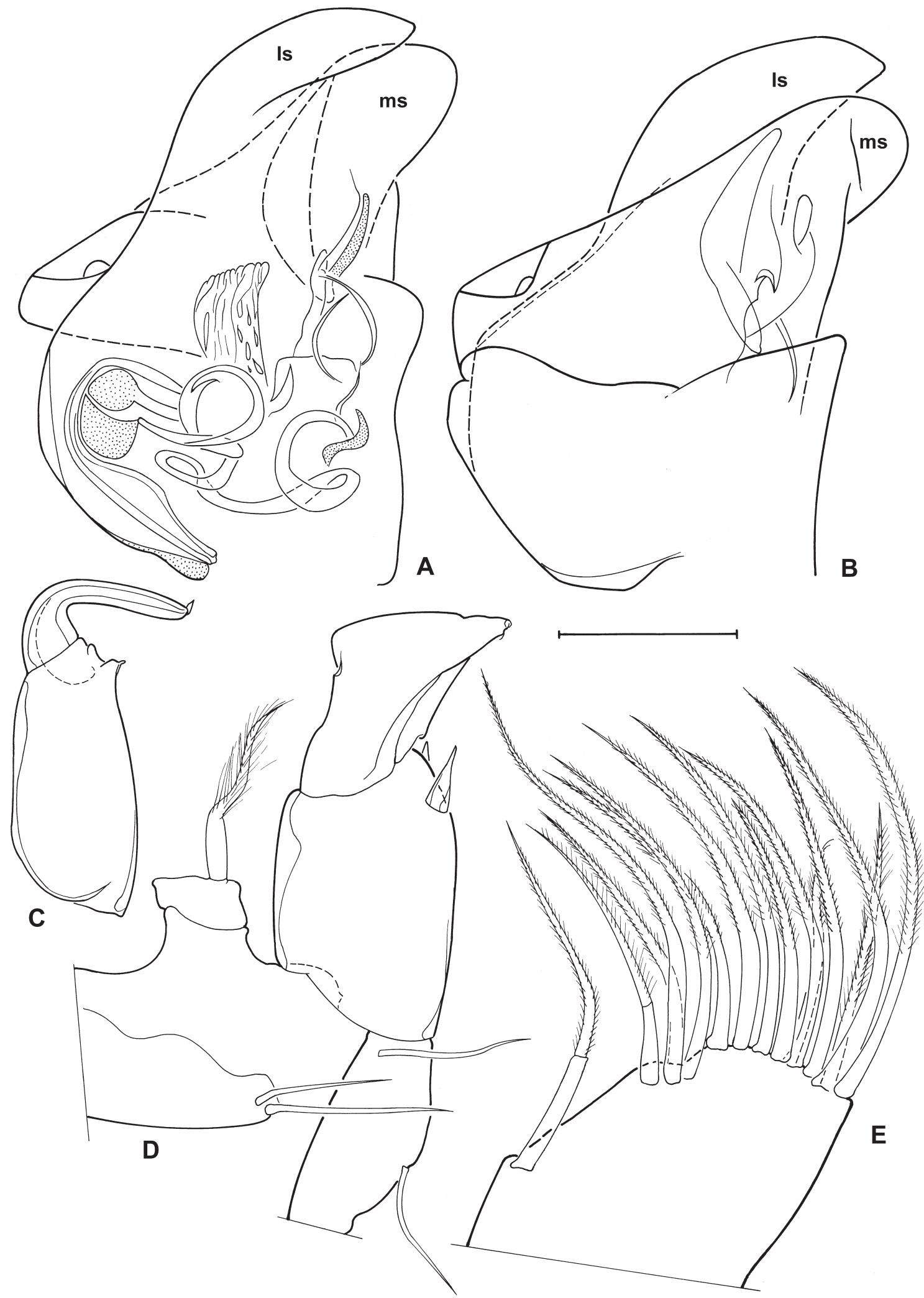

Fig. 8. Bennelongia cygnus sp. nov. (all from holotype §, WAM.C49370). A. Hemipenis, showing internal anatomy of labyrinth. B. Outline of other hemipenis. C. Left prehensile palp. D. Right T1, showing partial chaetotaxy and right prehensile palp. E. Right T1, showing distal chaetotaxy of endopodite. Scales: A-D $=92 \mu \mathrm{m} ; \mathrm{E}=37 \mu \mathrm{m}$. 


\section{Differential diagnosis}

Bennelongia cygnus sp. nov. defines the B. cygnus lineage by its triangular shape, the simple type of hemipensis and the pointed lapel. It can be distinguished from the other species in this lineage, B. frumenta sp. nov. (see below), by the absence of a cavity in the selvage near the lapel, the presence of a dorsal lobe on the ms of the hemipenes, the short second segment of the Lpp and the broad base of the second segment of the Rpp.

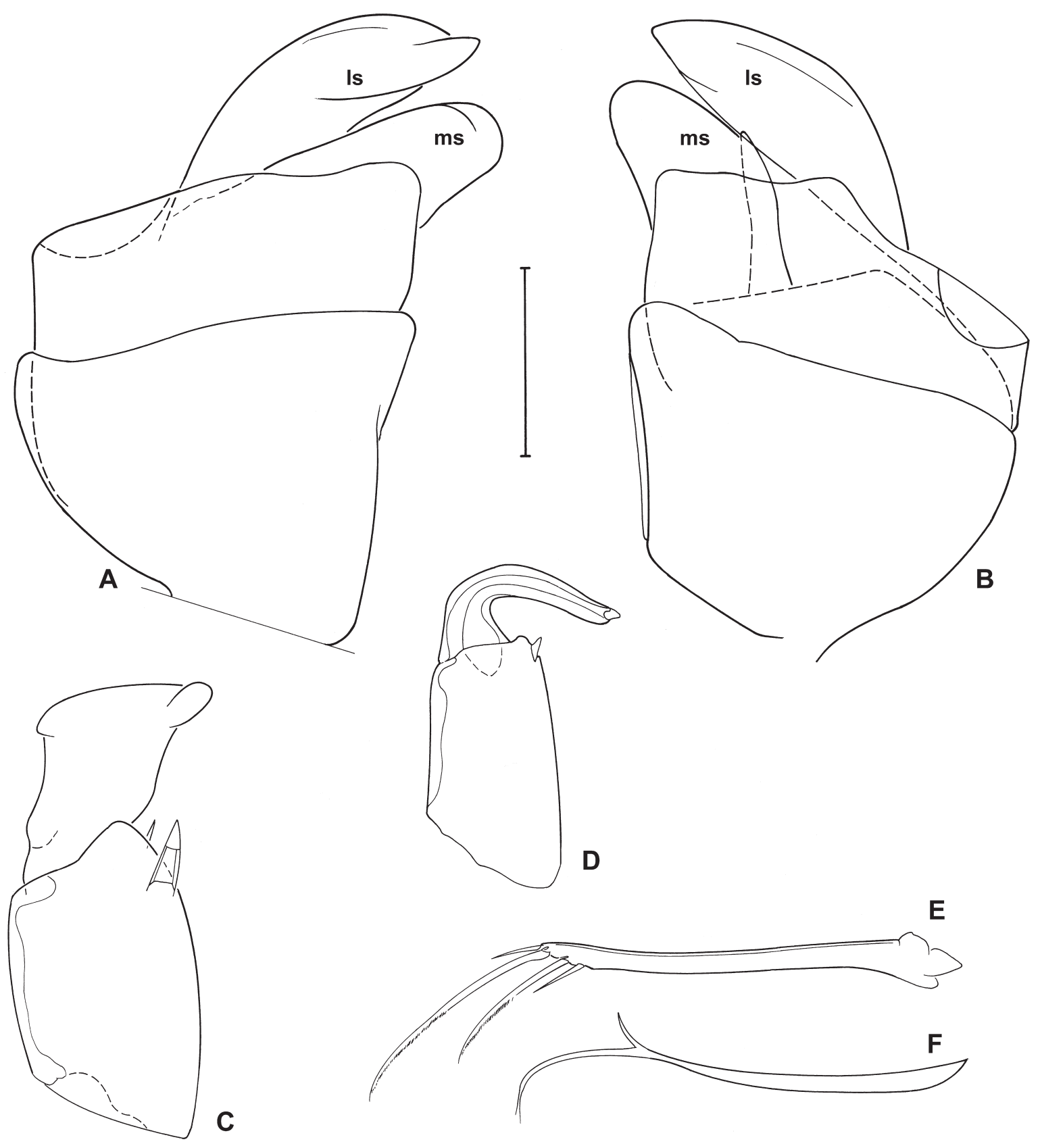

Fig. 9. Bennelongia cygnus sp. nov. đ̊. A. Outline of hemipenis (WAM.C49375). B. Outline of second hemipenis of same individual (WAM.C49375). C. Right prehensile palp (WAM.C49375). D. Left prehensile palp (WAM.C49375). E. Caudal ramus (holotype $\widehat{\jmath}$, WAM.C49370). F. Supporting branch of caudal ramus (holotype $\widehat{\jmath}$, WAM.C49370). Scales: A-D $=92 \mu \mathrm{m} ; \mathrm{E}, \mathrm{F}=184 \mu \mathrm{m}$. 


\section{Additional descriptions}

Male valves (Figure 5C, D) slightly smaller and more highly arched than female valves (Figure 5A, B, $\mathrm{H})$, otherwise very similar in appearance. Both valves triangular, with greatest height situated in the middle of the valves, dorsal margins equally sloping to both anterior and posterior margins, ventral margin almost straight. Valves weakly pitted and set with few, very short setae.

LV (Figure 5A, C) with posterior calcified lamella narrow, inner list running along valve margin and creating a narrow sulcus; the latter continuing towards the anterior side and widening up in between both inner lists (see diagnosis of genus); antero-ventral beak weakly developed.

RV (Figure 5B, D, H) of similar shape as LV, smaller and slightly less high; posterior and ventral margin set with tubercles, anterior calcified lamella with short inner list; lapel relatively long, rather ventrally situated and tear-shaped at its ventral edge (Figure 5I, J) ; posterior side with long inner list (reaching almost up to dorsal margin) and with selvage clearly inwardly displaced.

Width of carapace in dorsal (Figure 5E) and ventral (Figure 5F) views more than half the length, greatest width situated in the middle, LV overlapping RV on all sides, especially anteriorly and posteriorly (Figure 5), anterior rostrum very weakly built, to almost absent.

A1 (Figure 6E) with all segments relatively short and narrow, natatory setae long, chaetotaxy as typical of the family.

A2 (Figure 6A, C) with 5 natatory setae extending beyond tips of end claws, basic chaetotaxy and sexual dimorphism in chaetotaxy of penultimate segment as typical of the family: in female with claws G1-G3 and z1-3 setae; in males with G1 a short claw, G2 a large claw and G3 a seta of intermediate length; z1 and z2 large claws, z3 a long seta.

Md coxa (Figure 7A) relatively slender, without special features. Mandibular palp (Figure 7B-D, G) with chaetotaxy as typical of the family, endclaws and gamma seta unusually slender.

Mx1 (Figure 7E, F) with second palp segment rectangular, $c$. twice as long as basal width, 3 claws of this segment relatively slender. Third endite with smooth 'zahnborsten'. Sideways directed bristles on first endite of unequal length.

T1 (Figure 8C-E) with endite bearing 16, mostly hirsute, setae of unequal length. Females with endopod a palp bearing 3 unequal apical setae. Males with endepod developed in asymmetrical prehensile palps. Rpp (Figures 8D, 9C) with basal segment stout and only slightly longer than the largest width, subapically with two unequal sensory organs; second segment trapezioidal, with blunt dorsal and pointed ventral edge. Lpp (Figures 8C, 9D) with first segment more slender, almost twice as long as wide, distal segment sickle-shaped but relatively short ( $\mathrm{L}=<$ half $\mathrm{L}$ of first segment).

T2 (Figure 6B) a walking leg with seta $\mathrm{d} 1>\mathrm{d} 2$.

T3 (Figure 6D) a cleaning limb.

CR (Figure 9E) and its attachment (Figure 9F) slender.

Hemipenes (Figures 8A, B; 9A, B) almost symmetrical, with 1s slender, with rounded dorsal margin and bluntly pointed distal edge; ms consisting of two sub-lobes, one rectangular, the second one elongated and ventrally directed, with rounded edge.

\section{Ecology and distribution}

The species appears to be comparatively widespread in freshwater bodies in south-western parts of Western Australia. The species was found in clear or darkly coloured water with conductivity ranging from $80-3120 \mu \mathrm{S} \mathrm{cm}^{-1}$ and $\mathrm{pH}$ 6.8-8.5. 


\section{Remarks}

One male specimen (WAM.C49375 - Figure 9A, B) had aberrant morphology of hemipenes and Rpp. The hemipenes were asymmetrical, with one being typical of the species, the other bearing an additional thumb-like expansion of the 1s. The same specimen also had an additional distal thumb-like expansion of the second segment of the Rpp. Rather than considering this a different species, we decided that it is most likely a teratological specimen.

\section{Bennelongia frumenta sp. nov.}

(Figs 10-11)

\section{Etymology}

Bennelongia frumenta sp. nov. is typical of the south-western side of the Western Australian wheatbelt. Wheat $=$ frumenta in Latin.

\section{Diagnosis}

Valves triangular in lateral view, weakly pitted, width more than half the length in dorsal / ventral view and with rostrum well-developed. LV with beak weakly developed. RV with lapel triangular, ventrally pointed; selvage near lapel with a cavity, visible with SEM, but especially with transparent light. Hemipenis with 1s slightly extending beyond ms, 1s distally rounded and with bluntly pointed apex; ms ventrally and dorsally without lobe-like expansion. Rpp with trapezoidal distal segment; with nearly straight distal margin and very narrow base. Lpp with distal segment sickle-shaped, elongated, almost as long as first segment.

\section{Measurements (all measurements in $\mu \mathrm{m}$ )}

Male: $R V: L=1310 ; \mathrm{H}=907$. $L V: L=1430 ; \mathrm{H}=933$. $\mathrm{Cp}: \mathrm{L}=1320-1330 ; \mathrm{H}=841 ; \mathrm{W}=810-826$.

Female: RV: $\mathrm{L}=1320-1390 ; \mathrm{H}=851-905$. LB: $\mathrm{L}=1460-1500 ; \mathrm{H}=962 . \mathrm{Cp}: \mathrm{L}=1400-1520 ; \mathrm{H}=878$; $\mathrm{W}=901-907$.

\section{Type locality}

Kodjinup Melaleuca Swamp, $6 \mathrm{~km}$ N of Lake Muir in the Cranbrook shire (WA), collected by Adrian Pinder and Jane McRae on 2 Oct. 1998, approximate coordinates; $34^{\circ} 23^{\prime} 45^{\prime \prime S} 116^{\circ} 39^{\prime}$ 1'E (OSTR11A, SPS105).

\section{Type material}

\section{Holotype}

Female (WAM.C49380), with soft parts dissected in a sealed slide and valves stored dry in a micropalaeontological slide.

\section{Allotype}

Male (WAM.C49381), with soft parts dissected in a sealed slide, valves kept in EtOH (decalcified).

Paratypes

$\mathrm{LV}+\mathrm{RV}$ of a female (OC.3312); one female carapace (WAM.C49383); three male carapaces (WAM. C49382A-C); soft parts of one male (WAM.C49384 - valves lost).

Several in toto specimens in EtOH (voucher specimens WAM.C49385). 


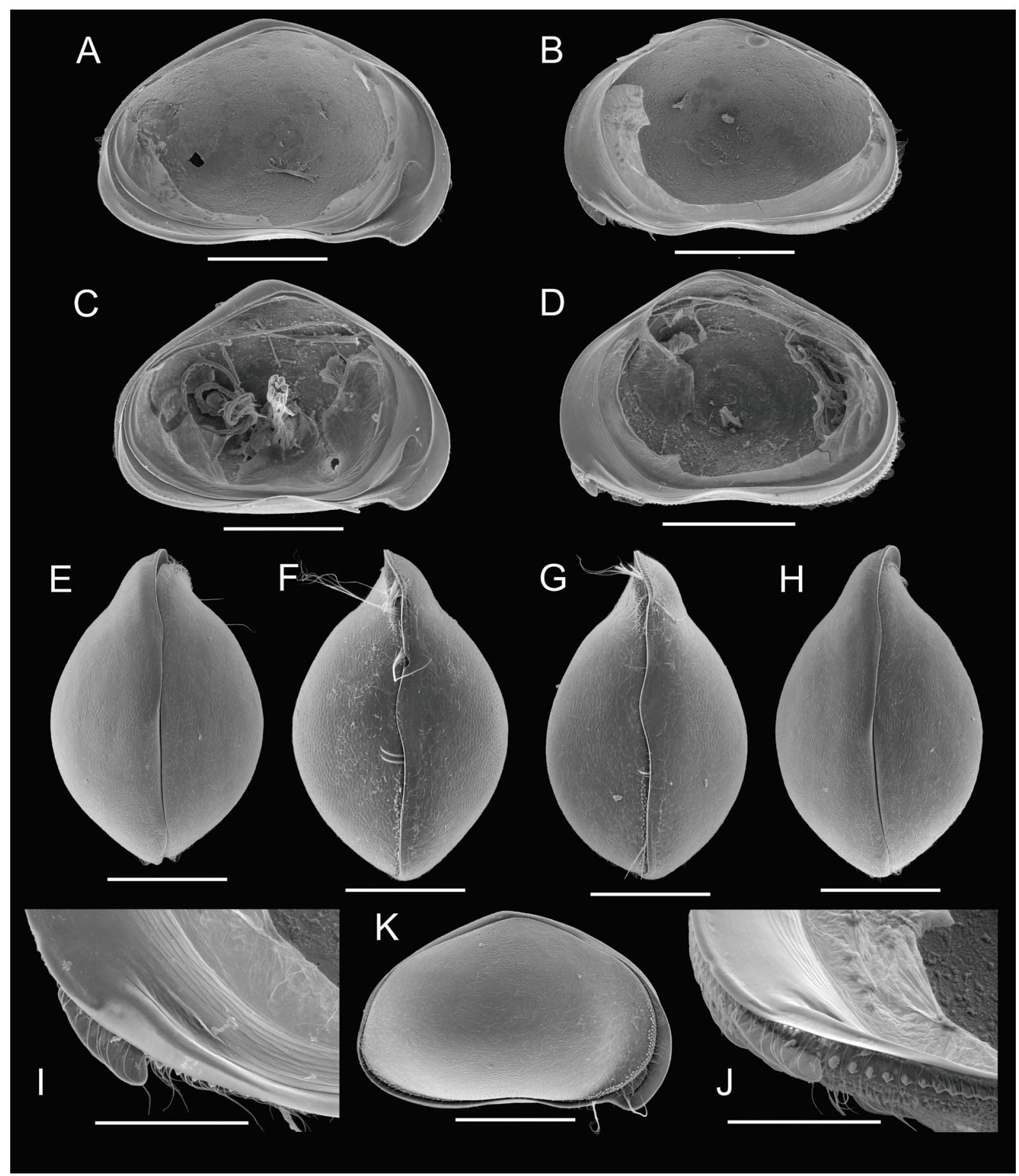

Fig. 10. Bennelongia frumenta sp. nov. A. LVi (holotype $q$, Kodjinup Melaleuca Swamp, WAM.C49380). B. RVi (†, Kodjinup Melaleuca Swamp, Idem). C. LVi (ð̋, West Kulunilup Swamp, OC.3313). D. RVi (ठ, West Kulunilup Swamp, Idem). E. Cp dorsal (†, Kodjinup Melaleuca Swamp, WAM.C49383). F. Cp ventral (q, Kodjinup Melaleuca Swamp, WAM.C49388). G. Cp ventral (ठ઼, West Kulunilup Swamp, WAM.C49382). H. Cp dorsal (ô, Kodjinup Melaleuca Swamp, WAM.C49382). I. RVi (detail anteriorly, holotype +, Kodjinup Melaleuca Swamp, WAM.C49380). J. RVi (detail anteriorly, , Kodjinup Melaleuca Swamp, Idem). K. CpRe ( + , Kodjinup Melaleuca Swamp, WAM.C49383). Scales: A-H, $K=500 \mu \mathrm{m} ; \mathrm{I}-\mathrm{J}=200 \mu \mathrm{m}$. 


\section{Other material investigated}

Wetland south east of Kodjinup Swamp, collected by Andrew Storey and SH on 21 Oct. 1997, approximate coordinates: $34^{\circ} 23^{\prime} 00^{\prime \prime} S 116^{\circ} 40^{\prime} 00^{\prime \prime}$. Specimens from this locality: a dissected male (WAM.C49386); LV+RV of a female (WAM.C49387).

Job's Sump, collected by Jane McRae and Mick Smith on 10 Oct. 1997, approximate coordinates: $32^{\circ}$ 21'15'S 117 39' 27'”E (SPS060).

West Kulunilup Swamp, collected by Andrew Storey and SH on 22 Oct. 1997, approximate coordinates: $34^{\circ} 20^{\prime} 00^{\prime \prime} \mathrm{S} 116^{\circ} 47^{\prime} 00^{\prime \prime}$. Specimens from this locality: several voucher specimens in EtOH (OSTR13E), slide \#38, a dissected male (OC.3313) and a female CP (WAM.C49388).

Unnamed claypan, Pingrup, collected by Adrian Pinder on 13 Sep. 2007, approximate coordinates: $33^{\circ}$ 26' 49"S $118^{\circ} 30^{\prime} 41^{\prime \prime}$. Specimens from this locality: several voucher specimens in EtOH (OSTR13G, $\mathrm{ABP} 051) ; \mathrm{LV}+\mathrm{RV}$ of a female (OC.3314).

Lake Wheatfield, collected by David Cale on 26 Oct. 2005, approximate coordinates: $33^{\circ} 48^{\prime} 46^{\prime \prime} \mathrm{S} 121^{\circ}$ 55'38'E (SPM005B).

\section{Differential diagnosis}

Bennelongia frumenta sp. nov. belongs to the B. cygnus lineage because of its triangular shape, the simple type of hemipenis and the pointed lapel. It can be distinguished from the other species in this lineage, B. cygnus sp. nov. (see above), by the presence of a cavity in the selvage near the lapel, the absence of a dorsal lobe on the ms of the hemipenes, the elongated second segment of the Lpp and the narrow base of the second segment of the Rpp.

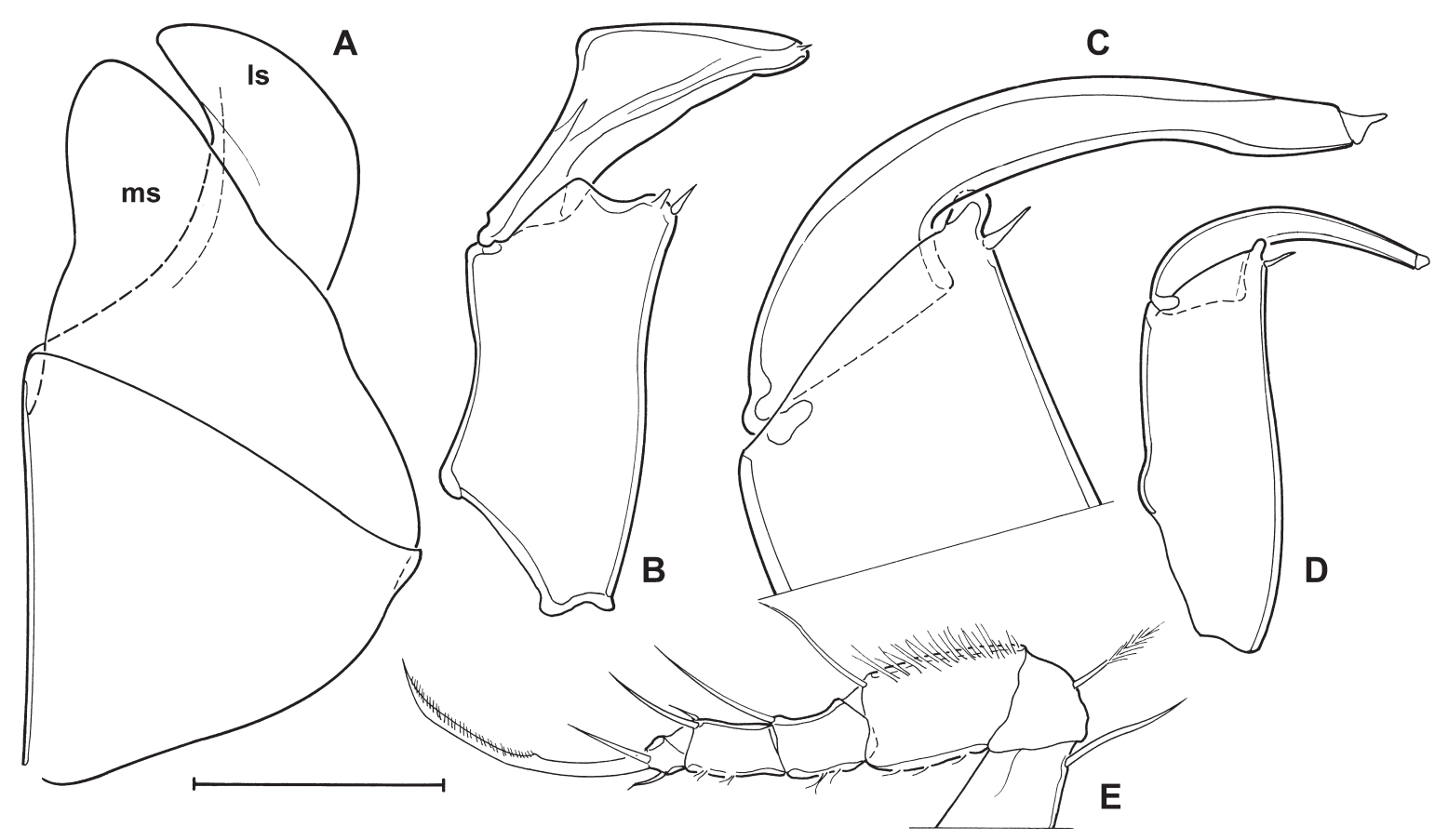

Fig. 11. Bennelongia frumenta sp. nov. (all allotype đ̂, WAM.C49381, Kodjinup Melaleuca, type locality). A. Outline of hemipenis. B. Right prehensile palp. C. Left prehensile palp, detail of distal part. D. Left prehensile palp. E. T2 (walking leg). Scales: $E=232 \mu \mathrm{m} ; \mathrm{A}-\mathrm{C}=92 \mu \mathrm{m} ; \mathrm{D}=37 \mu \mathrm{m}$. 


\section{Additional description}

Valves triangular (Figure 10A-D), with greatest height situated in the middle; LV overlapping RV on all sides (Figure 10K), dorsally only in the first half of the carapace, ventral margin almost straight; width of carapace in dorsal and ventral views (Figure 10E-H) more than half the length, greatest width situated in the middle, anterior rostrum strong; carapace weakly pitted and set with few, very short setae.

Male valves slightly smaller and more highly arched than female valves, otherwise very similar in appearance.

LV (Figure 10A, C) with posterior calcified inner lamella narrow, inner list running along valve margin and creating a narrow sulcus; this sulcus continuing towards the anterior side and widening up in between both anterior inner lists; antero-ventral beak weakly developed.

RV (Figure 10B, D) of similar shape as LV, smaller and slightly less high; posterior and ventral margin set with tubercles, anterior calcified inner lamella with short inner list, the latter forming a 'cavity' in and on the selvage near the lapel; lapel relatively long, rather ventrally situated and ventrally pointed (Figure 10I, J) ; inner margin of posterior calcified inner lamella with long inner list (reaching almost up to dorsal margin) and with selvage submarginal.

Most appendages as typical of the genus and without special features.

Rpp (Figure 11B) with basal segment elongated, c. $1.5 \mathrm{x}$ the central width; subapically with two unequal sensory organs; second segment trapezoidal, with blunt dorsal and pointed ventral edge, distal margin nearly straight, base of segment very narrow.

Lpp (Figure 11C, D) with first segment more slender, more than twice as long as wide, subapically with an elongated outgrowth, subapically with a short sensory organ; distal segment sickle-shaped and elongated, longer than dorsal margin of first segment.

Walking leg (Figure 11E) stout and hirsute.

Hemipenes (Figure 11A) symmetrical; LS with rounded dorsal margin and bluntly pointed distal edge; MS with oblique but straight distal margin, ventrally with a broadly rounded lobe, ventrally without additional lobe.

\section{Ecology and distribution}

The species has thus far been found in a variety of seasonal and, less commonly, permanent wetlands and streams in the south-western Wheatbelt of Western Australia and in higher rainfall areas. The species has been recorded in water with conductivity $1550-9260 \mu \mathrm{S} \mathrm{cm}^{-1}$ and $\mathrm{pH}$ 6.0-9.6.

\section{Bennelongia australis - lineage}

\section{Remarks}

Brady (1886) described Chlamydotheca australis based on empty valves collected by Prof R. Tate from Penola (South Australia). The description was incomplete and, as pointed out by De Deckker (1981a), most likely also erroneous: although the LV (Brady 1886, plate 9 fig. 7) is undoubtedly of a species of Bennelongia, the RV is not. De Deckker (loc.cit.) investigated the type material of Chlamydotheca australis in the British Musuem (presently the Natural History Museum, London) and found that the slide contained the illustrated Bennelongia LV as well as a second LV, most likely belonging to a species of Heterocypris. It is likely that this is the valve illustrated by Brady (1886, plate 9 fig. 8). As it is the RV that shows most specific features of Bennelongia species, the true identity of Bennelongia australis will be impossible to establish based on the type material only. New material from Penola will be necessary 
and topotypes must be established to determine what species is the true $B$. australis. Below, we describe 5 sibling species in this lineage, which can be identified based on shape of the valves, form of the lapel on the RV, shape of the hemipenis and of the prehensile palps. The identity of four of these species was confirmed by molecular screening (see above).

De Deckker (1981a) extensively redescribed what he thought to be B. australis, based on material from Western Australia (mainly from pools near Leonora and Cunderdin). Based on the illustrated lapels, it is clear that this redescription is based on at least two different species within the B. australis lineage, neither of which are present in our collections. Given the regional specificity of the species within this lineage, it is unlikely that the true B. australis, described from South Australia is amongst the species used by De Deckker (1981a).

Davies \& Christidis (1997) also illustrated a specimen of what they labelled B. australis, collected from lakes in and around Perth. We have collected material from two of the same lakes and describe this species below as B. gwelupensis sp. nov. The species figured by Davies \& Christidis (1997) as Bennelongia sp. was described above as $B$. cygnus sp. nov. Karanovic (2008) illustrated specimens from Pilbara as B. australis s.l. These specimens belong to B. strellyensis sp. nov. in the B. pinpi lineage (see below).

The $B$. australis lineage is characterized by relatively large carapaces, LV with intermediately sized beaks and RV with lapel. Most species described here also have rounded dorsal margins and have pronounced anterior (and sometimes posterior) rostrum in dorsal view.

Bennelongia coondinerensis sp. nov.

(Figs 12, 13, 14A, B)

\section{Etymology}

The species is named after its type locality, Coondiner Pool, Pilbara.

\section{Diagnosis}

$\mathrm{Cp}$ with pronounced anterior rostrum, and weaker posterior rostrum. LV with pronounced anteroventral beak and rounded dorsal margin. Lapel on RV tear-shaped, dorsally sloping towards valve margin. Hemipenis with MS with straight margin, ventrally widely produced as a rounded lobe; is in one hemipene rounded, and distally bluntly pointed, in second hemipenis distally with thumb-like process; tips of 1s and ms well-separated, 1s extending clearly beyond ms. Rpp with distal segment triangular, rather broad. Lpp with proximal segment bearing rectangular apical outgrowth; distal segment sickleshaped, tapering and rather elongated.

\section{Measurements (all measurements in $\mu \mathrm{m}$ )}

Male: RV: $\mathrm{L}=1640, \mathrm{H}=971$. LV: $\mathrm{L}=1690, \mathrm{H}=911$. Cp: $\mathrm{L}=1690-1710 ; \mathrm{W}=911-913$. Female: $R V: L=1750, H=1040 . L V: L=1860, H=1120 . C p: L=1810-1890 ; \mathrm{W}=1020-1080$.

\section{Type locality}

Coondiner Pool, Pilbara, WA (sample KIES14); approximate coordinates: 22 43'26'S 119 39' 23'E. All material used for the present description collected on 24 Apr. 2006 by the authors.

\section{Type material}

\section{Holotype}

Male (WAM.C49389), with soft parts dissected in a sealed slide and valves stored dry in a micropalaeontological slide. 
Allotype

Female (WAM.C49390), with soft parts dissected in a sealed slide and valves stored dry in a micropalaeontological slide.

Paratypes

One male dissected and stored as the holotype (OC.3315); three male carapaces (WAM.C49391A, WAM.C49392), two female carapaces (WAM.C49391B-C). 2RV+1LV of a female (OC.3317A-C).

Several in toto specimens in EtOH (WAM.C49393).

\section{Other material investigated}

Ethel Creek Clay pan, Pilbara, approximate coordinates: 22 49' 32"S $120^{\circ} 15^{\prime} 32^{\prime \prime}$. Collected by the authors on 24 Apr. 2006.

\section{Differential diagnosis}

The species belongs to the $B$. australis group because of the generally large size ( $\mathrm{L}>1500 \mu \mathrm{m}$ ), the presence of a lapel on the RV and of a strong anterior rostrum in dorsal view. It can be distinguished from the other species in this lineage by the rounded dorsal margin of the LV, the tear-shaped lapel, the broad second segment of the Rpp, the fact that tips of ls and ms of the hemipenes are well-separated from each other and that ls extends well beyond the ms.

The shape of the lapel somewhat resembles that of the second species redescribed by De Deckker (1981a) as B. australis (from a pool close to Cunderdin), yet these latter specimens have much more highly arched valves, while also the edge of the beak in the LV is less pointed than in $B$. coondinerensis sp. nov.

\section{Additional description}

Valves in lateral view with rounded dorsal margin (Figure 12A-D), LV overlapping RV on all sides (Figure 12K, L), greatest height anterior to the middle; in dorsal and ventral views (Figure 12E-H) with greatest width in the middle of the carapace; anterior rostrum well-developed, posterior side weakly pointed, LV dorsally ridge-like; external surface weakly pitted and set with setae of intermediate length.

LV in inner view (Figure 12A, C) with rounded dorsal margin, greatest height situated in the middle; antero-ventral beak-like expansion rather large; posterior part of ventral margin markedly sloping in dorsal direction.

RV (Figure 12D) in inner view with greatest height situated in front of the middle, dorsal margin almost straight for about the middle third; posterior selvage clearly inwardly displaced in the posterior half of the valve, posterior inner list merging with posterior selvage at about halfway the length of the latter; lapel tear-shaped (Figure 12I, J), dorsally sloping towards the valve margin, ventrally abruptly curving towards it; antero-ventral inner list running to about halfway the lapel; selvage at height of lapel expanded and slightly striate.

Most appendages as typical of the genus and without special features.

Rpp (Figure 13A) with first segment c. 1.5 times as long as wide, subapically with one long but slender, and one short sensory organ; second palp segment triangular, rather broad, with almost straight distal margin; apically with one small sensory organ.

Lpp (Figure 13B) with first segment elongated, more than twice as long as central width, subapically with one stout sensory organ, apically with a rectangular outgrowth, bearing one small sensory organ; second palp segment sickle-shaped and relatively elongated ( $>1 / 2 \mathrm{~L}$ of first segment).

T2 (Figure 13C) a hirsute walking leg, with seta d1 > seta d2. 


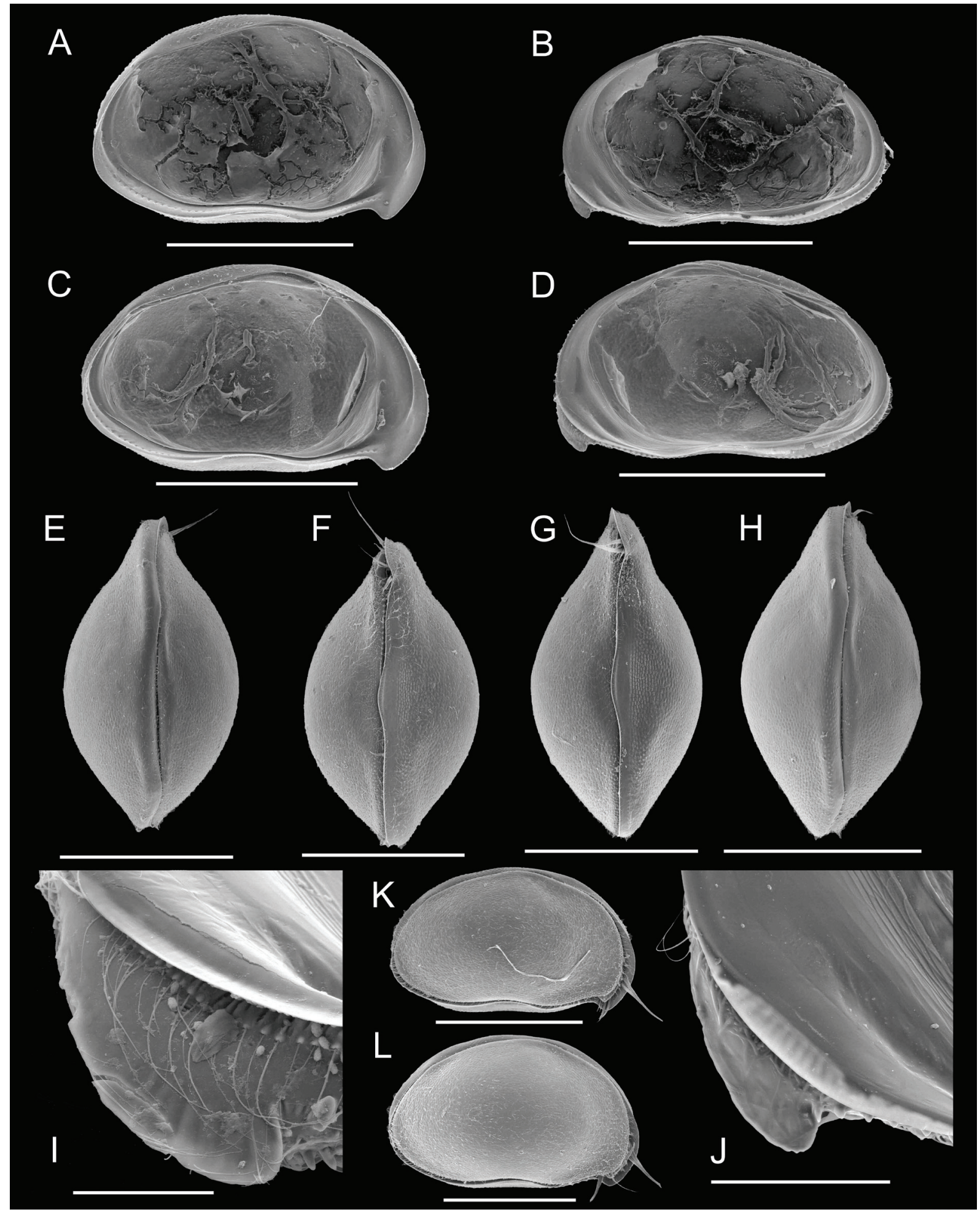

Fig. 12. Bennelongia coondinerensis sp. nov., all from Coondiner Pool (Type locality). A. LVi (allotype

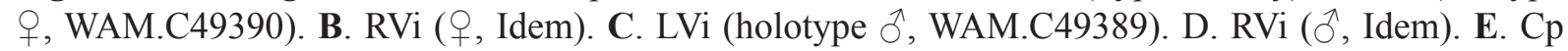
dorsal (q, WAM.C49391C). F. Cp ventral (ㅇ, WAM.C49391B). G. Cp ventral (đ̊, WAM.C49392B).

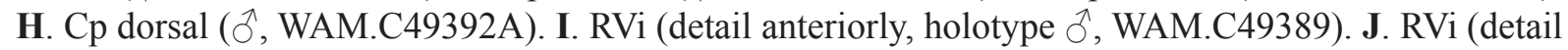

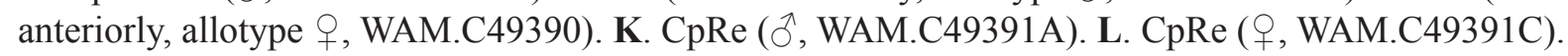
Scales: A-H, K-L $=1000 \mu \mathrm{m} ; \mathrm{J}=200 \mu \mathrm{m} ; \mathrm{I}=100 \mu \mathrm{m}$. 
Hemipenes (Figure 14A, B) with tips of 1s and ms well separated from one another, 1s reaching well beyond tip of $\mathrm{ms}$, distal part of ms produced into an elongated lobe; distal part of ls bluntly pointed with distal margin rounded in one hemipenis, ls almost rectangular with distal thumb-like process in the other.

\section{Ecology and distribution}

Bennelongia coondinerensis sp. nov. has thus far been found in two localities in the Pilbara region. Both clay pans had turbid waters (through suspended clay), with a thin layer of planktonic algae in the top few centimetres of turbid water. This ostracod species has been recorded in water with conductivity $104-197 \mu \mathrm{S} \mathrm{cm}^{-1}$ and $\mathrm{pH}$ 7.7-10.2. This high $\mathrm{pH}$ is almost certainly owing to photosynthetic activity of the mentioned algae.

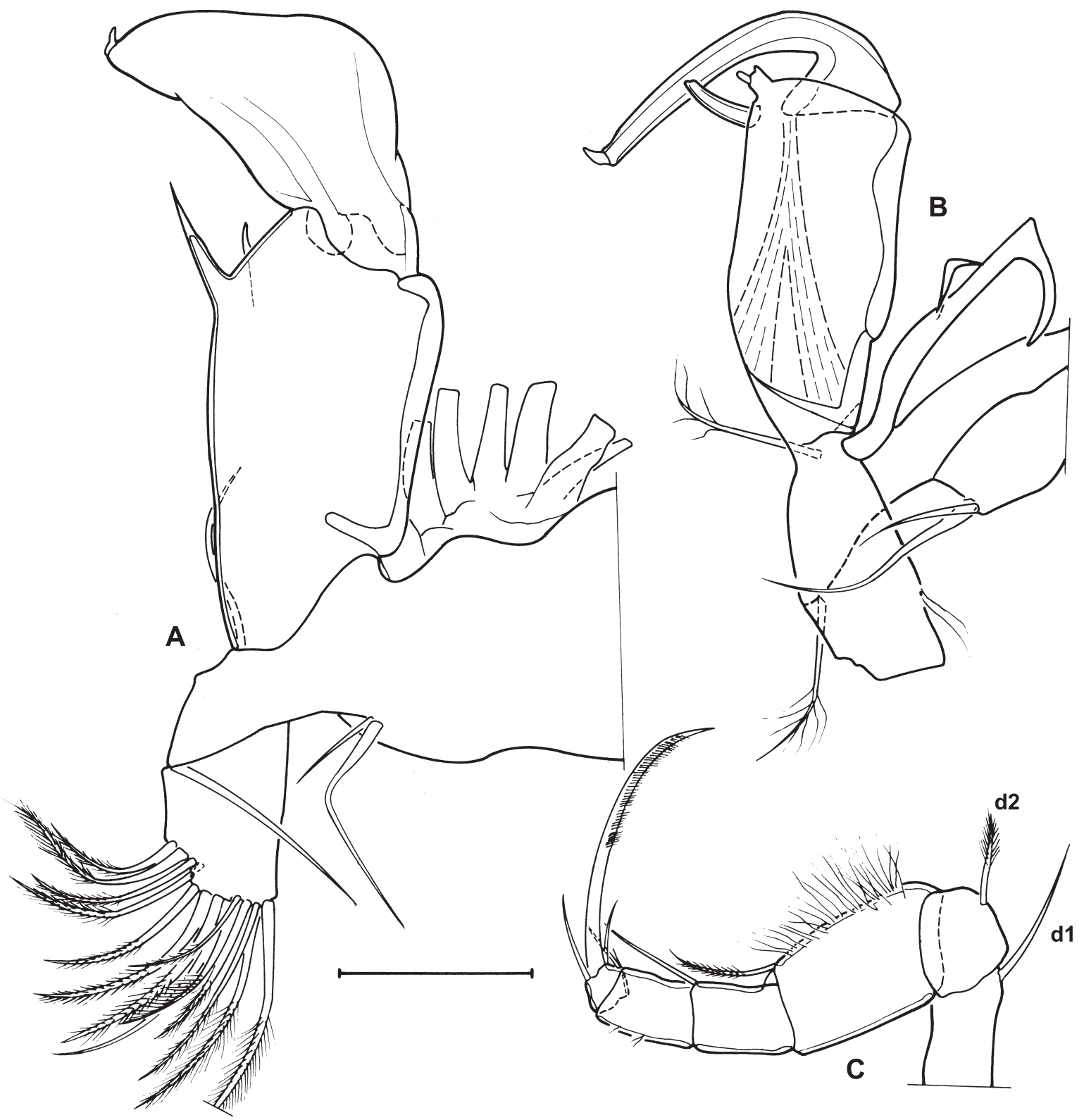

Fig. 13. Bennelongia coondinerensis sp. nov. §ิ. A. T1, showing right prehensile palp (holotype $\widehat{\partial}$, WAM.C49389). B. Left prehensile palp (Idem). C. T2 (OC.3315). Scales: C $=232 \mu \mathrm{m} ; \mathrm{A}, \mathrm{B}=92 \mu \mathrm{m}$. 

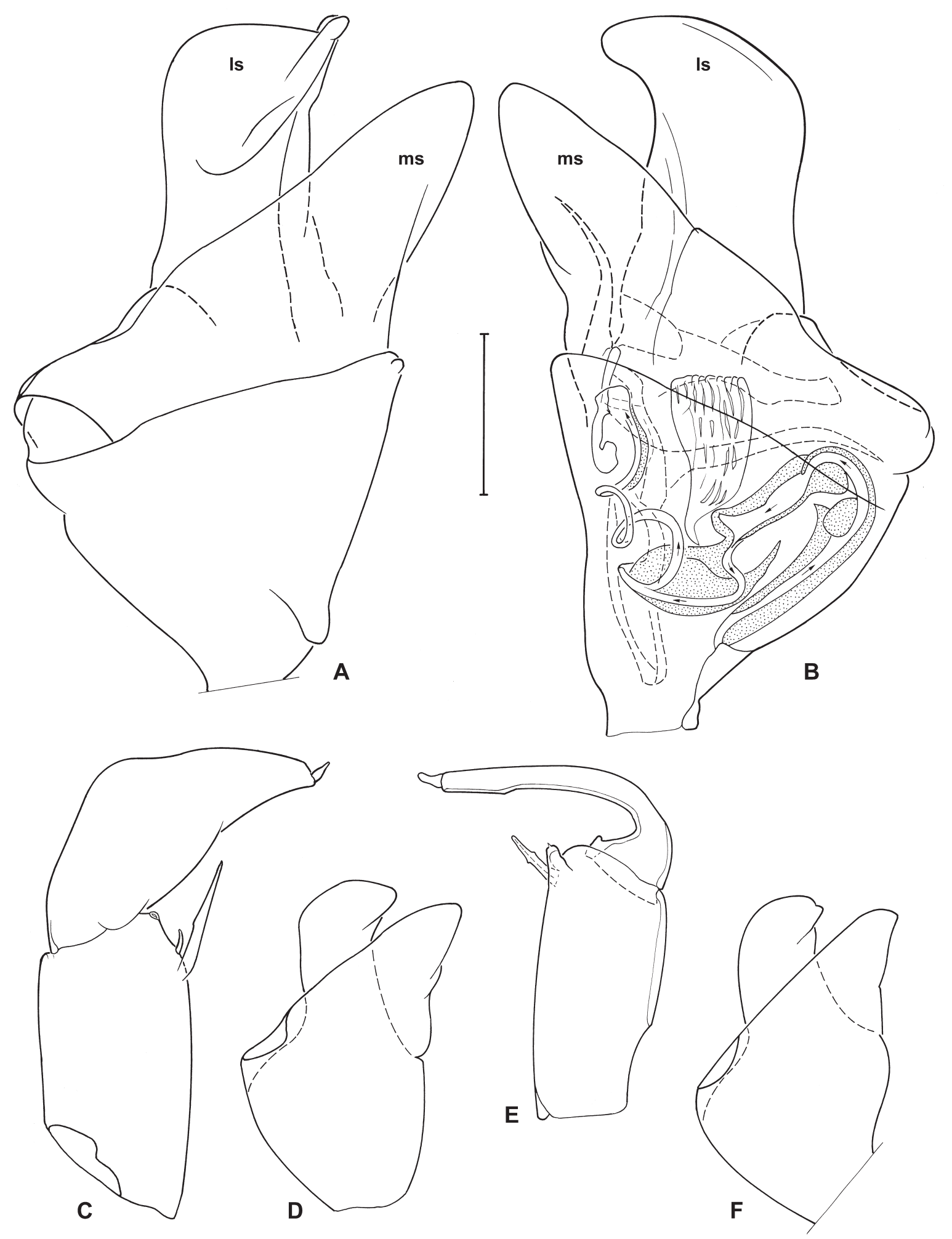

Fig. 14. A-B. Bennelongia coondinerensis sp. nov. (holotype đ, WAM.C49389); C-F. Bennelongia gwelupensis sp. nov. (ð, WAM.C49397). A. Hemipenis outline. B. Other hemipenis, showing inner anatomy. C. Right prehensile palp. D. Hemipenis outline. E. Left prehensile palp. F. Outline of second hemipenis, same individual. Scales: D, F = $232 \mu \mathrm{m}$; A, B, C, E $=92 \mu \mathrm{m}$. 
Bennelongia gwelupensis sp. nov.

(Figs 14C-F, 15)

Bennelongia australis (Brady, 1886) - Davies \& Christidis 1997: 81, figs 8.3.21a,b.

\section{Etymology}

Named after the type locality, Lake Gwelup, Perth.

\section{Diagnosis}

$\mathrm{Cp}$ with pronounced anterior rostrum, and weaker posterior rostrum. LV with pronounced anteroventral beak and rounded dorsal margin. Lapel on RV almost evenly rounded, dorsally sloping towards valve margin. Hemipenis with MS with straight margin, ventrally widely produced as a bluntly pointed lobe; 1s in both hemipenes evenly rounded, distally with blunt tip; tips of ls and ms well-separated, 1s and ms nearly equally long. Rpp with distal segment triangular, relatively elongated. Lpp with proximal segment bearing rectangular apical outgrowth with rounded tip; distal segment sickle-shaped, elongated, as long as first segment, and with almost parallel margins, except for distal part.

\section{Measurements (all measurements in $\mu \mathrm{m}$ )}

Female: $R V: L=1710 ; H=1040 . \mathrm{LV}: \mathrm{L}=1830 ; \mathrm{H}=1110 . \mathrm{Cp}: \mathrm{L}=1610-1820 ; \mathrm{H}=1080 ; \mathrm{W}=860-916$.

\section{Type locality}

Lake Gwelup, Perth (WA); approximate coordinates: $31^{\circ}$ 52' 37'S $115^{\circ} 47^{\prime} 18^{\prime \prime}$. Material used for the present description collected on 23 Dec. 2008 and on 15 July 2010 by the authors.

\section{Type material}

\section{Holotype}

A female (WAM.C49394), with soft parts dissected in glycerine in a sealed slide, valves stored dry in a micropalaeontological slide.

\section{Allotype}

As the population collected at the type locality is fully parthenogenetic, no males occurred (at least at the time of collection) and no allotype can be designated.

\section{Paratypes}

Four female carapaces (WAM.C49395A-D) and several in toto specimens in EtOH (WAM.C49396).

\section{Other material investigated}

Big Carine Swamp, Perth, collected by the authors on 15 July 2010, approximate coordinates: $31^{\circ} 51^{\prime}$ $08^{\prime \prime S} 115^{\circ} 47^{\prime}$ 04"E.

Several pools between Bunbury and Perth, collected by the authors on 04 July 2010 and 31 July 2010. The only male found thus far was in a dense population in a large ditch next to a parking lot beside Forrest Highway, just northeast of the Greenlands Road intersection, 32 38'29'S $115^{\circ} 48^{\prime}$ '34'E (sample MR/10). Specimens from this locality: a male (WAM.C49397) dissected and stored as the holotype; 3 female carapaces (WAM.C49398A-C). All other pools, as well as Lake Gwelup and Big Carine Swamp, held only parthenogenetic populations.

Small unnamed streamlet, inflowing in Leschenault Estuary, collected by the authors on 04 July 2010 and 31.7.2010 This is the most southern locality thus far of this species; approximate coordinates: $33^{\circ}$ 19' 10.3"S $115^{\circ} 41^{\prime} 17.3$ 'E (sample MR/09). Specimens from this locality: RV+LV of one female and a Cp of a female (OC.3316A-B); 


\section{Differential diagnosis}

This species belongs to the $B$. australis group because of the generally large size ( $\mathrm{L}>1500 \mu \mathrm{m}$ ), the presence of a lapel on the RV and of a strong anterior rostrum in dorsal view. It can be distinguished from the other species in this lineage by the rounded dorsal margin of the LV, the rounded lapel, the rather narrow second segment of the Rpp, the fact that tips of $1 \mathrm{~s}$ and $\mathrm{ms}$ of the hemipenes are wellseparated from each other and that $1 \mathrm{~s}$ and $\mathrm{ms}$ are almost equally long.

\section{Additional description}

Valves in lateral view with rounded dorsal margin (Figure 15A-B), LV overlapping RV on all sides (Figure 15C, H), greatest height anterior to the middle; in dorsal and ventral view (Figure 15E,G) with greatest width in the middle of the carapace; anterior rostrum well-developed (Figure 15F), posterior side bluntly pointed, LV dorsally ridge-like; external surface weakly pitted and almost devoid of setae.

LV (Figure 15A) in inner view with rounded dorsal margin, greatest height situated anterior to the middle; antero-ventral beak-like expansion rather large; ventral margin almost straight over most of its length.

RV (Figure 15B) in inner view with greatest height situated well in front of the middle, dorsal margin almost straight for about the middle third; posterior selvage submarginal, posterior inner list merging with posterior selvage at about halfway the length of the latter; lapel (Figure 15G, I, J) rounded, dorsally sloping towards the valve margin, ventrally gently curving towards it; antero-ventral inner list running to about halfway the lapel; selvage at height of lapel expanded, not striate.

Most appendages as typical of the genus and without special features.

Rpp (Figure 14C) with first segment c. 1.5 times as long as wide, subapically with one long but slender, and one short sensory organ; second palp segment triangular, rather elongate, with sinuous distal margin; apically with one small sensory organ.

Lpp (Figure 14E) with first segment elongated, more than twice as long as central width, subapically with one long but slender sensory organ, slightly swollen in the middle; apically with a short and distally rounded outgrowth, bearing one very small sensory organ; second palp segment nearly straight, sickleshaped and relatively elongated $(\mathrm{L}=\mathrm{L}$ of first segment); distal part of this segment straight and with nearly parallel margins.

Hemipenes (Figure 14D, F) symmetrical, with tips of ls and ms well separated from one another, 1s and ms almost equally long, distal part of ms produced into an elongated lobe; distal part of ls bluntly pointed with distal margin rounded.

\section{Ecology and distribution}

The species is common in Perth wetlands, where it occurs in large populations most of the year, and along the south-west coast of Western Australia. Its most southern known locality is a small stream entering Leschenault Estuary in Bunbury, where it occurred together with Cyprideis australiensis and Eucypris virens. The species has been recorded in water with conductivity $483-3880 \mu \mathrm{S} \mathrm{cm}^{-1}$ and $\mathrm{pH} 6.8$.

\section{Remarks}

Davies \& Christidis (1997) mention the presence of B. australis in 11 Perth wetlands. We have been able to identify two of these populations (Lake Gwelup, Big Carina swamp) as B. gwelupensis sp. nov., but most likely all of the populations of these 11 wetlands belong to this species. 


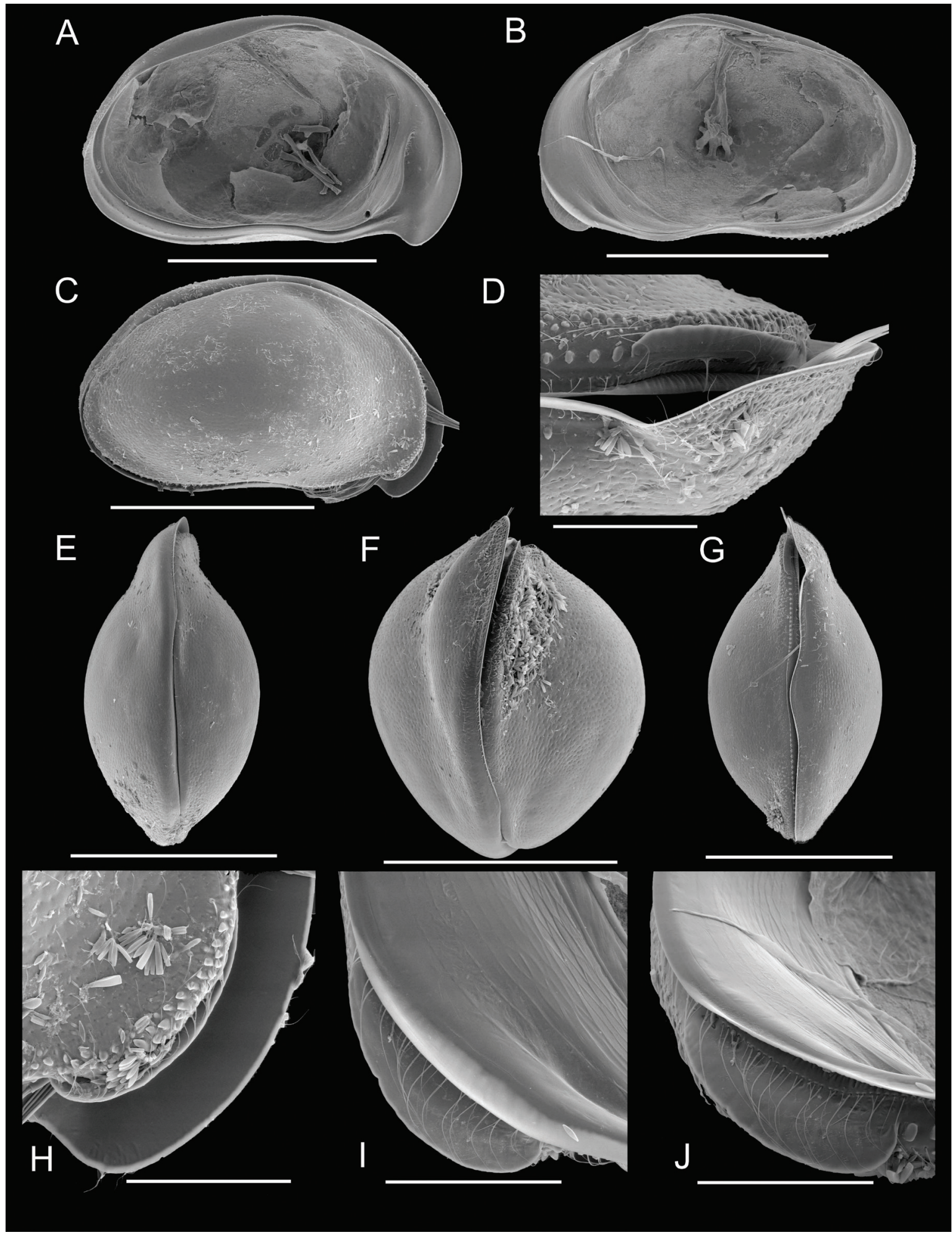

Fig. 15. Bennelongia gwelupsensis sp. nov. (all + , from Lake Gwelup, Perth - type locality). A. LVi (holotype 9 , WAM.C49394). B. RVi (Idem). C. Cp RL (WAM.C49395A). D. CpV (detail anteriorly, WAM.C49395B). E. CpD (WAM.C49395C). F. Cp anteriorly (animal inverted) (WAM. C49395D). G. CpV (WAM.C49395B), H. CpRL (detail anteriorly, WAM.C49395A). I. RVi (detail anteriorly, holotype + , WAM.C49394). J. RVi (detail anteriorly, tilted, Idem).

Scales: A-C, E, $\mathrm{G}=1000 \mu \mathrm{m} ; \mathrm{F}=500 \mu \mathrm{m} ; \mathrm{D}, \mathrm{H}-\mathrm{J}=200 \mu \mathrm{m}$. 


\section{Bennelongia lata sp. nov.}

(Figs 16, 17A-C)

\section{Etymology}

The species has a broad lapel on the RV. Broad = lata in Latin.

\section{Diagnosis}

$\mathrm{Cp}$ with pronounced anterior rostrum, posteriorly bluntly pointed. LV with relatively weak anteroventral beak and perfectly rounded dorsal margin. Lapel on RV broad, running parallel to selvage. Hemipenis with ms with straight margin, ventrally widely produced as a broad lobe; ls in both hemipenes boot shaped, distally with blunt tip; tips of ls and ms close together, ls slightly longer than ms. Rpp with distal segment triangular, broad. Lpp with proximal segment without apical outgrowth; distal segment sickleshaped, elongated, as long as first segment, and with almost parallel margins, except for distal part.

\section{Measurements (all measurements in $\mu \mathrm{m}$ )}

Male: $R V: L=1660-1700 ; H=930-962 . L V: L=1770-1810 ; H=995-1030 . \mathrm{Cp}: \mathrm{L}=1670-1800$; $\mathrm{H}=881-995$.

Female: $\mathrm{Cp}: \mathrm{L}=2000-2040 ; \mathrm{H}=1130 ; \mathrm{W}=1120-1170$.

\section{Type locality}

Yandoo Billabong, Boolathana Station, Gascoyne, WA (sample SIEK3); approximate coordinates $24^{\circ}$ $38^{\prime} 25^{\prime}$ 'S $113^{\circ} 55^{\prime} 20^{\prime \prime}$. All material was collected on 7 Apr. 2006 by the authors.

\section{Type material}

\section{Holotype}

Male (WAM.C49399), with soft parts dissected in a sealed slide, valves stored dry in a micropalaeontological slide.

\section{Allotype}

LV and RV of a female (WAM.C49400) stored dry in a micropalaeontological slide.

\section{Paratypes}

Two males dissected and stored as the holotype (WAM.C49401, OC.3318); two males and one female (WAM.C49402A-C) carapaces in a micropalaeontological slide.

Several juvenile specimens: one cp of a male (A-1) (WAM.C49403); 2 Cp and 1 LV female (A-1) and 1 Cp female (A-3) (WAM.C49404A-D).

Several specimens in EtOH (WAM.C49405).

\section{Other material investigated}

Tirigie Claypan, Boolathana Station, Gascoyne, WA (sample SIEK4), approximate coordinates: 24 $38^{\prime} 29^{\prime \prime S} 113^{\circ} 59^{\prime} 44^{\prime \prime}$. All material was collected on 7 Apr. 2006 by the authors.

\section{Differential diagnosis}

The species belongs to the $B$. australis group because of the generally large size ( $\mathrm{L}>1500 \mu \mathrm{m})$, the presence of a lapel on the RV and of a strong anterior rostrum in dorsal view. It can be distinguished from the other species in this lineage by the very rounded dorsal margin of both valves, the elongated lapel running parallel to the selvage, the very broad second segment of the Rpp, the fact that tips of ls and $\mathrm{ms}$ of the hemipenes are hardly separated from each other and that the ls is slightly longer than the ms. 


\section{Additional description}

Valves in lateral view (Figure 16A-D) with rounded dorsal margin, LV overlapping RV on all sides (Figure 16K), greatest height in the middle; in dorsal and ventral views (Figure 16E-H) with greatest width in the middle of the carapace; anterior rostrum well-developed, posterior side bluntly pointed, LV dorsally less ridge-like than in the other species of this lineage; external surface weakly pitted and sparsely set with short setae.

LV (Figure 16A, C) in inner view with rounded dorsal margin, greatest height situated in the middle; antero-ventral beak-like expansion moderate; ventral margin almost straight over most of its length.

RV (Figure 16B, D) in inner view with greatest height situated slightly in front of the middle, dorsal margin rounded; posterior selvage submarginal, posterior inner list merging with posterior selvage; remnant of valve margin visible between lapel and valve margin; antero-ventral inner list running to about halfway the lapel; selvage at height of lapel expanded, not striate, lapel (Figure 16I, J) broad and long, see specific name.

Most appendages as typical of the genus and without special features.

Rpp (Figure 17C) with first segment c. 1.5 times as long as wide, subapically with one long but slender, and one short sensory organ; second palp segment triangular, broad, with straight distal margin; apically with one small sensory organ.

Lpp (Figure 17A) with first segment elongated, more than twice as long as central width, subapically with one long, but slender sensory organ, slightly striate in the middle; apically without distinct outgrowth, but with one small sensory organ; second palp segment nearly straight, sickle-shaped and relatively elongated $(\mathrm{L}=c$. $\mathrm{L}$ of first segment); distal part of this segment straight and with nearly parallel margins.

Hemipenes (Figure 17B) asymmetrical, with tips of ls and ms situated closely together, 1s slightly longer than ms, distal part of ms produced into a blunt lobe; distal part of ls boot-shaped, bluntly pointed with distal margin rounded in one hemipenis, with thumb-like expansion in the other.

\section{Ecology and distribution}

The species is known from two semi-permanent turbid, freshwater billabongs in the Gascoyne area, namely the type locality Yandoo Billabong and Tirigie Claypan (see above). No further environmental data are available.

\section{Bennelongia cuensis sp. nov.}

(Figs 17D-H, 18)

\section{Etymology}

The species is named after a small outback town, Cue, near its type locality.

\section{Diagnosis}

$\mathrm{Cp}$ with pronounced anterior rostrum, posteriorly bluntly pointed; in right lateral view, LV overlapping $\mathrm{RV}$ on all sides, but with distinct overlap on the dorsal side. LV with relatively rounded anteroventral beak and almost straight dorsal margin. Lapel on RV broad, running parallel to selvage. Hemipenis with ms with straight and broad distal margin, ventrally produced as a long lobe, dorsally also protruding main peniferum as a rounded lobe; ls asymmetrical, in both hemipenes with rounded distal margin and distally with blunt tip, but in one hemipenis without and in the other hemipenis with additional (and unusually elongated) thumb-like expansion; tips of ls and ms well-separated, ls significantly longer than 


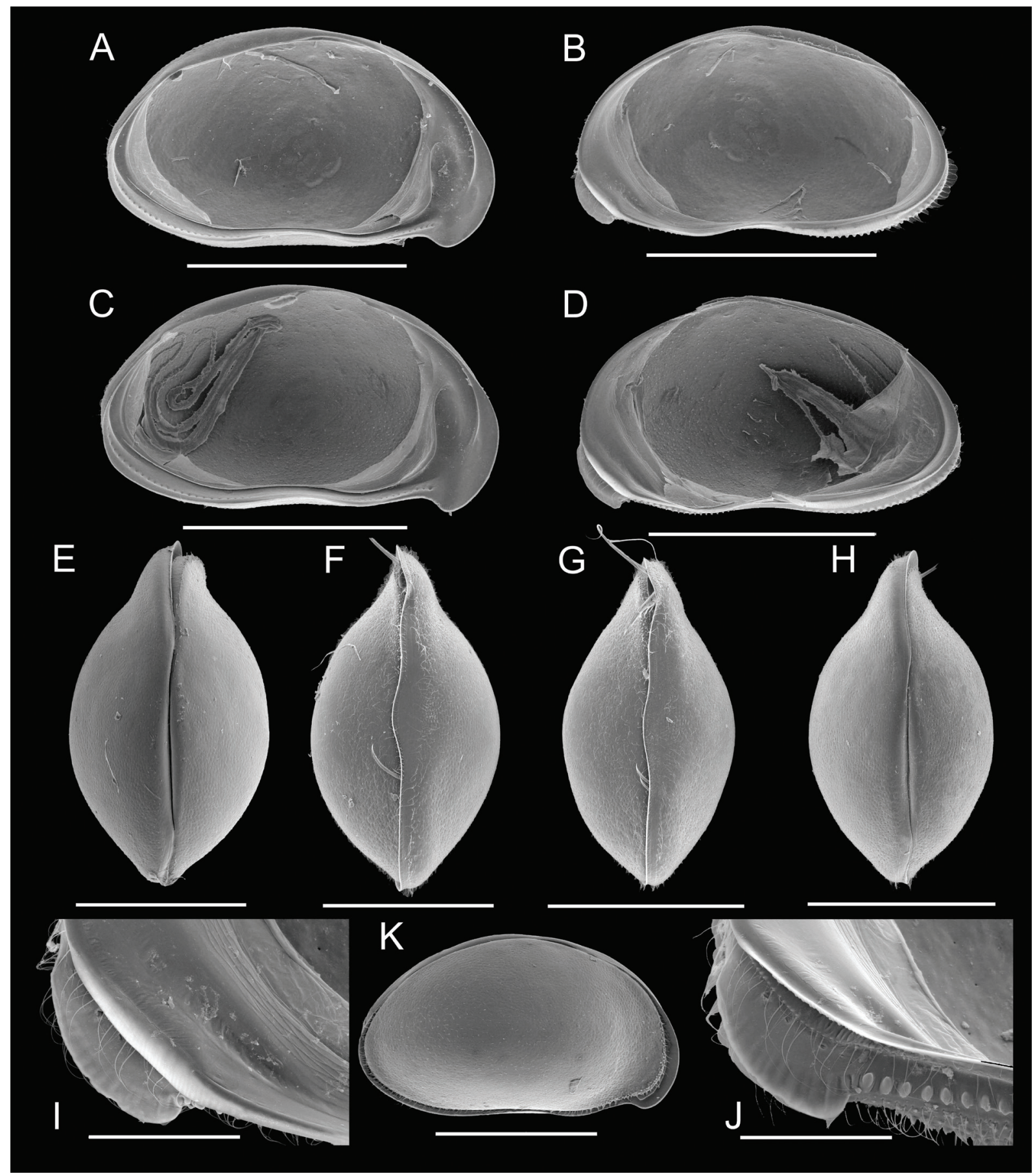

Fig. 16. Bennelongia lata sp. nov. (all from Yandoo Billabong, type locality). A. LVi (allotype ${ }_{\text {, }}$ WAM.

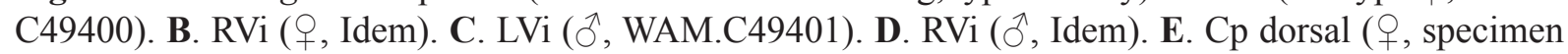

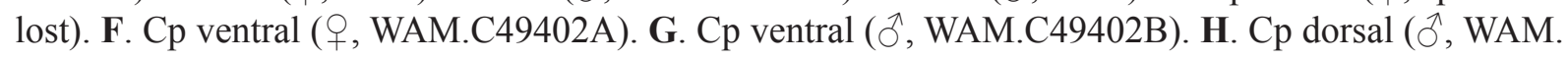
C49402C). I. RVi (detail anteriorly, allotype + , WAM.C49400). J. RVi (detail anteriorly, tilted, allotype

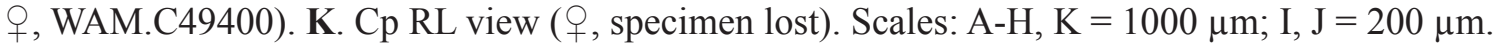




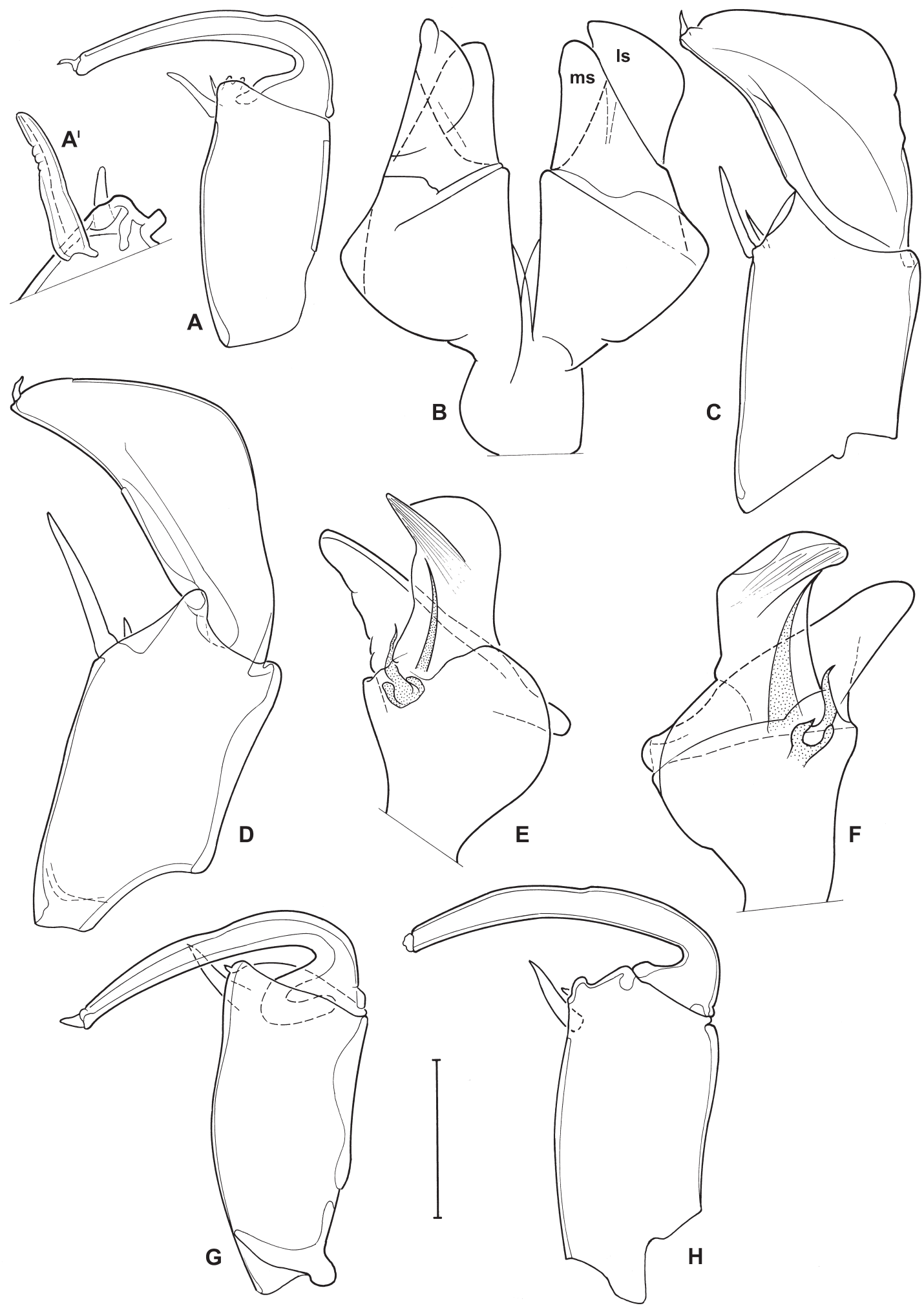

Fig. 17. A-C. Bennelongia lata sp. nov. (holotype $\widehat{O}$, WAM.C49399); D-H. Bennelongia cuensis sp. nov. (D-G = holotype $\widehat{\partial}$, WAM.C49406; H = OC.3319). A. Left prehensile palp and detail of apical sensory organs on first segment. B. outline of hemipenes (note that distal shield is folded in left hemipenis). C. Right prehensile palp. D. Right prehensile palp. E. Outline of hemipenis. F. Outline of second hemipenis, same individual. G. Left prehensile palp. H. Left prehensile palp. Scales: B, E, F = $232 \mu \mathrm{m}$,; A, C, D, G, H = $92 \mu \mathrm{m} ; \mathrm{A}^{\prime}=37 \mu \mathrm{m}$. 
ventral lobe of ms. Rpp with distal segment triangular, relatively elongated and with narrow base. Lpp with proximal segment with small, triangular apical outgrowth; distal segment sickle-shaped, elongated, as long as first segment, and with almost parallel margins, except for distal part.

\section{Measurements (all measurements in $\mu \mathrm{m}$ )}

Male: $R V: L=1810 ; H=1040 . ~ L V: L=1930 ; H=1130 . C p: L=1820-1960 . H=1090 . W=1040-1080$. Female: $\mathrm{Cp}: \mathrm{L}=2170-2230 ; \mathrm{H}=1360 ; \mathrm{H}=1180-1300$.

\section{Type locality}

Pool along Great Northern Highway, near Cue, WA, approximate coordinates: $27^{\circ} 15^{\prime} 20^{\prime \prime} \mathrm{S} 117^{\circ} 58^{\prime}$ 58"E. All specimens collected by SH on 6 Sep. 2006.

\section{Type material}

\section{Holotype}

Male (WAM.C49406), with soft parts dissected in a sealed slide, RV stored dry in a micropalaeontological slide (LV lost).

\section{Allotype}

A carapace of a female (WAM.C49407) stored dry in a micropalaeontological slide.

\section{Paratypes}

Three males (WAM.C49408-49409, OC.3319) dissected and stored as the holotype; two male carapaces (WAM.C49410).

Several specimens in EtOH (WAM.C49411).

\section{Other material investigated}

The species is thus far known from its type locality only.

\section{Differential diagnosis}

The species belongs to the $B$. australis group because of the generally large size ( $\mathrm{L}>1500 \mu \mathrm{m}-$ it is the largest species here described), the presence of a lapel on the RV and of a strong anterior rostrum in dorsal view. It can be distinguished from the other species in this lineage by the considerable dorsal overlap of the RV by the LV, the straight dorsal margin of the LV, the elongated lapel running parallel to the selvage, the rather narrow second segment of the Rpp, the fact that tip of ls and ms of the hemipenes are well-separated from each other and that the ls extends much longer than the ventral lobe of the ms. Bennelongia cuensis sp. nov. is similar to the previously described species, $B$. lata sp. nov., especially in the shape of the lapel on the RV, but can be easily distinguished by the shape of the carapace in right lateral view (rounded with limited dorsal overlap in B. lata sp. nov., sub quadrate with considerable dorsal and ventral overlap in B. cuensis sp. nov.) and especially by the shape of the ms on the hemipenis (ventrally bluntly pointed and short and without dorsal lobe in B. lata sp. nov., with elongated and narrow lobes on both dorsal and ventral sides in B. cuensis sp. nov.)

\section{Additional description}

Valves (Figure 18A, B) in lateral view with straight dorsal margin, LV overlapping RV on all sides (Figure 18G, H), but with considerable dorsal overlap, greatest height situated in the middle; in dorsal and ventral views (Figure 18C-F) with greatest width in the middle of the carapace; anterior rostrum well-developed, posterior side bluntly pointed, LV dorsally ridge-like; external surface weakly pitted and set with short setae. 
LV (Figure 18A) in inner view with rather straight dorsal margin, greatest height situated in the middle; antero-ventral beak-like expansion moderate and rounded; ventral margin slightly sinuous in the middle.

RV (Figure 18B) in inner view with greatest height situated slightly in front of the middle, dorsal margin rounded; posterior selvage sub marginal, posterior inner list merging with posterior selvage; remnant of valve margin visible between lapel and valve margin; antero-ventral inner list running to about halfway

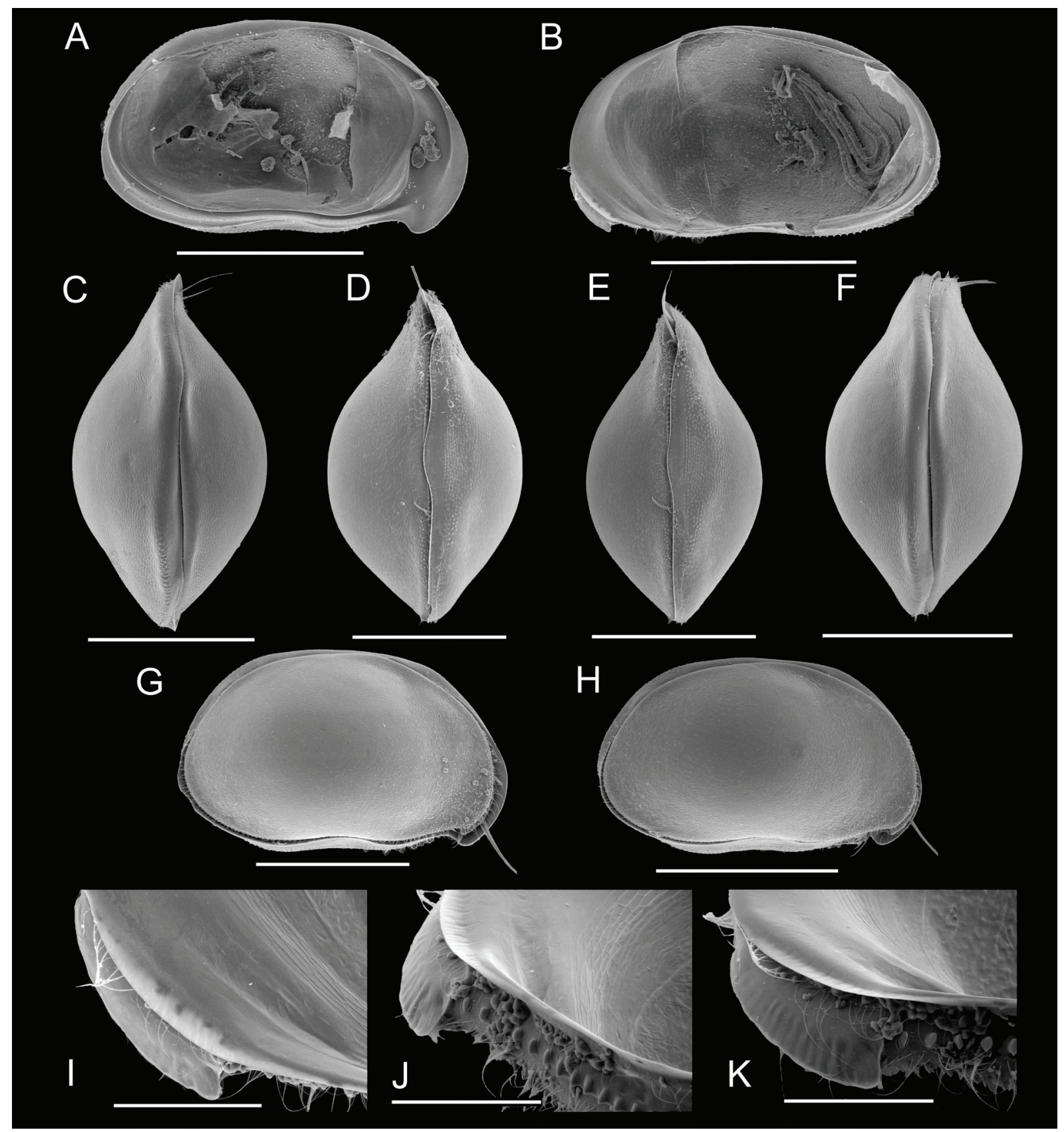

Fig. 18. Bennelongia cuensis sp. nov. (all from pan near Cue, type locality). A. LVi (ô, WAM.C49408). B. RVi (ð̂, Idem). C. Cp dorsal ( $($, specimen lost). D. Cp ventral ( + , same specimen lost). E. Cp ventral

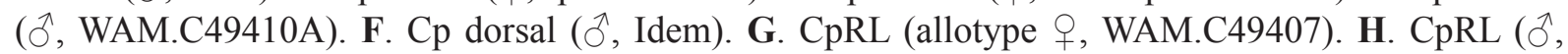
WAM.C49410B). I. RVi (detail anteriorly, ठ̃, WAM.C49408). J. RVi, detail anteriorly (tilted $\partial^{\lambda}$, Idem). K. RVi (detail anteriorly, tilted $\widehat{\partial}$, Idem). Scales: A-H $=1000 \mu \mathrm{m}$; I-K $=200 \mu \mathrm{m}$. 
the lapel; selvage at height of lapel expanded, striate; lapel (Figure 18I-K) broad, running parallel to selvage, slightly striate.

Most appendages as typical of the genus and without special features.

Rpp (Figure 17D) with first segment c 1.5 times as long as wide, subapically with one long but slender, and one short sensory organ; second palp segment elongate, with narrow base, apically with one small sensory organ.

Lpp (Figure 17G, H) with first segment elongated, more than twice as long as central width, subapically with one long, stout sensory organ; apically with small, rounded outgrowth, a small sensory organ at the base of this lobe; second palp segment nearly straight, sickle-shaped and relatively elongated, as long as first segment; distal part of this segment straight and with nearly parallel margins.

Hemipenes (Figure 17E, F) asymmetrical, with tips of ls and ms well-separated, ls extending well beyond $\mathrm{ms}$, ventral part of ms produced into an elongated, pointed lobe, dorsally also extending beyond peniferum with a rounded lobe; distal part of ls bluntly pointed with distal margin rounded in one hemipenis, with elongated thumb-like expansion in the other.

\section{Ecology and distribution}

The species is known from its type locality only, a small seasonal claypan with fresh turbid water. No further environmental data are available.

\section{Bennelongia bidgelangensis sp. nov.}

(Figs 19, 20)

\section{Etymology}

The species is named after it type locality, Bidgelang Pool on Callytharra Springs Station in the Gascoyne, WA.

\section{Diagnosis}

$\mathrm{Cp}$ with pronounced anterior rostrum, posteriorly bluntly pointed; highly arched in right lateral view, LV overlapping RV on all sides. LV with relatively rounded anteroventral beak, rounded dorsal margin and large postero-ventral flange. RV in lateral view highly arched, with highest point of dorsal margin at about $1 / 3$ of the total length. Lapel on RV broad, dorsally slightly sloping towards selvage. Hemipenis with ms with straight distal margin, ventrally produced as a pointed lobe, dorsally slightly protruding main peniferum as a bluntly pointed lobe; ls asymmetrical, in both hemipenes with straight distal margin and distally with blunt tip, but in one hemipenis with additional elongated thumb-like expansion; tips of ls and ms almost touching, ls very slightly longer than ventral lobe of ms; hallway perniferum with additional small internal lobe. Rpp with distal segment elongated and with narrow base. Lpp with proximal segment with broad, rectangular apical outgrowth; distal segment sickle-shaped, elongated, as long as first segment, and with almost parallel margins, except for distal part.

\section{Measurements (all measurements in $\mu \mathrm{m}$ )}

Male: RV: $L=1700-1780 ; \mathrm{H}=952-1030 . \mathrm{LV}: \mathrm{L}=1890 ; \mathrm{H}=1040-1110 . \mathrm{Cp}: \mathrm{L}=1920 ; \mathrm{W}: 1030$.

Female: $R V: L=1950 ; H=1170$. LV: $L=2130 ; H=1260$. Cp: $L=2030-2090 ; H=1230 ; W=1130$ 1210. 


\section{Type locality}

Bidgelang Pool, Callytharra Springs Station, Gascoyne (WA), approximate coordinates: 24 $34^{\prime}$ '32'S $115^{\circ} 36^{\prime} 01^{\prime \prime E}$. All material collected by SH on 25 Aug. 1994 (OSTR14D).

\section{Type material}

\section{Holotype}

Male (WAM.C49412), with soft parts dissected in a sealed slide, valves stored dry in a micropalaeontological slide.

Allotype

LV and RV of a female (WAM.C49413) stored dry in a micropalaeontological slide.

\section{Paratypes}

Three males dissected and stored as the holotype (WAM.C49414, WAM.C49417, OC.3320); one male (WAM.C49415A) and three females (WAM.C49415B-D) carapaces stored dry in a micropalaeontological slide, RV+LV of one male (WAM.C49416).

Several specimens in EtOH (WAM.C49418).

\section{Other material investigated}

The species is known from its type locality only.

\section{Differential diagnosis}

The species belongs to the $B$. australis group because of the generally large size ( $\mathrm{L}>1500 \mu \mathrm{m}$ ), the presence of a lapel on the RV and of a strong anterior rostrum in dorsal view. It can be distinguished from the other species in this lineage by the highly arched aspect of carapace and valves, the strongly produced postero-ventral flange on the LV (unique character for this species in the B. australis lineage), the broad and elongated lapel on the RV, dorsally sloping towards the selvage, the narrow second segment of the Rpp, and the fact that the tips of ls and ms of the hemipenes are almost touching each other.

\section{Additional description}

Valves in lateral view (Figure 19A-D) with middle part of dorsal margin almost straight, LV overlapping RV on all sides (Figure 19K), greatest height situated posteriorly from the middle; in dorsal and ventral views (Figure 19E-H) with greatest width in the middle of the carapace; anterior rostrum well-developed, posterior side bluntly pointed, LV dorsally ridge-like; external surface weakly pitted and set with short setae.

LV (Figure 19A, C) in inner view with slightly rounded dorsal margin, greatest height situated in the middle; antero-ventral beak-like expansion moderate and rounded; ventral margin slightly sinuous in the middle; postero-ventral flange strongly produced.

RV (Figure 19B, D) in inner view with greatest height situated at about $1 / 3$ of total length, dorsal margin rounded; posterior selvage not sub-marginal, well inwardly displaced, posterior inner list merging with posterior selvage below half of the height of the valve; remnant of valve margin visible between lapel and valve margin; antero-ventral inner list running to about $1 / 4$ of length of the lapel; selvage at height of lapel expanded, striate; lapel broad, dorsally slightly sloping towards selvage, slightly striate (Figure 19I, J).

Most appendages as typical of the genus and without special features.

Rpp (Figure 20A, E) with first segment c. 1.5 times as long as wide, subapically with one long and basally stout, and one very short sensory organ; second palp segment elongate and with narrow base, with straight distal margin; apically with one small sensory organ. 


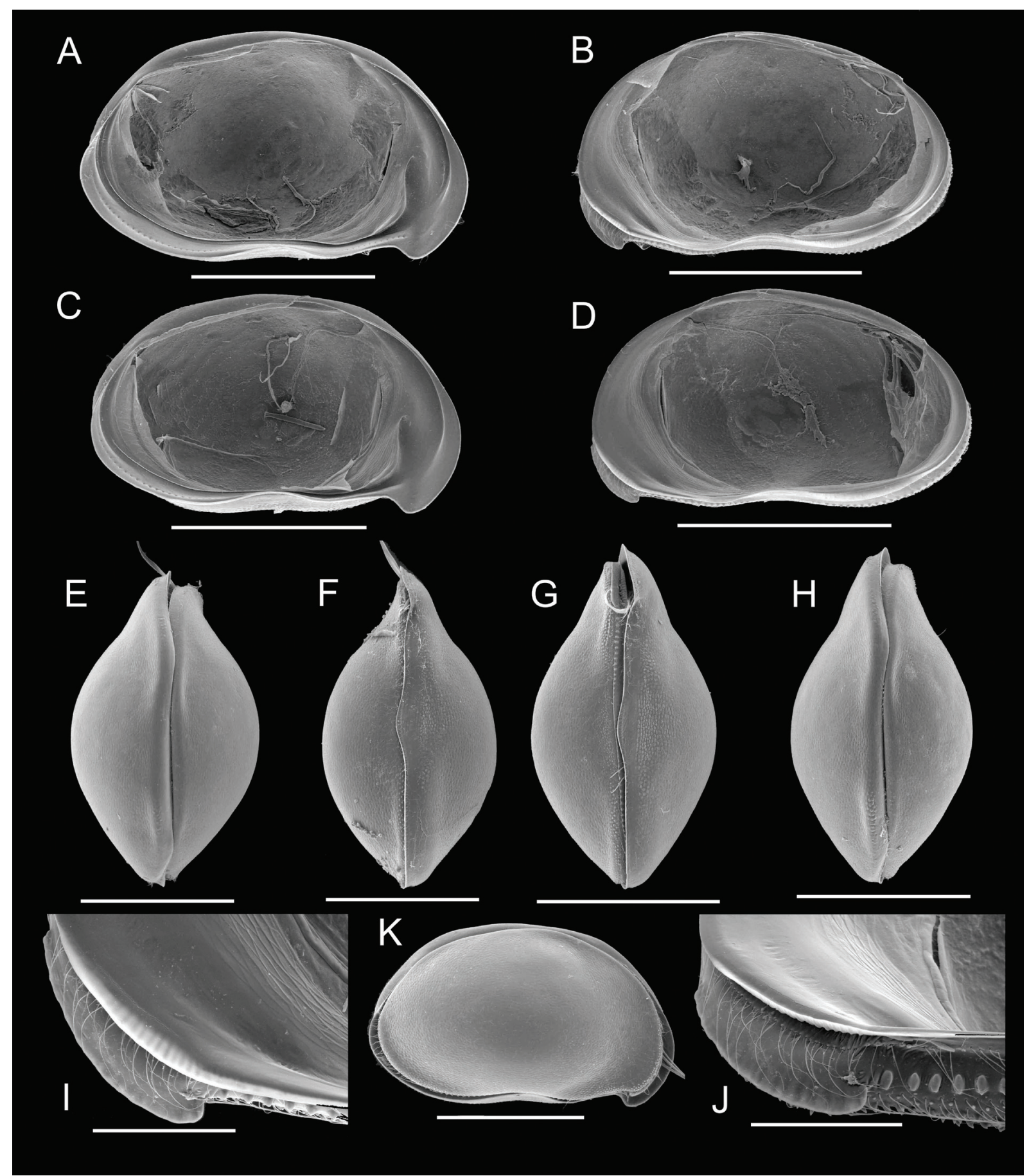

Fig. 19. Bennelongia bidgelangensis sp. nov. (all from Bidgelang Pool, type locality). A. LVi (allotype o, WAM.C49413). B. RVi (q, Idem). C. LVi (holotype ô, WAM.C49412). D. RVi (ô, Idem). E. Cp

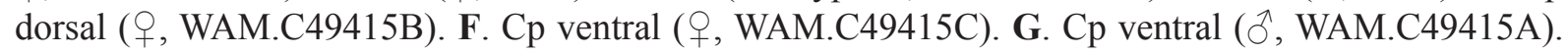
H. Cp dorsal (ð̂, Idem). I. RVi (detail anteriorly, holotype $\widehat{\jmath}$, WAM.C49412). J. RVi (detail anteriorly, tilted, ${ }^{\lambda}$, Idem). K. Cp RL (क, WAM.C49415D). Scales: A-H, K = $500 \mu$ m; I, J = $200 \mu \mathrm{m}$. 
Lpp (Figure 20C, D) with first segment elongated, length $c .1 .5 \mathrm{x}$ central width as central width, subapically with one long, stout sensory organ; apically with broad, rectangular outgrowth, a small sensory organ at the base of this lobe; second palp segment nearly straight, sickle-shaped and relatively elongated, as long as first segment; distal part of this segment straight and with nearly parallel margins.

Hemipenes (Figure 20B) asymmetrical, with tips of 1s and ms almost touching, 1s and ms almost equally long; ventral part of ms produced into a bluntly pointed lobe, dorsally also extending beyond peniferum with a rounded lobe; 1s almost rectangular, distal margin almost straight in both hemipenes, ventrally bluntly pointed in one hemipenis, with elongated thumb-like expansion in the other.

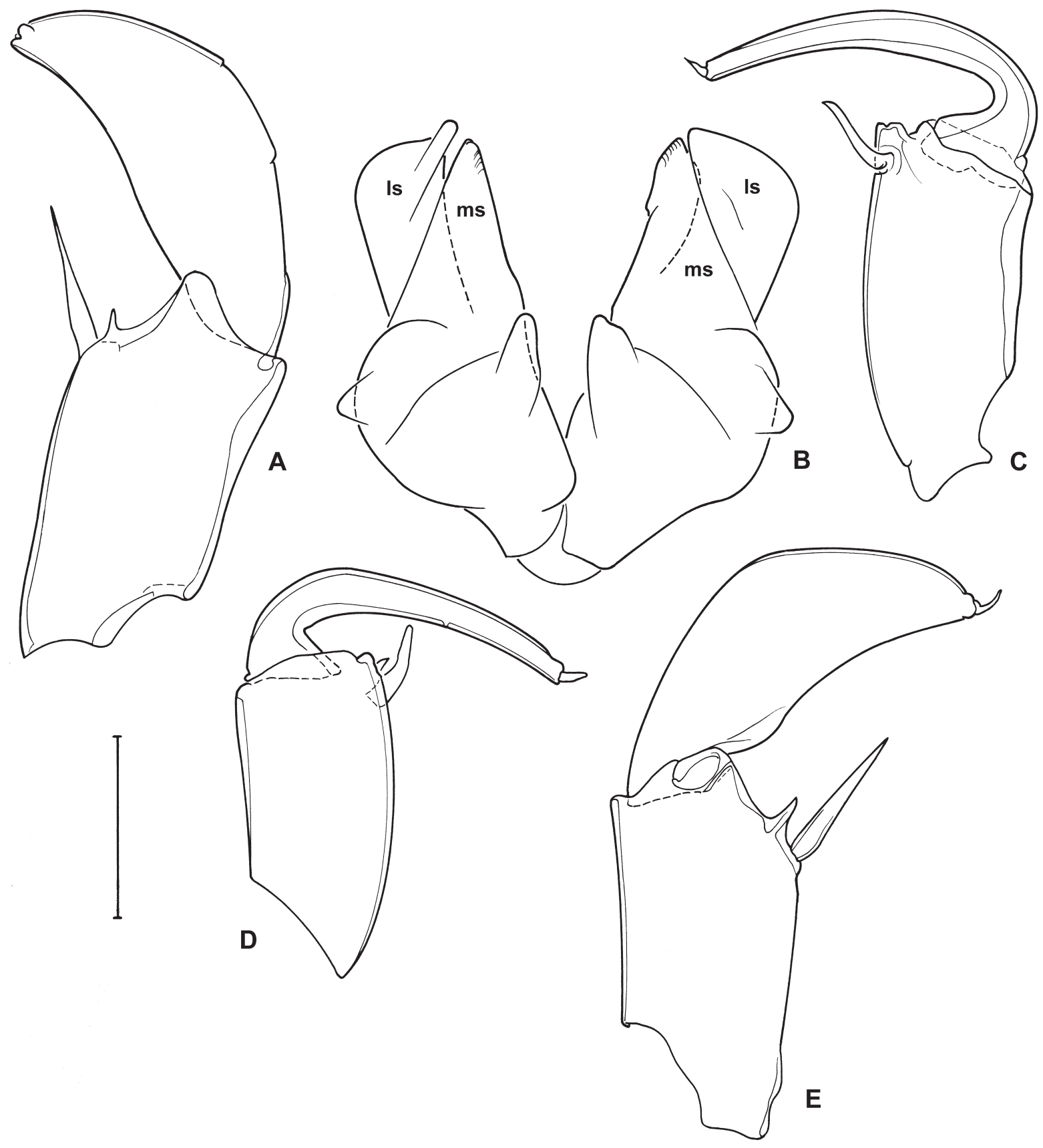

Fig. 20. Bennelongia bidgelangensis sp. nov. (A-C = holotype $\hat{\partial}$, WAM.C49412; D-E = WAM.C49414). A. Right prehensile palp. B. Outline of hemipenes. C. Left prehensile palp. D. Left prehensile palp. E. Right prehensile palp. Scales: $B=232 \mu \mathrm{m} ; \mathrm{A}, \mathrm{C}-\mathrm{E}=92 \mu \mathrm{m}$. 


\section{Ecology and distribution}

The species is known from its type locality only, a permanent river pool along the mostly dry Wooramel River. Water conductivity was $106 \mu \mathrm{S} \mathrm{cm}^{-1}$ and $\mathrm{pH}$ 7.7.

\section{Bennelongia pinpi - lineage}

\section{Remarks}

Bennelongia pinpi De Deckker, 1981 was described from Pine Tree Creek Lagoon in Queensland and is characterized by a very pronounced antero-ventral beak-like expansion in the LV, more so than in any other species of Bennelongia, and also by the absence of an antero-ventral lapel on the RV and by the presence of an antero-ventral expansion of the RV.

The following two species are allocated to this species group based on the latter two features, as the beak on the LV is not particularly large in either of them. An additional character might be the heavily sclerotized dorsal margins of the A1 in this species group (Figure 24F).

Bennelongia strellyensis sp. nov.

(Figs 21, 22)

Bennelongia australis s.l. (Brady, 1886) - Karanovic 2008: 282-286, figs 10-12.

\section{Etymology}

Named after the type locality, Strelley Station, Pilbara (WA).

\section{Diagnosis}

$\mathrm{Cp}$ with pronounced anterior rostrum, posteriorly bluntly pointed; rounded in right lateral view, LV overlapping RV on all sides, external valve surface centrally almost completely smooth and devoid of setae. LV with pronounced anteroventral beak, and highly arched, rounded dorsal margin. RV in lateral view rather elongated, with highest point of dorsal margin at about $1 / 3$ of the total length; lapel on RV absent, but valves building a triangular bulbous expansion in the same location; anterior selvage with flange-like expansion and with additional inner submarginal list.

Hemipenis symmetrical, heavily sclerotized. ms forming a three-dimensional structure, embracing ls along three sides (proximal, ventral, distal). 1s a large, slightly curved lobe, with almost parallel sides, distally bluntly pointed in ventral direction. About halfway the hemipenal body, one additional lobe present.

Rpp with distal segment short and rounded, with blunt tip bearing a sensory organ. Lpp with distal segment sickle-shaped, rounded and short.

\section{Measurements (all measurements in $\mu \mathrm{m}$ )}

Male: $R V: L=1710-1900 ; H=1090-1130 . L V: L=790-2010 ; H=1080-1220 . C p: L=1860-1880$; $\mathrm{H}=1120 ; \mathrm{W}=1140-1150$.

Female: $R V: L=1870 ; H=1130 . L V: L=1980 ; H=1200 . C p: L=1880-2000 ; H=1170 ; W: 1160-1230$. 


\section{Type locality}

Unnamed roadside pool on Strelley Station, Pilbara, WA (KIES3), approximate coordinates: $20^{\circ} 31^{\text {' }}$ $24^{\prime \prime S} 119^{\circ} 03$ ' 40"E. All material collected on 22 Apr. 2006 by the authors.

\section{Type material}

\section{Holotype}

Male (WAM.C49419), with soft parts dissected in a sealed slide, valves stored dry in a micropalaeontological slide.

\section{Allotype}

LV and RV of a female (WAM.C49420) stored dry in a micropalaeontological slide.

\section{Paratypes}

Three males (WAM.C49421, 49422, OC.3321) dissected and stored as the holotype; three females (WAM.C49423A-C) and two males (WAM.C49424A,B) carapaces stored dry in a micropalaeontological slide; RV+LV of a male (WAM.C49425).

Several juvenile specimens: RV+LV of males (A-1) (WAM.C49426); 3 Cp of females (A-1) and 3 Cp of females (A-3) (WAM.C49427AF).

Several specimens in EtOH (WAM.C49428).

\section{Other material investigated}

Cooliarin Pool, Pilbara (WA), collected by Adrian Pinder on 10 Sep. 2004, approximate coordinates: $20^{\circ} 30^{\prime} 20^{\prime \prime} \mathrm{S} 118^{\circ} 37^{\prime} 20^{\prime \prime} \mathrm{E}$ (PSW033). Specimens from this locality: RV+LV of two females (WAM. C49429, 49330).

Errawallana Spring, Pilbara (WA), collected by Adrian Pinder on 10 Sep. 2004, approximate coordinates: $21^{\circ} 37^{\prime} 48^{\prime \prime}$ S $117^{\circ} 46^{\prime} 14^{\prime \prime}$ (PSW055). Specimens from this locality: a male, dissected and stored as the holotype (WAM.C49431).

\section{Differential diagnosis}

Bennelongia strellyensis sp. nov. belongs to the B. pinpi lineage, and therefore differs from all other species in the genus not belonging to this lineage by a combination of the following characters: large species, with well-developed anterior rostrum and bluntly pointed posterior end in dorsal view; RV without antero-ventral lapel, but with bulbous expansion of the valve there; antero-ventral selvage with an additional submarginal inner list. LV with antero-ventral beak well-developed. Hemipenis stout and well-sclerotized; ms a ventral, 3-dimensional structure enveloping the 1s. Rpp with short and rounded second segment. Lpp with second segment sickle-shaped and short.

Within this lineage, B. strellyensis sp. nov. differs from $B$. pinpi by the length of the antero-ventral beak in the LV (longer in B. pinpi) and by the shape of the valves in lateral view (more highly arched in B. pinpi). The differences between $B$. strellyensis sp. nov. and B. kimberleyensis sp. nov. will be outlined below.

\section{Additional description}

Valves in lateral view (Figures 21A-D) with rounded dorsal margin, LV overlapping RV on all sides (Figures $21 \mathrm{~K}, \mathrm{~L}$ ), greatest height in the middle; in dorsal and ventral views (Figures 21E-H) with greatest width in the middle of the carapace; anterior rostrum well-developed, posterior side bluntly pointed, LV. Dorsally only anteriorly ridge-like; external valve surface centrally almost completely smooth and devoid of setae. 


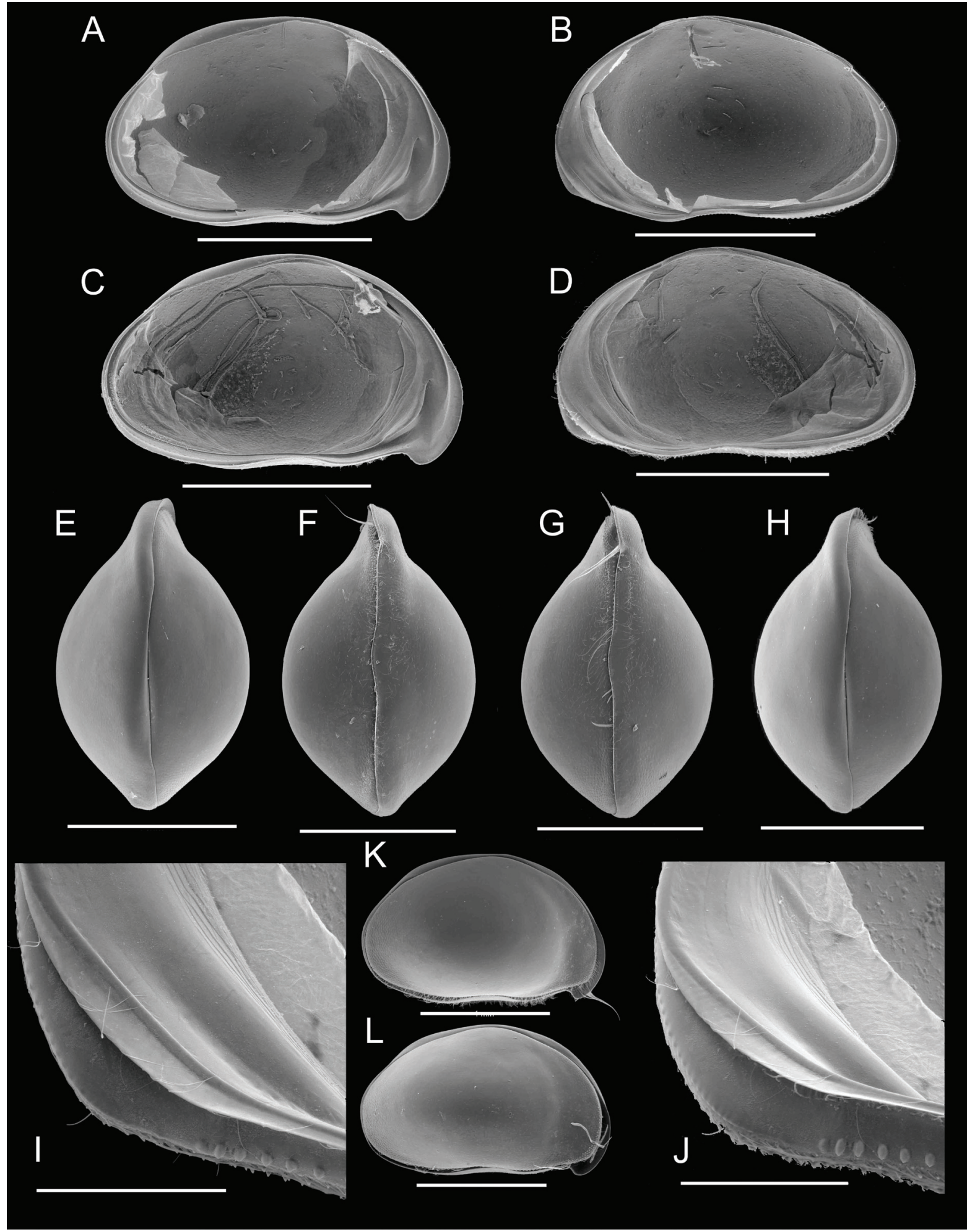

Fig. 21. Bennelongia strelleyensis sp. nov. (all from Strelley station, Pilbara, type locality).

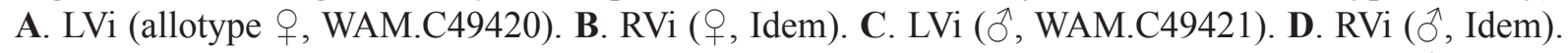
E. Cp dorsal (q, WAM.C49423A). F. Cp ventral ( $q$, WAM.C49423B). G. Cp ventral ( ${ }^{\lambda}$, WAM. C49424B). H. Cp dorsal (ô, WAM.C49424A). I. RVi (detail anteriorly, allotype +, WAM.C49420). J. RVi (detail anteriorly, + , Idem). K. CpRL ( + , WAM.C49423C). L. CpRL (ô, WAM.C49424A). Scales: A-H, $\mathrm{K}=1000 \mu \mathrm{m} ; \mathrm{L}=500 \mu \mathrm{m} ; \mathrm{I}-\mathrm{J}=200 \mu \mathrm{m}$. 
LV (Figure 21 A, C) in inner view with rounded dorsal margin, greatest height situated in front of the middle; antero-ventral beak-like expansion large.

RV (Figure 21B, D) in inner view with greatest height situated well in front of the middle, dorsal margin rounded; posterior selvage submarginal; lapel on RV absent, but valves building a triangular bulbous expansion in the same location (Figure 21I, J); anterior selvage with flange-like expansion and with additional inner submarginal list dorsally merging with selvage.

Most appendages as typical of the genus and without special features.

Rpp (Figures 22 B, 24D) with first segment $c$. twice as long as central width, subapically with one longer (but less so than in species of the previous lineage), and one short sensory organ; second palp segment triangular, broad, without clear ventro-apical corner and rounded distal margin; apically with one small sensory organ.

Lpp (Figure 22C, D) with first segment elongated, more than $2.5 \mathrm{x}$ as long as central width, subapically with one large and stout sensory organ, apically with rounded outgrowth, without sensory organ; second palp segment sickle-shaped short, and asymmetrically curved over $c .180^{\circ}$, distally with a small sensory organ.

Hemipenes (Figure 22A) symmetrical, ls protruding well beyond ms, distally bluntly pointed towards the ventral side, proximally with nearly parallel sides; ms actually consisting of three lobes: distal part of $\mathrm{ms}(\mathrm{ms} 1)$ produced into a three-dimensional lobe, embracing the ls on proximal and distal sides (this not visible in drawing, which is made of a flattened hemipenis in a slide) and with a small additional dorsal lobe; $\mathrm{ms} 2$ with distal margin nearly straight, ms 3 straight and incomplete. (Remark: ms 2 in some populations weakly developed and almost invisible - see below).

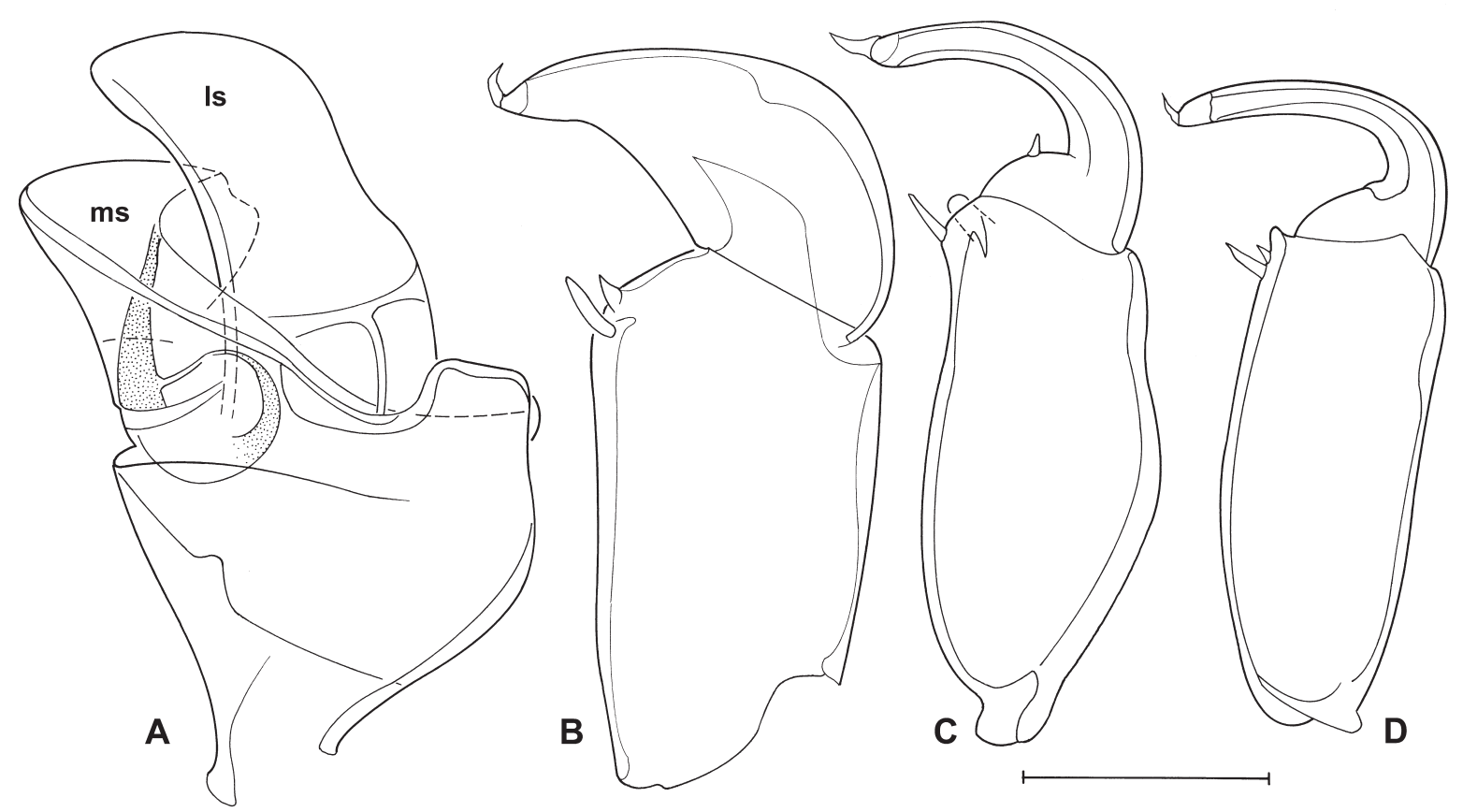

Fig. 22. Bennelongia strellyensis sp. nov. (all from Strelley Station, Pilbara, type locality; đ̊; A-C = holotype $\widehat{\jmath}$, WAM.C49419; D=OC.3321). A. Hemipenis outline. B. Right prehensile palp. C. Left prehensile palp. D. Left prehensile palp. Scales: A $=232 \mu \mathrm{m}$; B-D $=92 \mu \mathrm{m}$. 


\section{Ecology and distribution}

The species is common in moderately turbid claypans and roadside pools, and in clear water springs, in the Pilbara where it may occur in high densities. The species has been recorded in waters with conductivity $82-1391 \mu \mathrm{S} \mathrm{cm}^{-1}$ and $\mathrm{pH}$ 7.5-8.9.

\section{Remarks}

The present species closely resembles $B$. kimberleyensis sp. nov. described below, as was the case of the 5 sibling species in the previous $B$. australis lineage. The specific status of both new taxa was nevertheless confirmed by molecular methods (see results above), where all the Pilbara and all the Kimberley specimens clustered together in two distinct groups.

\section{Bennelongia kimberleyensis sp. nov.}

(Figs 23, 24)

\section{Etymology}

The species is named after the area in which it occurs, namely the Kimberley in the northern part of Western Australia.

\section{Diagnosis}

$\mathrm{Cp}$ with pronounced anterior rostrum, posteriorly bluntly pointed; rounded in right lateral view, LV overlapping RV on all sides, external valve surface centrally almost completely smooth and devoid of setae. LV with pronounced anteroventral beak, and highly arched, rounded dorsal margin. RV in lateral view rather elongated, with highest point of dorsal margin at about $1 / 3$ of the total length; lapel on RV absent, but valves building a triangular bulbous expansion in the same location, this expansion very pronounced; anterior selvage with flange-like expansion and with additional inner submarginal list.

Hemipenis symmetrical, heavily sclerotized. ms forming a three-dimensional structure, embracing ls along three sides (proximal, ventral, distal). 1s a large, slightly curved lobe, with almost parallel sides, distally bluntly pointed in ventral direction. About halfway the hemipenal body, one additional lobe present.

Rpp with distal segment short and triangular, with a distinct dorso-apical corner, and with blunt tip bearing a sensory organ. Lpp with distal segment sickle-shaped, very curved, and short.

\section{Measurements (all measurements in $\mu \mathrm{m}$ )}

Male: RV: $L=1998 ; H=1159$. LV: $L=2093 ; H=1230$. Cp: $L=2150-2177 ; H=1289 ; \mathrm{W}=1298$.

Female: RV: $\mathrm{L}=2068 ; \mathrm{H}=1243$. Cp: $\mathrm{L}=2139-2230 ; \mathrm{H}=1300 ; \mathrm{W}=1223-1268$.

\section{Type locality}

Taylors Lagoon, Broome, collected by the authors on 21 July 2011, approximate coordinates: $17^{\circ} 49^{\prime}$ 184" S 122 41'936"E (KIMB-01).

\section{Type material}

Holotype

Male (WAM.C49432), with soft parts dissected in a sealed slide, valves stored dry in a micropalaeontological slide.

Allotype

LV and RV of a female (WAM.C49433) stored dry in a micropalaeontological slide. 
Paratypes

Two males (WAM.C49434, OC.3322) dissected and stored as the holotype; three female (WAM.C49435) and three male (WAM.C49436) carapaces stored dry in micropalaeontological slides; RV+LV of a male (WAM.C49437) stored dry in micropalaeontological slides.

Several specimens in EtOH (WAM.C49438).

\section{Other material investigated (all from Kimberley)}

Parry Lagoons, collected by Andrew Storey on 21 Sep. 2000, approximate coordinates: 15'34' 00"S $128^{\circ} 17^{\prime} 00^{\prime \prime} \mathrm{E}$ (sample NS-028). Specimens from this locality: two males, dissected and stored as the holotype (OC.3323; WAM.C49441); RV+LV of a male (WAM.C49440); soft parts of a male (WAM. C49442); RV+LV of a female (WAM.C49439).

Small dam beside natural wetland along Great Northern Highway, collected by the authors on 21 July 2011, approximate coordinates: $17^{\circ} 45^{\prime}$ 05'S 122 $56^{\circ}$ ' 14"E (KIMB-04).

Roadside pool E of Fitzroy River, Willare, collected by the authors on 21 July 2011, approximate coordinates: $17^{\circ} 44^{\prime} 19^{\prime \prime S} 123^{\circ} 38^{\prime} 30^{\prime \prime}$ (KIMB-05).

Roadside pool containing cane grass, E of Fitzroy River along Great Northern Highway, collected by the authors on 21 July 2011, approximate coordinates: $17^{\circ} 44^{\prime} 22^{\prime \prime S} 123^{\circ} 37^{\prime} 54^{\prime \prime} \mathrm{E}$ (KIMB-06).

Myall Bore, E pool, collected by the authors on 22 July 2011, approximate coordinates: $17^{\circ} 20^{\prime} 53$ "S 123 39' 59”'E (KIMB-10).

Pool N side of Gibb Rd, collected by the authors on 22 July 2011, approximate coordinates:17 $21^{\circ}$ ' $09^{\prime \prime} \mathrm{S}$ $123^{\circ} 44^{\prime} 11$ '” (KIMB-11).

(Identification of KIMB04,06,10 \& 11 was confirmed using barcoding).

\section{Differential diagnosis}

The present species is slightly larger than B. strellyensis sp. nov. (up to $2.2 \mathrm{~mm}$ in Kimberley, up to 2.0 $\mathrm{mm}$ in Pilbara), and has a slightly larger antero-ventral beak in the LV, while also the antero-ventral bulbous expansion in the RV is slightly larger.

The second segment of the Rpp in B. kimberleyensis sp. nov. is more triangular, i.e. with a clear dorsoapical corner. The second segment of the Lpp is less curved, but this also depends partially on the position of this segment relative to the first segment (the second segment can hinge). The hemipenis has a broader ls, while in some Kimberley populations, lobe ms 2 is hardly visible, but still present (visible at least on the ventral side at high magnification).

\section{Additional description}

Valves in lateral view (Figure 23A-D) with rounded dorsal margin, LV overlapping RV on all sides (Figure 23K, L), greatest height in the middle; in dorsal and ventral views (Figure 21E-H) with greatest width in the middle of the carapace; anterior rostrum well-developed, posterior side bluntly pointed, LV dorsally only anteriorly ridge-like; external valve surface centrally almost completely smooth and devoid of setae.

LV (Figure 23A, C) in inner view with rounded dorsal margin, greatest height situated in front of the middle; antero-ventral beak-like expansion large.

RV (Figure 23B, D) in inner view with greatest height situated well in front of the middle, dorsal margin rounded; posterior selvage submarginal; lapel on RV absent, but valves building a triangular bulbous expansion in the same location (Figure 23I, J); anterior selvage with flange-like expansion and with additional inner submarginal list dorsally merging with selvage.

Most appendages as typical of the genus and without special features. 


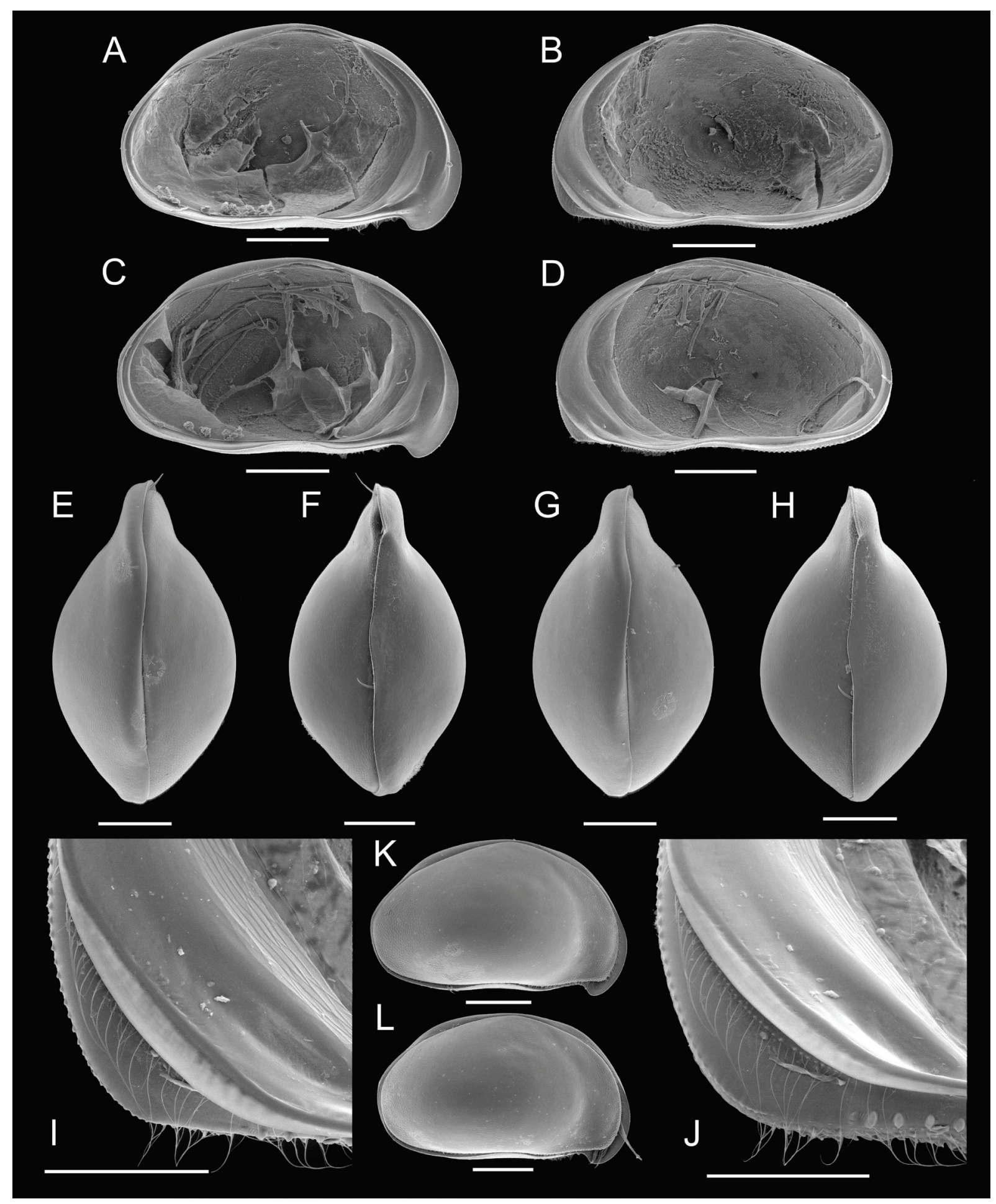

Fig. 23. Bennelongia kimberleyensis sp. nov. (all from Taylors Lagoon, Kimberley, type locality).

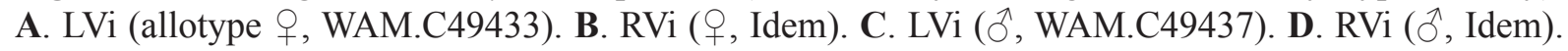
E. Cp dorsal (q, WAM.C49435A). F. Cp ventral (q, WAM.C49435C). G. Cp ventral (ô, WAM. C49436A). H. Cp dorsal (ô, WAM.C49436B). I. RVi (detail anteriorly, allotype ㅇ, WAM.C49433). J. RVi (detail anteriorly, + , Idem). K. CpRe (†, WAM.C49435B). L. CpRe (ð̋, WAM.C49436C). Scales: A-H, K-L $=500 \mu \mathrm{m}$; I-J $=200 \mu \mathrm{m}$. 

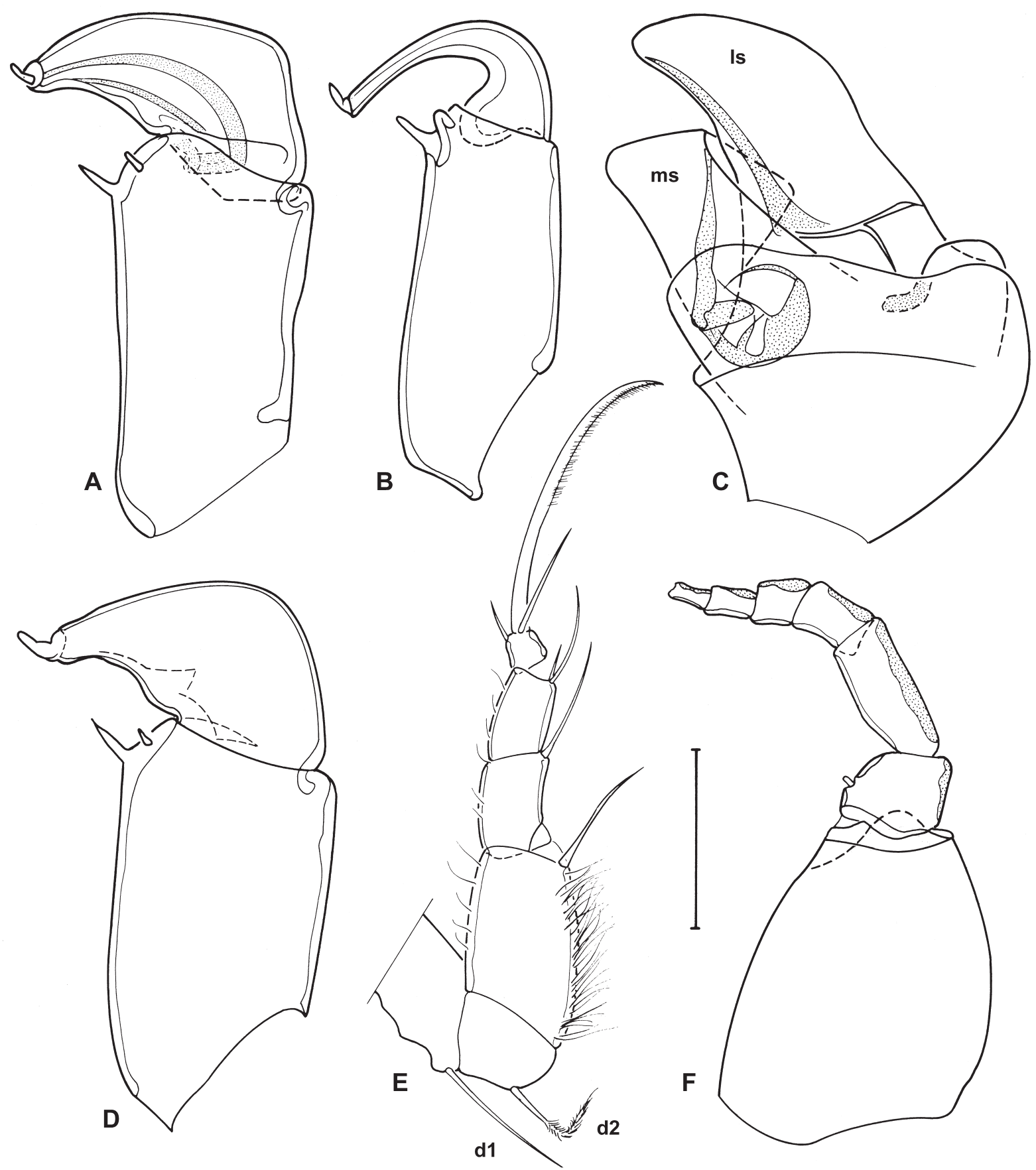

Fig. 24. A-C, E, F. Bennelongia kimberleyensis sp. nov. (ð̊, OC.3323, Parry’s Lagoon, Kimberley); D. B. strellyensis sp. nov. (ふ̂, WAM.C49421, Strelley Station, Pilbara). A. Right prehensile palp. B. Left prehensile palp. C. Hemipenis outline. E. T2. F. A1, without chaetotaxy, showing strongly sclerified dorsal margins of segments. D. Right prehensile palp. Scales: C, E, F $=232 \mu \mathrm{m}$; A, B, D = $92 \mu \mathrm{m}$. 
Rpp (Figure 24A) with first segment $c$. twice as long as central width, subapically with one longer (but less so than in species of the previous lineage), and one short sensory organ; second palp segment triangular, broad, with clear ventro-apical corner and almost straight distal margin; apically with one small sensory organ.

Lpp (Figure 24B) with first segment elongated, more than $2.5 \mathrm{x}$ as long as central width, subapically with one large and stout sensory organ, apically with rounded outgrowth, without sensory organ; second palp segment sickle-shaped short, and asymmetrically curved over $c .180^{\circ}$, distally with a small sensory organ.

T2 (Figure 24E) a hirsute walking leg.

Hemipenes (Figure 24C) symmetrical, 1s protruding well beyond ms, distally bluntly pointed towards the ventral side, proximally with nearly parallel sides; ms actually consisting of three lobes: distal part of $\mathrm{ms}(\mathrm{ms})$ produced into a three-dimensional lobe, embracing the ls on proximal and distal sides (this not visible in drawing, which is made of a flattened hemipenis in a slide) and with a small additional dorsal lobe; ms 2 with distal margin nearly straight, ms3 straight and incomplete.

\section{Ecology and distribution}

This species occurred in a third of all our localities (pools, clay pans) sampled during 2010 in the southwestern Kimberley and was also found in the north-east near the mouth of the Ord River. The species appears to be common through the Kimberley and occurs in fresh, clear or slightly turbid water. No further environmental data are available.

\section{Discussion}

\section{Morphological characters}

Presence/absence and morphology of the antero-ventral lapel on the $R V$

The lapel on the RV is a newly identified character typical of most species of Bennelongia (with exception of species in the $B$. pinpi lineage). Its homology can easily be deduced from the SEM pictures of the tilted RV: the row of marginal tubercles continues into the lapel, so both tubercles and lapel are the remnants of an outer list (Figure 4C-E). The lapel forms part of the system of filter feeding, which also includes the anterior sulcus in the LV, and which is formed by both anterior inner lists on the calcified inner lamella and which runs into the antero-ventral beak-like expansion in the LV. This sulcus is used to direct the stream of particles sucked in during filter feeding and the lapel is necessary to close the entrance of the sulcus when valves need to be closed tightly (e.g. during a predatory attack or during periods of desiccation). In species without a lapel (see above the species of the $B$. pinpi lineage), the antero-ventral bulbous expansion of the RV has the same function.

\section{Asymmetrical valves}

The extreme anterior asymmetry of the valves is a result of the development of the filter feeding apparatus, mainly in the LV. The extreme LV/RV overlap means that natatory setae of A1 and A2 extend out of the valves during swimming in an angle of almost 90 degree to the direction (plane) of swimming. In most other swimming ostracods these setae extend out of the valves in dorsal (A1) and ventral (A2) direction, which means that their movement is within the same plane as the swimming direction. Nevertheless, species of Bennelongia are able to swim rapidly, and no special morphological adaptations to A1 and A2 to the different orientation are visible. 


\section{Diversity and radiation of Bennelongia in (Western) Australia}

The type species of Bennelongia, B. harpago De Deckker \& McKenzie, 1981, was described from several localities in Queensland (De Deckker \& McKenzie 1981). Later, De Deckker (1981a) also described B. barangaroo (from several localities in Western Australia, South Australia, Queensland, New South Wales and even New Zealand), B. nimala (Northern Territory) and B. pinpi (Queensland) and redescribed what he thought to be $B$. australis (Brady, 1886) using new material from Western Australia (see above). De Deckker (1982) finally added B. tunta from Queensland (Table 2).

Based on the present interpretation of new characters, such as presence/absence and shape of the lapel on the RV, the excellent SEM illustrations of De Deckker (1981a) allow us to determine that at least for his description of $B$. barangaroo and the redescription of $B$. australis, material from several species has been used. This inclusion of multiple species was also suggested by the presumed wide distribution of these species as indicated by De Deckker (1981). Analysis of Western Australian material has indicated that it is unlikely that any of the five species in this lineage described here are the true $B$. australis and that topotype material near Penola (SA) must be used for a redescription of the true B. australis. Type material from B. barangaroo De Deckker, 1981 from the type locality itself (Lake Buchanan, QLD) must be used to establish the identity of that species.

There are at present 15 nominal and described species in the genus (including the nine species described in the present paper), and if one ignores the presumed wide occurrences of $B$. barangaroo and $B$. australis based on the description of multiple species, all have clearly delimited regional distributions (Table 2). Furthermore, it is clear that there are also many more species in this genus. The illustrations of B. australis in De Deckker (1981a) comprise at least two as yet undescribed species in the B. australis lineage and there is at least a further undescribed species in the B. nimala lineage (De Deckker 1981a, figure 9), possibly several more. Our own collections from Western Australia comprise at least another ten new species in three different lineages within the genus Bennelongia; these will be described elsewhere. After this a key to the species will be provided. Whether or not the largest radiation has taken place in Western Australia remains to be determined. Four very different species are already known from Queensland and the Northern Territory remains virtually unsampled.

\section{Congruence of genetic and morphological species definitions}

We have used four different methodological approaches to identify species entities from the obtained mitochondrial COI DNA sequence data in species from the B. australis and the B. pinpi lineages: phylogenetic tree constructions, genetic networks, the $4 \mathrm{x}$ rule and the GYMC algorithm. The first three methods all identify six different species, which are all described here as nominal species: $B$. gwelupensis sp. nov., B. coordinerensis sp. nov., B. lata sp. nov., B. cuensis sp. nov., B. strelleyensis sp. nov. and B. kimberleyensis sp. nov.

Only the GYMC algorithm deviates from other molecular identifications, with fewer species being recognized. Using the GYMC algorithm, three species, B. cuensis sp. nov., B. coordinerensis sp. nov. and B. lata sp. nov., were identified as a phylogenetic species, while $B$. gweulpensis sp. nov., $B$. strelleyensis sp. nov. and $B$. kimberleyensis sp. nov. were recognized as different. Since all newly described Bennelongia species have distinctive morphological character states, it appears that the GYMC algorithm underestimated the real biological diversity. This appears to be a general characteristic of the method, because similar discrepancies have been described in other faunal groups when results are, for example, compared to results of the $4 \mathrm{x}$ rule (Birky et al. 2011; Birky \& Barraclough 2009). The failure of the GYMC algorithm to identify all species may be explained by rather recent speciation events that cannot yet be discriminated from the coalescent processes used in the GYMC algorithm. 


\section{Cryptic Diversity}

The present results show that there is a large potential for cryptic diversity in Bennelongia. Within the radiations of the $B$. australis and the $B$. pinpi lineages, new species initially identified with molecular techniques could also be recognized morphologically using new character and character states, such as position and shape of the lapel on the RV. Thus, these species are not really cryptic and their discovery just accentuated the need for detailed morphological analyses to reveal small, but significant, morphological differences between species. However, without the genetic information there may have been insufficient use of detailed morphological characters.

Martens et al. (2008) foreshadowed that cryptic diversity in non-marine Ostracoda may be important and might increase the number of extant ostracod species by one or even two orders of magnitude. Bode et al. (2010) demonstrated this convincingly by identifying close to 40 cryptic species with the Eucypris virens species complex in Europe. Some of these cryptic species have meanwhile also been found in southern (De Deckker 1981b) and Western Australia (Koenders et al., in press).

As Martens \& Savatenalinton (2011) have pointed out, from a species conservation perspective, it is important to undertake further research into the extent of cryptic diversity. Sometimes, as with the species of Bennelongia described, this diversity may not be truly cryptic but requires more detailed morphological characters than usually used to distinguish all species. Whether cryptic or only nearcryptic, until these species are described they will remain unprotected by the processes of conservation planning because "what we do not know, we cannot protect".

\section{Conclusions}

The present contribution is the first in a series of papers on Australian Bennelongia, with the ultimate aim to test if Bennelongia is indeed a surviving remnant of the large Mesozoic Cypridea-radiation. Here we have demonstrated that the taxic diversity of Bennelongia in Western Australia is much higher than was previously assumed. We have described 9 new species in three different lineages within the genus and foreshadow the presence of at least another 10 new species in Bennelongia. We have also demonstrated the usefulness of molecular and population-genetic methods to strengthen the recognition of potentially cryptic species that might otherwise have remained undetected, but that can indeed be recognised using new and micro-scale characters and character states.

\section{Acknowledgements}

The authors gratefully acknowledge the financial support by an ABRS-grant (nr RF211-33 : 'Biodiversity and taxonomy of Ostracoda (Crustacea) from temporary water bodies of inland Western Australia') and of the Edith Cowan University Industry Collaboration grant. KM \& IS acknowledge the Western Australian Department of Environment and Conservation (2006) and Bennelongia Pty Ltd (2008, 2009, 2010) for financial support during several scientific stays in Perth, as well as the financial contribution of the FWO Vlaanderen (Fund for Scientific Research, Flanders) in the form of travel grants in 2010 (V4.172.10N \& V4.173.10N) and the projects 1.5.172.09 (krediet aan navorsers) and G.0118.03N (projectonderzoek). KM and IS also thank the people of Bennelongia Pty Ltd (Perth, WA) for continuous logistic support (lab space, use of microscopes etc.) and for unfailing companionship in the lab and their son Emrys for invaluable help with sorting living specimens in the field as well as in the lab. Julien Cilis and Claudine Behen (RBINSc, Brussels, Belgium) provided technical assistance with the SEM micrographs and with the line drawings, respectively. Jane McRae (Bennelongia Pty Ltd, Perth, WA) 
compiled the SEM plates and Mike Scanlon (Bennelongia Pty Ltd, Perth, WA) produced the map. IS thanks Annette Koenders (Edith Cowan University, Perth) and Mike Johnson (University of Western Australia, Perth) for providing laboratory space for the molecular part of this research. Prof. Patrick De Deckker (ANU, Canberra, Australia) and Prof. W. Birky (Univ of Arizona, USA) are thanked for their valuable comments as referees.

\section{References}

Altschul S.F., Gish W., Miller W., Myers E.W. \& Lipman D.J. 1990. Basic local alignment search tool. Journal of Molecular Biology 215: 403-410.

Balian E., Segers H., Lévêque C. \& Martens K. 2008. The freshwater animal diversity assessment: an overview of the results. In: Balian E. et al. (eds.), Freshwater animal diversity assessment. Hydrobiologia 595: 627-637. http://dx.doi.org/10.1007/s10750-007-9246-3

Birky C.W. Jr., Adams J., Gemmel M \& Perry J. 2010. Using Population Genetic Theory and DNA sequences for species detection and identification in asexual organisms. PLOS ONE 5: e10609. http:// dx.doi.org/10.1371/journal.pone.0010609

Birky C.W. Jr. \& Barraclough T.G. 2009. Asexual speciation. In: Schön I., Martens K. \& Van Dijk P. (eds), Lost sex: 201-216. Springer Scientific Publishers, Dordrecht. http://dx.doi.org/10.1007/978-90$\underline{481-2770-2 \quad 10}$

Birky C.W. Jr., Ricci C., Melone G. \& Fontaneto D. 2011. Integrating DNA and morphological taxonomy to describe diversity in poorly studied microscopic animals: new species of the genus Abrochtha Bryce, 1910 (Rotifera: Bdelloidea: Philodinavidae). Zoological Journal of the Linnean Society 161: 723-734. http://dx.doi.org/10.1111/j.1096-3642.2010.00674.x

Bode S.N.S., Adolfsson S., Lamatsch D.K., Martins M.J.F., Schmit O., Vandekerkhove J., Mezquita F., Namiotko T., Rossetti G., Schön I., Butlin R.K. \& Martens K. (2010). Exceptional cryptic diversity and multiple origins of parthenogenesis in a freshwater ostracod. Molecular Phylogeny and Evolution 54: 542-552. http://dx.doi.org/10.1016/j.ympev.2009.08.022

Brady G.S. 1886. Notes on Freshwater Entomostraca from South Australia. Proceedings of the Zoological Society of London 54: 82-93.

Broodbakker N.W. \& Danielopol D.L. 1982. The chaetotaxy of Cypridacea (Crustacea, Ostracoda) limbs: proposals for a descriptive model. Bijdragen tot de Dierkunde 52: 103-120.

Clement M., Posada D. \& Crandall K. 2000. TCS: a computer program to estimate gene genealogies. Molecular Ecology 9: 1657-1660.

Davies J. \& Christides F. 1997. A guide to the wetland invertebrates of southwestern Australia. Western Australian Museum, Perth.

De Deckker P. 1981a. Taxonomy and ecological notes of some ostracods from Australian inland waters. Transactions of the Royal Society of South Australia 105 (3): 91-138.

De Deckker P. 1981b. Ostracoda from Australian inland waters - notes on taxonomy and ecology. Transactions of the Royal Society of Victoria 93 (1): 43-85.

De Deckker P. 1982. On Bennelongia tunta De Deckker sp.nov. A Stereo-Atlas of Ostracod Shells 9 (21): 117-124. 
De Deckker P \& McKenzie K.G. 1981. Bennelongia, a new Cyprididid ostracod genus from Australasia. Transactions of the Royal Society of South Australia 105 (2): 53-58.

Folmer O., Black M., Hoeh W., Lutz R. \& Vrijenhoek R. 1994. DNA primers for amplification of mitochondrial cytochrome c oxidase subunit I from diverse metazoan invertebrates. Molecular Marine Biology and Biotechnology 3 (5): 294-299.

Fontaneto D., Herniou E.A., Boschetti C., Caprioli M., Melone G., Ricci C., Barraclough T. 2007. Independently evolving species in asexual bdelloid rotifers. PLoS Biology 5: e87. http://dx.doi. org/10.1371/journal.pbio.0050087

Fontaneto D., Kaya, M., Herniou E.A., Barraclough T.G. 2009. Extreme levels of hidden diversity in microscopic animals (Rotifera) revealed by DNA taxonomy. Molecular Phylogenetics and Evolution 53: 182-189. http://dx.doi.org/10.1016/j.ympev.2009.04.011

Guindon S. \& Gascuel O. 2003. PhyML - a simple, fast, and accurate algorithm to estimate large phylogenies by maximum likelihood. Systematic Biology 52: 696-704.

Halse S.A. 2002. Diversity of Ostracoda (Crustacea) in inland waters of Western Australia. Verhandlungen Internationale Vereinigung für theoretische und angewandte Limnologie 28: 914-918.

Harmon L.J., Weir J.T., Brock C.D., Glor R.E. \& Challenger W.L. 2008. GEIGER: investigating evolutionary radiations. Bioinformatics 24: 129-131. http://dx.doi.org/10.1093/bioinformatics/btm538

Hart M.W. \& Sunday J. 2007. Things fall apart: biological species form unconnected parsimony networks. Biological Letters 3: 509-512.

Horne D.J. \& Martens K. 1998. An assessment of the importance of resting eggs for the evolutionary success of non-marine Ostracoda (Crustacea). In: Brendonck L., De Meester L. \& Hairston N. (eds.), Evolutionary and ecological aspects of crustacean diapause. Advances in Limnology 52: 549-561.

Horne D.J., Cohen A. \& Martens K. 2002. Taxonomy, Morphology and Biology of Quaternary and Living Ostracoda. In: Holmes, J.A. \& Chivas A.R. (eds), The Ostracoda: Application in Quaternary Research. Geophysical Monograph 131: 5-36.

Horne D.J. \& Colin J.P. 2005. The affinities of the ostracod genus Cypridea Bosquet, 1852, and its allies, with consideration of implications for the phylogeny of non-marine Cypridoidean ostracods. Revue de Micropaléontologie 48: 25-35.

Huelsenbeck J.P. \& Ronquist F. 2001. MRBAYES: Bayesian inference of phylogenetic trees. Bioinformatics 17: 754-755. http://dx.doi.org/10.1093/bioinformatics/17.8.754

IUCN 2012. The IUCN Red List of Threatened Species [online]. Available from http://www.iucnredlist. org/ [accessed 10.1.2012].

Karanovic I. 2007. Candoninae (Ostracoda) from the Pilbara region in Western Australia. Crustaceana Monographs 7: 1-433, Brill.

Karanovic I. 2008. Three interesting Cyprididae (Ostracoda) from Western Australia. Records of the Western Australian Museum 24: 267-287.

Koenders A., Martens K., Halse S.A. \& Schön I. (submitted). The empire strikes back - English cryptic species of the Eucypris virens species complex (Ostracoda, Crustacea) have invaded Western Australia. Biological Invasions.

Larkin M.A., Blackshields G., Brown N.P., Chenna R., McGettigan P.A., McWilliam H., Valentin F., Wallace I.M., Wilm A., Lopez R., Thompson J.D., Gibson T.J. \& Higgins D.G. 2007. Clustal W and Clustal X version 2.0. Bioinformatics 23: 2947-2948. http://dx.doi.org/10.1093/bioinformatics/btm404 
Lévêque C., Balian E.V. \& Martens K. 2005. An assessment of animal species diversity in continental waters. Hydrobiologia 542: 39-67. http://dx.doi.org/ 10.1007/s10750-004-5522-7

Martens K. 1987. Homology and functional morphology of the sexual dimorphism in the antenna of Sclerocypris Sars, 1924 (Crustacea, Ostracoda, Megalocypridinae). Bijdragen tot de Dierkunde 57: 183190.

Martens K. 1990. Taxonomic revision of African Cypridini. Part I. The genera Cypris O.F. Müller, Pseudocypris Daday and Globocypris Klie. Bulletin van het Koninklijk Belgisch Instituut voor Natuurwetenschappen, Biologie 60: 127-172.

Martens K. 1992. Taxonomic revision of African Cypridini. Part II. Description of Ramotha gen.nov. Annals of the South African Museum 102 (2): 91-130.

Martens K. 2007. On a new species and genus in the Cypridini (Crustacea, Ostracoda, Cyprididae) from South Africa, with a phylogenetic analysis of the tribe and a discussion on the genus concept in this group. Journal of Natural History 41 (5-8): 381-399.

Martens K., Schön I., Meisch C. \& Horne D.J. 2008. Global biodiversity of non-marine Ostracoda (Crustacea). Hydrobiologia 595: 185-193. http://dx.doi.org/ 10.1007/s10750-007-9245-4

Martens K. \& Savatenalinton S. 2011. A subjective checklist of the Recent, free-living non-marine Ostracoda (Crustacea). Zootaxa 2855: 1-79.

Meisch C. 2000. Freshwater Ostracoda of Western and Central Europe. In: Schwoerbel, J. \& Zwick P. (eds), Süßwasserfauna von Mitteleuropa 8/3: 1-522. Spektrum Akademischer Verlag, Heidelberg, Berlin.

Nunes Brandao S., Sauer J. \& Schön I. 2010. Circumantarctic and eurybathid distribution in Southern Ocean benthos? A genetic test using Macrocyprididae (Crustacea, Ostracoda) as model organism. Molecular Phylogenetics and Evolution 55: 1055-1069. http://dx.doi.org/10.1016/j.ympev.2010.01.014

Paradis E., J. Claude \& K. Strimmer 2004. APE: analyses of phylogenetics and evolution in R language. Bioinformatics 20: 289-290. http://dx.doi.org/10.1093/bioinformatics/btg412

Pinder A.M., Halse S.A., Shiel R.J. \& McRae J.M. 2000. Granite outcrop pools in south-western Australia: foci of diversification and refugia for aquatic invertebrates. Journal of the Royal Society of Western Australia 83: 149-161.

Pons J., Barraclough T., Gomez-Zurita J., Cardoso A., Duran D., Hazell S., Kamoun S., Sumlin W., Vogler A. 2006. Sequence-based species delimitation for the DNA taxonomy of undescribed insects. Systematic Biology 55: 595-609. http://dx.doi.org/10.1080/10635150600852011

Posada D. 2008. jModelTest: Phylogenetic model averaging. Molecular Biology and Evolution 25: 1253-1256. http://dx.doi.org/10.1093/molbev/msn083

Savatenalinton S. \& Martens K. 2010. On the subfamily Cypricercinae McKenzie, 1971 (Crustacea, Ostracoda) from Thailand, with the description of six new species. Zootaxa 2379: 1-77.

Schmidt H.A., Strimmer K., Vingron M., \& von Haeseler A. 2002. TREE-PUZZLE: maximum likelihood phylogenetic analysis using quartets and parallel computing. Bioinformatics 18: 502-504. http:// dx.doi.org/10.1093/bioinformatics/18.3.502

Swofford D.L. 1998. PAUP. Phylogenetic Analysis Using Parsimony (and other methods), version 4.0. Sunderland Associates, Sunderland, Massachusetts.

Tamura K., Peterson D., Peterson N., Stecher G., Nei M. \& Kumar S. 2011. MEGA5: Molecular Evolutionary Genetics Analysis using Likelihood, Distance, and Parsimony methods. Molecular Biology and Evolution 28 (10): 2731-2739. http://dx.doi.org/10.1093/molbev/msr121 
Whatley R.C. 1992. The reproductive and dispersal strategies of Cretaceous non-marine Ostracoda: the key to pandemism. In: Mateer N.J. \& Chen P.J. (eds.), Aspects of non-marine Cretaceous geology: 177192. China Ocean Press, Bejing.

Manuscript received: 19 November 2011

Manuscript accepted: 26 January 2012

Published on: 7 March 2012

Topic editor: Rudy Jocqué

In compliance with Article 8.6 of the ICZN, printed versions of all papers are deposited in the libraries of the institutes that are members of the EJT consortium: Muséum National d'Histoire Naturelle, Paris, France; National Botanic Garden of Belgium, Meise, Belgium; Royal Museum for Central Africa, Tervuren, Belgium; Natural History Museum, London, United Kingdom; Royal Belgian Institute of Natural Sciences, Brussels, Belgium; Natural History Museum of Denmark, Copenhagen, Denmark. 